\title{
Promoting HIV-testing among MSM in the Netherlands: the systematic development of an online HIV prevention intervention
}

\author{
Citation for published version (APA):
}

Mikolajczak, J. (2008). Promoting HIV-testing among MSM in the Netherlands: the systematic development of an online HIV prevention intervention. [Doctoral Thesis, Maastricht University]. Datawyse / Universitaire Pers Maastricht. https://doi.org/10.26481/dis.20080919jm

Document status and date:

Published: 01/01/2008

DOI:

10.26481/dis.20080919jm

Document Version:

Publisher's PDF, also known as Version of record

Please check the document version of this publication:

- A submitted manuscript is the version of the article upon submission and before peer-review. There can be important differences between the submitted version and the official published version of record.

People interested in the research are advised to contact the author for the final version of the publication, or visit the DOI to the publisher's website.

- The final author version and the galley proof are versions of the publication after peer review.

- The final published version features the final layout of the paper including the volume, issue and page numbers.

Link to publication

\footnotetext{
General rights rights.

- You may freely distribute the URL identifying the publication in the public portal. please follow below link for the End User Agreement:

www.umlib.nl/taverne-license

Take down policy

If you believe that this document breaches copyright please contact us at:

repository@maastrichtuniversity.nl

providing details and we will investigate your claim.
}

Copyright and moral rights for the publications made accessible in the public portal are retained by the authors and/or other copyright owners and it is a condition of accessing publications that users recognise and abide by the legal requirements associated with these

- Users may download and print one copy of any publication from the public portal for the purpose of private study or research.

- You may not further distribute the material or use it for any profit-making activity or commercial gain

If the publication is distributed under the terms of Article $25 \mathrm{fa}$ of the Dutch Copyright Act, indicated by the "Taverne" license above, 


\section{PROMOTING HIV-TESTING AMONG MSM IN THE NETHERLANDS}





\section{PROMOTING HIV-TESTING AMONG MSM IN THE NETHERLANDS}

The systematic development of an online HIV-prevention intervention

\section{PROEFSCHRIFT}

ter verkrijging van de graad van doctor

aan de Universiteit Maastricht,

op gezag van de Rector Magnificus,

Prof. mr. G.P.M.F. Mols

volgens het besluit van het College van Decanen,

in het openbaar te verdedigen

op vrijdag 19 september 2008 om 14.00 uur

door

Jochen Mikolajczak

geboren op 21 april 1979

te Genk 


\section{Promotores}

Prof. dr. G.J. Kok

Prof. dr. H.J. Hospers

\section{Beoordelingscommissie}

Prof. dr. H.P. Schaalma (voorzitter)

Prof. dr. L.K Bartholomew

Dr. J.E.A.M. van Bergen (SoaAids Nederland)

Prof. dr. B. van den Borne

Dr. U. Davidovich (GGD Amsterdam)

\section{Colofon}

Cover design and lay-out by Jochen Mikolajczak

Printing by Datawyse, Universitaire Pers Maastricht

The studies presented in this thesis were conducted at The Maastricht Center for Research on HIV/AIDS Prevention and Education (RESHAPE). RESHAPE participates in The Research Institute for Psychology \& Health (P\&H), accredited by the Royal Netherlands Academy of Arts and Sciences (KNAW).

The studies presented in this thesis were conducted with financial support from The Netherlands Organisation for Health Research and Development (ZonMw).

Boehringer Ingelheim and GlaxoSmithKline financially supported the printing and distribution of this thesis. 


\section{CONTENTS}

CHAPTER ONE

General introduction and thesis outline

CHAPTER TWO

A qualitative study of reasons for not taking an HIV-test among

Dutch men who have sex with men (MSM)

CHAPTER THREE

Social-cognitive determinants of HIV-testing intentions

CHAPTER FOUR

A qualitative study of environemental factors related to HIV

CHAPTER FIVE

A systematic review of the effects of HIV-testing on sexual risk behavior

\section{CHAPTER SIX}

Developing a theory- and evidence-based Internet intervention

CHAPTER SEVEN

Evaluating the effects of the intervention

CHAPTER EIGHT

General discussion

REFERENCES

SUMMARY

SAMENVATTING 


\section{CHAPTER ONE}

General introduction and thesis outline 


\section{INTRODUCTION}

Since the beginning of the 1980's, when the Human Immunodeficiency Virus (HIV) was first reported on in two papers in the Morbidity and Mortality Weekly Report (CDC, 1981), it has become one of the most rapidly spreading retroviruses in the world. Over time, HIV has had a serious impact on a range of different populations. In Western countries, men who have sex with men (MSM) and intravenous drug users (IDU) are the groups that have been affected most by the virus. In developing countries, heterosexual men and women, and children have been affected most. Infection with the virus causes the human immune system to degrade, and ultimately develops into the Acquired ImmunoDeficiency Syndrome (AIDS) if no medical treatment is available or timely and adequately initiated (The Durban Declaration, 2000). In this latter stage of the infection, the human immune system's functioning is destroyed and heavily impaired, making an HIV-infected individual extremely susceptible to opportunistic infections, such as pneumocystis pneumonia, tuberculosis or cryptococal meningitis. In general, such opportunistic infections will ultimately be fatal for HIV-infected individuals (Rozendaal, 1990).

Until fairly recently in the HIV-epidemic, effective treatment for HIVinfection has been unavailable. In the absence thereof, policy makers and health promotion professionals rightly focused their efforts and activities on the prevention of HIV-infection. Health promotion activities that focus on preventing individuals from acquiring or developing a particular health problem, such as HIV-infection, are commonly referred to as primary prevention. Among MSM, traditionally one of the groups at highest risk for HIV-infection in Western countries (Matic, 2006), this led to the development of safe sex health education programs that focused primarily on the promotion of condom use. The latter was a consequence of the fact that unprotected sexual intercourse, particularly unprotected anal intercourse (UAI), was found to be the most important transmission route of HIV among MSM (van Griensven, 1990). In the Netherlands this initially led to the so called "double message", which was first formulated in 1984 and stated that in order to prevent HIVinfection, MSM should avoid having anal sex in the first place and use a condom if they were unable to do so. One must keep in mind that at the beginning of the 1980's, condoms were not considered a reliable protective option since they were not specifically designed for anal sex and their reported failure rate was found to be high (de Zwart, Sandfort \& van Kerkhof, 1998). Although this double message, which emphasized abstinence from anal sex, was initially considered to comprise the most effective strategy to prevent MSM in the Netherlands from getting infected with HIV, it was changed at the 
beginning of the 1990's for a number of reasons. First of all, condoms had become more reliable and condom failure now appeared to be the result of incorrect use and not technical shortcomings. Thus, correct condom use had to be taught to MSM. However, prevention workers found this to be difficult in the context of a prevention message that focused on abstinence from anal sex in the first place. Finally, and possibly most importantly, it appeared that many MSM continued to have anal sex, and abstinence was probably an unrealistic expectattion (de Zwart et al., 1998). As a result, the double message was ultimately changed in 1992, into a new prevention message that focused on the promotion of condom use among MSM in the Netherlands to prevent HIVinfection. Up to the present day, the promotion of condom use has been the general prevention message and will probably continue to be the most effective strategy to prevent the transmission of HIV among MSM. It should be noted that among MSM involved in a steady relationship, prevention strategies like negotiated safety (Kippax, Noble, Prestage, Crawford, Campbell, Baxter, et al., 1997 ) have gained more attention over the past few years (Davidovich, de Wit \& Stroebe, 2000).

Today, HIV-infection remains incurable. However, a major leap forward in terms of HIV-infection treatment was accomplished in 1996 when Highly Active AntiRetroviral Therapy (HAART) was introduced. Since its introduction and application, several studies have reported on the positive effects of HAART on both life-expectancy (Ives, Gazzard \& Easterbrook, 2001; Palella, Delaney, Moorman, Loveless, Fuhrer, Satten, et al., 1998), and quality of life (Brechtl, Breitbart, Galietta, Krivo \& Rosenfeld, 2001; Cohen, Revicki, Nabulsi, Sarocco \& Jiang, 1998; Saunders \& Burgoyne, 2002) of HIV-infected individuals. Although HAART can have negative side-effects, its overall health advantages are currently widely acknowledged and accepted. Therefore, in the Western world, HIV-infection is no longer perceived as a lethal disease, but as a manageable chronic condition, given that treatment works and that one does not become resistant to the medication (Hospers, 2006; Rietmeijer, 2004).

In terms of health promotion, HAART opened a new window of opportunity for policy makers and health promotion professionals. In addition to a continued and much needed focus on the prevention of HIV-infection, attention could now also be focused on the (early) detection of HIV-infection by promoting HIV-testing. In terms of health promotion, the latter is known as a form of secondary prevention. Particularly in the Netherlands, the availability of HAART marked a new era in the fight against HIV/AIDS. In the absence of effective treatment, finding out being HIV-positive was considered to be of no advantage to HIV-infected individuals. Also, it had long been unclear what the effects of finding out one's serostatus, either HIV-positive or HIV-negative, on 
subsequent sexual risk behavior were. In addition, it should be noted that initially, the gay community in the Netherlands heavily opposed HIV-testing. As a community, they were concerned that HIV-testing - the HIV-test became available in 1984 - would put extra responsibility for the HIV-epidemic on the shoulders of HIV-infected men and consequently lead to more stigmatization and possibly criminalization (Mooij, 2004). As a result, the Dutch HIV-testing policy at that time did not promote HIV-testing among MSM and taking an HIV-test was advised against in most cases. However, in the context of HAART availability, evidence soon showed that detection of HIV-infection at an early stage of infection was advantageous, since it allowed adequate monitoring of an individual's health status, proper treatment initiation, and the creation of opportunities for educating newly diagnosed individuals with respect to treatment, care, and support. Also, early detection allowed HIV-infected individuals to better prepare for treatment (Chadborn et al., 2005). In addition, evidence showed that finding out one's serostatus contributes to the prevention of HIV-infection as well. Weinhardt et al. (1996) were amongst the first to clearly demonstrate that finding out being HIV-positive, subsequently led to a significant reduction in sexual risk behavior, particularly among MSM (Weinhardt, 1996; Mikolajczak, Hospers \& Kok, 2006). As a result, the Dutch Health Council reviewed its position towards HIV-testing in 1999 and advised the Dutch Ministry of Health, Welfare and Sport to update the Dutch HIVtesting policy: HIV-testing should no longer be advised against. Instead, it should be actively promoted among individuals such as MSM, who are at high(est) risk for HIV-infection. According to the Dutch Health Council, the balance between pro's and con's of taking an HIV-test had shifted with the introduction and application of HAART, and the cons no longer outweighed the pros (Gezondheidsraad, 1999). In 2003, the Ministry finally changed the national HIV-testing policy, thereby following the initial advice of the Dutch Health Council (VWS, 2003).

\section{HIV AND HIV-TESTING RATES AMONG MSM IN THE NETHERLANDS}

In the Netherlands, the most recent estimates are that about 16000 to 23000 adult individuals are infected with HIV, of which only approximately 12000 are actually aware of their infection (RIVM, 2006). As is the case in most Western countries (Matic, 2006), MSM make up the group at highest risk for HIVinfection in the Netherlands as well (Smit, Geskus, Uitenbroek, Mulder, van den Hoek, Coutinho, et al., 2004). As can be seen in Table 1, 52\% of all new HIV- 
infections in the Netherlands in 2005 were diagnosed among MSM (RIVM, 2006).

Table 1. Number of new HIV-diagnoses in the Netherlands in 2005

\begin{tabular}{|c|c|c|c|}
\hline Tansmission risk group & Male & Female & Total \\
\hline MSM & $501(67 \%)$ & $(0 \%)$ & $501(52 \%)$ \\
\hline Heterosexual contact & $162(21 \%)$ & $212(95 \%)$ & $374(39 \%)$ \\
\hline Injecting drug users & $8 \quad(1 \%)$ & $2 \quad(1 \%)$ & $10 \quad(1 \%)$ \\
\hline Other or unknown & $75 \quad(11 \%)$ & $12(4 \%)$ & $85 \quad(8 \%)$ \\
\hline Total & 746 & 224 & 970 \\
\hline
\end{tabular}

Source: RIVM (2006)

In total, shown in Table 2, MSM accounted for about $52 \%$ of all registered HIVcases in the Netherlands, registered at the National HIV Monitoring Foundation in 2005 (Gras, van Sighem, Smit, Zaheri \& de Wolf, 2006).

Table 2. Number of registered HIV-infected adults in the Netherlands in 2005

\begin{tabular}{lllll}
\hline Adult transmission risk & Male & \multicolumn{2}{l}{ Female } & Total \\
\hline Homosexual & $6234(67 \%)$ & 0 & $(0 \%)$ & $6234(52 \%)$ \\
Heterosexual & $1664(18 \%)$ & $2336(87 \%)$ & $4000(34 \%)$ \\
Injecting drug users & $445(5 \%)$ & $162 \quad(6 \%)$ & $607 \quad(5 \%)$ \\
Other or unknown & $911 \quad(10 \%)$ & $201 \quad(7 \%)$ & $1112(9 \%)$ \\
\hline Total & 9254 & 2699 & 11953 \\
\hline
\end{tabular}

Source: Gras et al. (2006)

HIV-testing rates among MSM in the Netherlands have traditionally been among the lowest compared to other Western countries (Bochow, Chiarotti, Davies, Dubois-Arber, Dur, Fouchard, et al., 1994). Although HIV-testing rates among MSM in the Netherlands have increased over the past years, recent data show that in 2006 only 60\% of MSM had ever taken an HIV-test (Hospers, Dörfler \& Zuilhof, 2006; Mikolajczak et al., 2007). Compared to countries such as Switzerland or Spain, where HIV-testing rates among MSM of $80 \%$ (and higher) have been reported (Dubois-Arber, Moreau-Gruet \& Jeannin, 2002; Pérez, Rodes \& Casabona, 2002), the Dutch figure remains relatively low. In Australia, several studies reported HIV-testing rates among MSM between 80\% and 95\% (National Center in HIV Social Research, 2001; 2002). Moreover, recent figures from the Sydney Gay Periodic Survey (2006), for example, show that $63 \%$ of MSM in Sydney had taken an HIV-test in the past 12 months. 
As a result of low HIV-testing rates among MSM in the Netherlands, a significant number of untested men are living with HIV, but are not aware of the fact that they are infected with the virus. Consequently, these men are likely to access treatment at a relatively late(r) stage of their infection, which poses limits to the effectiveness of treatment (Chadborn et al., 2005; Hocking, Rodger, Rhodes \& Crofts, 2000) In addition, these men also (continue to) place other MSM at risk for getting infected with HIV if they practice risky sexual behavior such as UAI, which in turn adds to the spread of HIV in the MSM population in the Netherlands. In the United States, for example, individuals who are unaware of their HIV-infection are estimated to account for $54 \%$ to $70 \%$ of all new HIV-infections transmitted through sexual behavior (Marks, Crepaz \& Janssen, 2006).

The Netherlands' new HIV-testing policy, which focuses on the promotion of HIV-testing among individuals at high risk for HIV-infection, has prompted the development of interventions that focus on motivating MSM in the Netherlands to take an HIV-test. The context of low HIV-testing rates among MSM in the Netherlands highlights the need for such interventions. The project that is described in the following chapters of this thesis was initiated in 2003 on the request of the Dutch Ministry of Health, Welfare and Sport. The aim of the project was to better understand HIV-testing behavior and its related social-cognitive determinants, and to develop a theory- and evidence-based intervention to motivate MSM in the Netherlands to take an HIV-test. The latter was hypothesized to lead to more HIV-infected MSM in the Netherlands to become aware of their HIV-positive status. As a result, they would be able to gain access to treatment with HAART and additional care, and could be motivated and educated to adopt safe sexual behavior to avoid further spread of the virus in the MSM population. Before outlining the remainder of the present thesis, the Intervention Mapping protocol - a framework that ensures theory- and evidence-based intervention development - will be briefly introduced and explained. In addition, using the Internet for research purposes and for the delivery of health promotion programs will also be introduced.

\section{INTERVENTION MAPPING}

Health promotion programs ultimately aim to reduce the burden of a specific health problem or the consequence thereof, among a specific group of individuals. Motivating individuals to adopt or execute a particular behavior in this case taking an HIV-test - implies changing the (social-cognitive) cognitions that are related to the behavior on the one hand, and creating an 
environment that facilitates adoption or execution of the behavior on the other hand. As is the case with any health promotion intervention, an intervention aimed at promoting HIV-testing among MSM in the Netherlands is most likely to be effective when it is systematically planned and developed, building on theory and evidence (Kok, 1999). The Intervention Mapping (IM) protocol, shown in figure 1, provides a framework that ensures the use of theory and evidence in the development of such health promotion interventions, thereby maximizing the interventions' chances of being effective in achieving its goals (Bartholomew et al., 2001; 2006). As such, it should be noted that Intervention Mapping is not a theory of behavior or behavior change in itself.

Figure 1. Intervention Mapping (Bartholomew, Parcel, Kok \& Gottlieb, 2006)

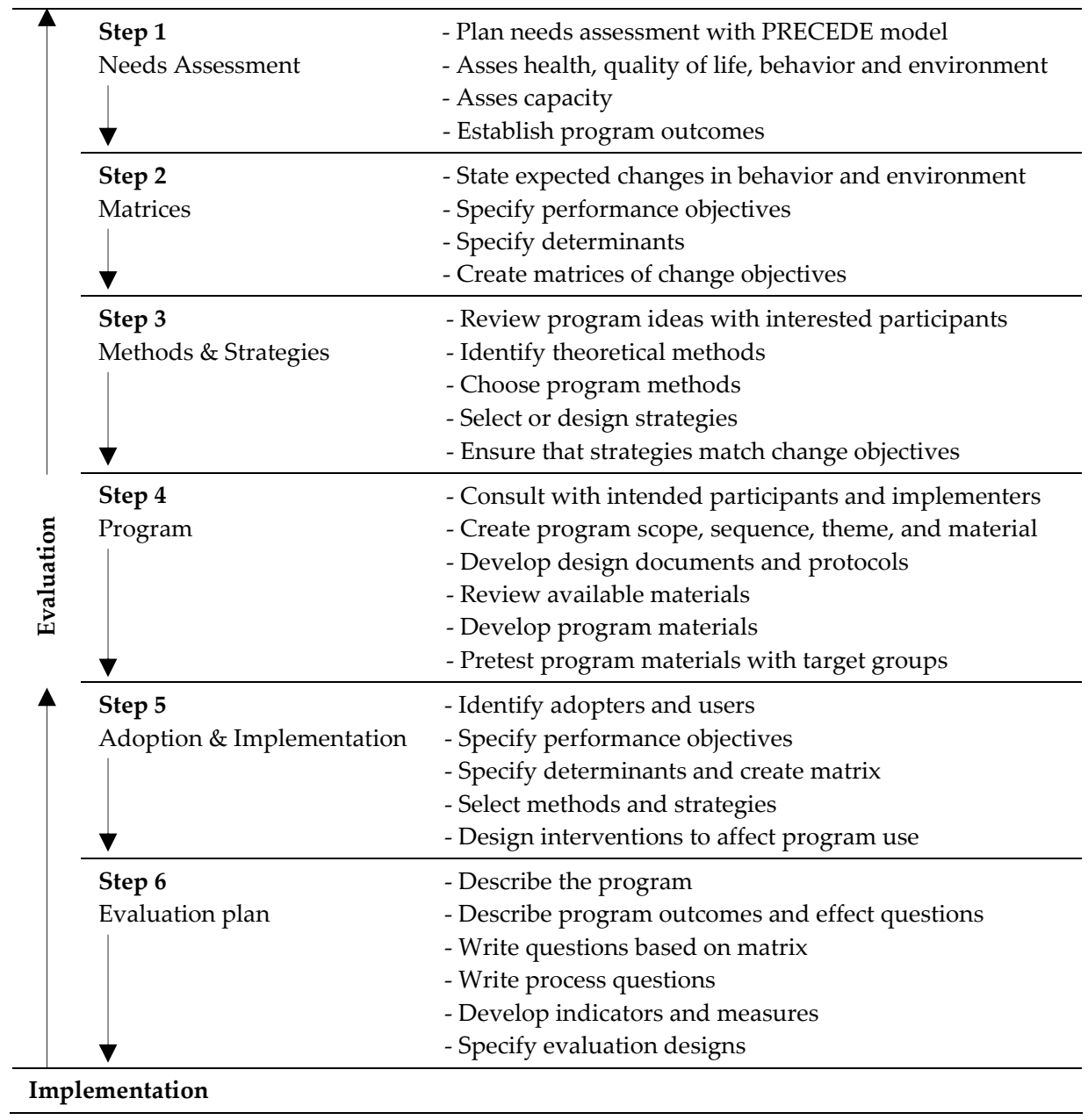


Development of a health promotion program within the IM framework starts with a thorough needs assessment. During this first step in IM, program planners must get a clear picture of the actual health problem at hand, identify related behavioral and environmental factors, and seek out the consequences of the health problem in terms of its effects on quality of life. Green and Kreuters' (2005) PRECEDE model provides program planners with a tool to conduct the needs assessment during step one of IM. The outcome of the needs assessment provides planners with the relevant input that is needed to accomplish the second step in IM. During this second step of IM, matrices of change objectives are created. These matrices can be considered the blueprints for the health promotion program, since they identify what and who should change as a result of a program. Once the matrices are created, relevant theoretical methods for behavior change are selected and linked to the change objectives, at step three of IM. Because methods for behavior change are derived from theory and only describe a mechanism or process to achieve the desired change, each of the selected methods must also be operationalized in a practical application or strategy. The fourth step in IM consists of the actual development of a health promotion program in terms of program materials, for example the actual brochure or website. During this step, planners must ensure that all the different strategies that were developed during the previous step of IM are incorporated in the program material. Only then will all the change objectives from the matrices that were developed in step two be covered in the actual program. Next, adoption, implementation and sustainability of a health promotion program should be anticipated on during the fifth step of IM. This is important since any health promotion program is deemed to be unsuccessful in achieving its goal(s) if it is not adequately adopted and/ or implemented. As such, adoption and implementation are to be anticipated on from the start of program planning within IM. The latter also illustrates the iterative nature of the IM framework: program planners are invited to move back and forth throughout the different steps in IM, and its application to the development of a health promotion program. Finally, during the sixth step of IM, both a processand an effect-evaluation of a program are prepared and conducted. To allow evaluation of the programs' effects, it should ideally be embedded in an experimental study design which includes an available alternative program, i.e. best available practice. 


\section{RESEARCH ON THE INTERNET}

Most of the research that is described in this thesis was conducted by using the Internet. The quantitative study that is described in chapter two, and both the intervention study and our health promotion program described in chapters five and six, were all conducted online. Using the Internet as a medium for most of our research was based on number of reasons. First of all, research had shown that the Internet had become a popular medium among MSM for seeking and finding sex partners, (Bull, Lloyd, Rietmeijer \& McFarland, 2004; Hospers, Kok, Harterink \& de Zwart, 2005), for example through chatting or placing a profile on a dedicated website. In addition, whereas only $17 \%$ of Dutch MSM in the first Dutch Monitoring Study (Hogeweg \& Hospers, 1999) reported Internet use, 79\% reported Internet use in the third Monitoring Study (Hospers, Dörfler \& Zuilhof, 2003). As such, the Internet provided us with a medium through which we were able to reach a large group of sexually active MSM in the Netherlands. Secondly, research also showed that certain subgroups are more easily reached through the Internet. Hospers et al. (2005), were able to demonstrate that compared to a wave of offline recruited MSM, the online MSM sample comprised significantly more bisexuals, more men with a non-Dutch or a mixed (Dutch and non-Dutch) cultural background and significantly fewer men who had ever taken an HIV-test. Given the aim of our health promotion program, the latter would allow us to reach a relatively large group of MSM that had never taken an HIV-test. Thirdly, evidence also showed that people tend to be more open and more honest in answering questions on sensitive topics, such as drug use or in our case HIV-testing (Turner, Ku, Rogers, Leidberg, Pleck \& Sonestein, 1998). Finally, a recent study conducted by Goslin, Vazire, Srivastava and John (2004) concluded that findings from Internet research are comparable and consistent with findings from studies that use more traditional research methods such as paper and pencil questionnaires.

Despite a number of advantages, using the Internet for research purposes also has limitations and challenges that must be considered when planning a Internet. One of the major issues of concern is related to the relatively low level of response or participation rate that is often found in Internet studies that make use of e-mails to (re)invite people to fill in a questionnaire or participate in an intervention. Bull et al. (2004) for example collected follow-up data for the evaluation of an MSM HIV-prevention intervention of only $15 \%$ of all participants $(n=1776)$ that were invited for follow-up. Lefever, Dal and Matthiasdóttir (2007) reported a response rate to an e-mail request for participation in an online questionnaire of only $24 \%$ among students. With respect to HIV-related Internet studies, Pequegnat et al. (2007) suggest several 
options to overcome high levels of attrition, such as sending out reminder emails, giving a monetary or other valuable reward to participants, and limiting the length of a questionnaire. In a recently conducted online intervention to promote safe sex among Dutch MSM, Hospers et al. (2005) applied most of the above cited suggestions and were able to collect follow-up data on $50 \%$ of all participants who were invited for follow-up. Another issue of concern which should be well considered is the fact that the Internet is a very fast, dynamic and rapidly changing medium. If people become bored with an online intervention or questionnaire, or they are confronted with technical shortcomings such as routing errors, chances are high that they will leave the study with a single click. According to Pequegnat et al. (2007) researchers who plan to conduct online studies should spend sufficient time identifying the preferences of the intended users for particular backgrounds, colors, animation(s) and audio. For our online intervention for example, we consulted with members of our MSM target population to ensure that its appearance matched their expectations and preferences. In addition, we also spend a lot of time pre-testing our online studies to overcome routing errors or other technical shortcomings. Finally, another important aspect that has to be taken into account when planning an online study is related to privacy and confidentiality. All data provided by participants in an online study should be stored on a dedicated server that is well protected against viruses, hackers and other individuals that are not involved with the study. In addition, researchers should correctly inform participants about the purpose of the study and obtain informed consent from the participant before allowing entrance into the study.

\section{THESIS OUTLINE}

The different chapters in this thesis each cover different steps in the application of Intervention Mapping (Bartholomew et al., 2006) to the development of an online HIV prevention intervention to promote HIV-testing among MSM in the Netherlands. Chapter two presents the findings of a small scale qualitative study among 32 untested Dutch MSM. This study was set up to get an in depth understanding of the problem of HIV-testing among Dutch MSM and explored which factors contributed to Dutch MSM not taking an HIV-test. Chapter three describes the findings from a large scale online quantitative study, set up to get a better understanding of the determinants of HIV-testing. Also, reasons for not taking an HIV-test among Dutch MSM are further explored in the study described in this chapter. In terms of Intervention Mapping, the empirical evidence that is reported in both chapters was used as input for the 
development of the intervention. Chapter four contains a systematic review of the scientific literature on HIV-testing since 1996. In doing so, it provides a statof-the-art update of the current knowledge about the relationship between HIVtesting and counseling, and subsequent (sexual) risk behavior. Chapter five contains the outcomes of a qualitative study, conducted in Sydney (Australia) between November 2004 and February 2005. The aim of this study was to get a better understanding of the different environmental or external factors that (had) contributed to Australia's successful HIV-testing program. It provides a historical perspective of the Australian response to the HIV-epidemic and sought to find out whether any of the environmental factors identified could be implemented in the intervention that were planning to develop. That way, we would maximize the chances for the intervention to be successful in motivating Dutch MSM to actually take an HIV-test. In chapter six, the systematic development of our HIV-prevention intervention is described. Whereas the health promotion literature provides many papers on the evaluation of the effect(s) of a health promotion intervention, few papers contain a proper and detailed description of the content and the development of the intervention. In absence of such descriptions, it is hard for other researchers and health promotion professionals to get a full understanding of what the intervention aims to achieve and which methods for behavior change are used to actually realize these goals. Moreover, the absence of such descriptions makes it virtually impossible for other researchers to do what science is all about in the long run, namely replicating the findings of a study (Abraham \& Michie, 2007). The seventh chapter of this thesis contains the data on the evaluation of our intervention. This chapter describes the effect of our HIV-prevention intervention on both the motivation of Dutch MSM to take an HIV-test and their subsequent HIV-testing behavior. Finally, chapter eight summarizes the work that is described in the different chapters of this thesis and discusses the outcomes of the different studies conducted. Also, future opportunities and directions for HIV-prevention activities among MSM in the Netherlands are provided in the final chapter of this thesis. 



\section{CHAPTER TWO}

A qualitative study of reasons for not taking an HIV-test among Dutch men who have sex with men (MSM)

This chapter has been published as:

Mikolajczak, J., Van Kesteren, N., Hospers, H.J., \& Kok, G. (2004). Een

kwalitatief onderzoek naar redenen om niet te testen op HIV bij Nederlandse mannen die seks hebben met mannen. TSG: Tijdschrift voor

Gezondheidswetenschappen, 7, 450-456. 


\section{INTRODUCTION}

When we consider the final two decades of the twentieth century, one of the most notable things was the advance of a new disease, characterized by a severely impaired immunological resistance. Given the name Acquired Immune Deficiency Syndrome (AIDS), this disease characteristically leads to an extremely low resistance to viral, bacterial and other infections that can cause a broad range of symptoms to which a person with AIDS ultimately succumbs. The strongly weakened immunological resistance is a result of the destruction of the immune system by the Human Immunodeficiency Virus (HIV).

To facilitate the control and prevention of HIV/AIDS in the Netherlands, an active HIV-testing policy was introduced in 1999 at the recommendation of the Health Council of the Netherlands and has been in effect since then (Health Council of the Netherlands, 1999). In concrete terms, this means that HIVtesting should be actively promoted among the members of a group that is at risk of becoming infected with HIV, and those individuals should be educated about the pros and cons of an HIV-test. In this connection, the Health Council of the Netherlands mentioned the four groups that are listed in table 1.

Table 1. People at high risk for HIV-infection in the Netherlands

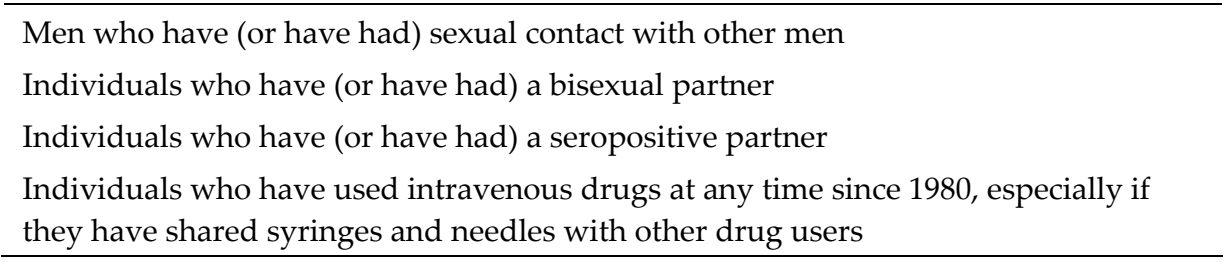

Source: Health Council of the Netherlands (1999)

Until 1999, the Netherlands' policy on HIV-testing had been more hesitant, meaning that people were usually advised against getting tested for HIV unless they had clear symptoms. In those days, there weren't any effective treatments to offer those who tested positive, and a positive result could have had highly negative psychosocial and social consequences for the person concerned. Moreover, there were indications that a positive result had only a slight effect if any - on the preventive behavior of the individuals involved.

The beneficial effects of the Highly Active Anti-Retroviral Therapy (HAART) on the course of the disease contributed significantly to the change in the HIV-testing policy in the Netherlands. Thanks to the development and use of HAART, one could clearly favorably influence the course of an HIVinfection: for the majority of those who were infected with HIV, this treatment led to substantial gains in terms of the length and quality of their lives. An 
active HIV-testing policy is meant first of all to enable the diagnosis of an HIVinfection at an early stage, so that one can start treatment with HAART at an appropriate time. Moreover, meta-analyses have shown that - especially among people who are seropositive - knowing one's own serostatus does indeed lead to a reduction of risky sexual behavior (Weinhardt et al., 1999).

Since 2001, the formulation of an active HIV-testing policy has also had the official sanction of the World Health Organization (WHO, 2001). If someone tests seronegative, the $\mathrm{WHO}$ feels this should be an incentive for that person to take preventive measures to exclude the possibility of becoming infected with HIV in the future. A seropositive test result should serve on the one hand as an incentive for the person in question to learn to live with his or her infection with a positive outlook and to try to preclude infecting others by making proper use of prophylactics or taking other precautionary measures, while on the other hand it should signal the beginning of a proper treatment.

Figures collected from September 1998 through September 1999 for the first Monitoring Study in the Netherlands - an instrument for gatering data relevant to HIV-prevention from men who have sex with men (MSM) - showed that $58 \%$ of the 1336 respondents had never been tested for HIV (Hogeweg \& Hospers, 2000). When these data were collected, however, there was still no active HIV-testing policy in the Netherlands, a fact that was mentioned at that time as a possible explanation for this figure. More recent data concerning the percentage of Dutch MSM who had still never been tested for HIV nevertheless show that this figure remained stable over a period of three years. In a study that Harterink et al. (2003) conducted among more than 5000 gay or bisexual men who actively use chat boxes, the respondents were asked if they had ever been tested for HIV in the past. Here, too, it turned out that $58 \%$ of the respondents had still never been tested for HIV.

Considering the fact that the MSM population is still one of the most important groups at risk of an HIV-infection in the Netherlands, it is striking first of all that the percentage of Dutch MSM who have never been tested for HIV is so high. Second, it is remarkable that this percentage remained unchanged between 1999 and 2002, despite the new active HIV-testing policy. Finally, a third fact that is worthy of attention is that in an international perspective, the percentage of MSM who had ever been tested for HIV was substantially higher in many other Western countries than in the Netherlands (see Table 2). Research by Bochow et al. (1994) showed that, about ten years ago, only $33 \%$ of the gay and bisexual men in the Netherlands had been tested. At the time, that was the lowest percentage among the nine European countries studied: in six out of the nine countries, the percentage of those who had ever been tested was then already higher than $50 \%$. More recent data from Seattle, 
London and a number of Australian cities show percentages between $80 \%$ and $95 \%$.

Table 2. Percentage of men who have sex with men (MSM) ever tested for HIV

\begin{tabular}{|c|c|c|c|}
\hline Study & Location & Respondents & $\%$ Ever tested \\
\hline $\begin{array}{l}\text { Bochow et al. } \\
\text { (1994) }\end{array}$ & $\begin{array}{l}9 \text { European } \\
\text { countries } \\
\text { data collection in } \\
1992\end{array}$ & Gay press & $\begin{array}{l}\text { France: } 79 \% \\
\text { Denmark: } 75 \% \\
\text { Switzerland: } 72 \% \\
\text { Austria: } 67 \% \\
\text { West germany: } 63 \% \\
\text { Italy: } 58 \% \\
\text { United Kingdom: } \\
44 \% \\
\text { East Germany: 39\% } \\
\text { The Netherlands: } \\
33 \%\end{array}$ \\
\hline $\begin{array}{l}\text { Campsmith et } \\
\text { al. (1997) }\end{array}$ & Seattle, WA, USA & Random digit dialing & Seattle: $82 \%$ \\
\hline $\begin{array}{l}\text { Elford et al. } \\
(2001)\end{array}$ & London, UK & Men in London gyms & London: $79 \%$ \\
\hline $\begin{array}{l}\text { National } \\
\text { Centre in HIV } \\
\text { Social Research } \\
(2001)\end{array}$ & $\begin{array}{l}\text { Sydney } 1999 \\
\text { Melbourne } 1998 \\
\text { Queensland } 1999 \\
\text { Perth } 1996 \\
\text { Adelaide } 1999\end{array}$ & Periodic surveys & $\begin{array}{l}\text { Sydney: } 90 \% \\
\text { Melbourne: } 83 \% \\
\text { Queensland: } 87 \% \\
\text { Perth: } 83 \% \\
\text { Adelaide: } 85 \%\end{array}$ \\
\hline $\begin{array}{l}\text { National } \\
\text { Centre in HIV } \\
\text { Social Research } \\
\text { (2002) }\end{array}$ & Sydney 2002 & Baseline data & Sydney: 95\% \\
\hline
\end{tabular}

The low percentage of MSM in the Netherlands who had ever been tested for HIV was the reason for the present study. Indeed, the central question for this research is: Why don't Dutch men who have sex with men get tested for HIV? The most important goal of this study is to gain insight into the various factors that might explain why Dutch MSM have failed to get tested for HIV. In turn, the knowledge gained in this way can play an important and vital role in the development of an effective intervention program aimed at promoting HIVtesting among MSM in the Netherlands in the future.

The theoretical framework of this study is described in Section two, with special attention being given to factors that could potentially explain why so few MSM in the Netherlands have been tested for HIV. Section tree deals with 
the methods and setup of the study. The results of the investigation are presented in Section four. Finally, Section five contains a discussion of those results.

\section{THEORETICAL BACKGROUND}

This section outlines the theoretical framework that served as the basis for the present study. We discuss various theories and concepts that can be seen in connection with the failure of Dutch MSM to get tested for HIV. It is important to emphasize that the various explanations presented here are not necessarily mutually exclusive. A comprehensive explanation for the lack of testing for HIV among Dutch MSM is sure to be complex, with most if not all of the various factors discussed in this section playing more or less of a role.

\section{Knowledge}

Knowledge is perhaps one of the most obvious factors that can influence the HIV-testing behavior of Dutch MSM. The role that knowledge plays in putting healthy behavior into practice has become clear from the findings of the studies mentioned below, among others. Research conducted by Van Empelen (2001), for example, showed that knowledge about HIV/AIDS had a significant impact on risk behavior among Dutch drug users. Drug users who had sufficient knowledge about risks in relation to HIV/AIDS were less apt to share needles with other drug users than those who had insufficient knowledge in that respect. Research by Siegel, Schrimshaw and Dean (1999) revealed that insufficient knowledge about HIV and the symptoms of an HIV-infection was their respondents' most important reason for not getting tested for HIV. The subjects in that study claimed they felt healthy, saying they hadn't experienced any symptoms of disease over the course of many years, which made them think it unlikely that they had been infected with HIV. The Monitor Study (Hogeweg \& Hospers, 2000) has shown that while MSM claim to know a lot about risky sexual techniques, they are significantly less aware about the HIVtest and HAART.

Knowledge is also a component of most other behavioral determinants. For example, risk perception and the perception of social standards and values are at least partially based on factual knowledge (Brug, Schaalma, Kok, Meertens \& van der Molen, 2000). Although having the right knowledge is a first and necessary condition for carrying out preventive or healthy behavior, putting it into practice effectively often requires more. Research conducted among homosexual men has shown for example that while their level of knowledge about HIV and AIDS is generally quite high, some men in this 
group continue to have unsafe sex (Hospers, 1999). Facente (2001) points out that knowledge about HIV-testing (e.g. testing opportunities and testing procedures), plays an important role in one's decision about whether or not to get tested.

In summary, a lack of sufficient knowledge about HIV/AIDS and about HIV-testing can contribute to the failure of Dutch MSM to get tested. In particular, the lack of sufficient knowledge about the possibilities and procedures in terms of an HIV-test, but also about the benefit of the early detection of an HIV-infection (the testing-treatment argument), may play an important role in this regard.

\section{Risk perception}

The degree to which and the way in which people perceive risks or a threat can contribute to their not getting tested for HIV. A study that Campsmith et al. (1997) conducted among MSM in Seattle showed that a subject's belief that he ran almost no risk of an HIV-infection was the most important reason for his not having been tested for HIV. Likewise, a study conducted by Downing et al. (2001) among drug users demonstrated that their self-assessment as being at low risk of an HIV-infection was for most respondents the most important reason for not getting tested.

A relevant theoretical model in which risk perception plays an important role as a determinant for healthy behavior is the Health Belief Model (HBM). According to the HBM, people will get tested for HIV when they are convinced that they are susceptible to becoming infected with HIV and that an HIVinfection would entail a serious threat. It is also important that they are convinced that getting tested for HIV will contribute to a reduction of their perceived vulnerability.

Moreover, the perceived advantages in connection with an HIV-test need to offset the costs involved (Strecher \& Rosenstock, 1997). The literature dealing with risk perception nevertheless shows that people usually don't deal with risks properly and often underestimate the risks they run (Brug, Schaalma, Kok, Meertens \& van der Molen, 2000). Research has shown, for example, that people often underestimate risks because they fail to take multiple opportunities for infection and cumulative risks into account (van der Pligt, 1991). Many people do not realize for example that while one incidence of unsafe sex might entail a relatively small chance of an HIV-infection, repeating this behavior more often will increase the risk of an HIV-infection considerably. The fact that many Dutch MSM don't get tested for HIV might therefore also be explained by the erroneous assessment of the risk that one thinks one runs of an HIV-infection. 
Especially when people are confronted with risks in connection with an unpleasant event, it turns out that they systematically assess their chances of being exposed to such a risk as lower than those of others like them. The sense of being in control of the risk plays an important role in this regard. One is especially apt to underestimate risks that are connected to an occurrence that one considers to be highly controllable, for example an HIV-infection, and to consider those risks as being more applicable to one's peers than to oneself (van der Pligt \& Otten, 1993). This phenomenon, known as unrealistic optimism, stems from the fact that one is well aware of the measures that one takes oneself to prevent an HIV-infection but forgets that most others take comparable measures. This often makes people think they do more to prevent the risk of an HIV-infection than others and thus they underestimate their own risk of an HIV-infection (van der Pligt, 1991). Another explanation for unrealistic optimism is the development of a stereotypical image of a group or individual at risk. One sees this stereotypical image as being very different from oneself, which leads to the conclusion that the risks pertain primarily to others.

Research done by Offir, Fisher, Williams and Fisher (1993) has shown that people can also actively reason away the risks of an HIV-infection and in this way maintain their perceived low-risk status. When one has exposed oneself to certain risks of an HIV-infection, a state of cognitive dissonance arises as the result of an inconsistency between one's personal views ("unsafe sex is dangerous") and one's actual behavior ("I had unsafe sex"). As a consequence of this cognitive dissonance, one is motivated to eliminate this state by changing one or more inconsistent cognitions or by adding extra cognitions. The above-mentioned study by Offir et al. (1993) showed for example that half of the 41 homosexual respondents reported having had unprotected sex, while at the same time explaining why no risk had been involved whatsoever. Respondents said for example that they had not been the receptive partner or that they didn't come into their partner. Making use of dissonance-reducing techniques in this way, one incorrectly perceives the risk one has run of an HIVinfection as being low.

\section{Fear}

Fear can best be defined as an unpleasant emotional state caused, among other things, by the perception of a threat that is evaluated as grave and personally relevant. Theoretical models that describe the effects of frightening information assume that feelings of fear and perceptions of threats lead to different actions, referred to as fear control and danger control, respectively (Ruiter, 2000). Danger control assumes that a perception of threat motivates people to take action to eliminate the threat. However, people will only perform the 
recommended action if they are convinced that the desired behavior is an effective way of dealing with the threat and if they consider themselves to be capable of carrying out the desired behavior.

In the case of testing for HIV, it is important in this connection that people are confident that they can deal with the consequences of a positive test result. If the level of confidence is estimated to be low, the situation will arise in which a threat is present, but one does not know how to deal with it. In that case, feelings of fear will gain the upper hand and people will subsequently attempt to reduce those unpleasant feelings as quickly as possible - for example by denying the threat or avoiding information about the risk - in order to achieve a feeling a safety.

Numerous studies have shown that fear is a possible explanation for the failure of many Dutch MSM to get tested for HIV. While fear does not necessarily have to have anything directly to do with an HIV-test itself, it does often relate to a number of aspects that are connected to that. In a recent study by Downing et al. (2001) that looked into the factors that influence the HIVtesting behavior of intravenous drug users for example, the fear of a positive test result turned out to be the most important reason for their not getting tested for HIV. Similarly, a telephone survey that Campsmith et al. (1997) conducted among 603 MSM in Seattle to study their reasons for not getting tested for HIV showed that the fear of a positive test result was for these men one of the main reasons for not getting tested. A study that Siegel et al. (1998) conducted among HIV-infected women in New York showed moreover that the fear of a positive test result was the most important thing that had kept them from getting tested earlier for HIV. In a study that Stall et al. (1996) conducted among homosexual men, it turned out that the decision not to get tested for HIV could also have to do with the fact that the individuals are afraid that the test results are not $100 \%$ anonymous and that they fear that a positive test result would lead to the loss of their job or the loss of friends and relationships.

The fear of being stigmatized - and consequently of being exposed to all kinds of negative reactions from one's environment - may also contribute to the decision of many Dutch MSM not to get tested for HIV. Indeed, recent research by Chesney and Smith (1999) in the US has shown that the stigmatization of people with an HIV-infection was one of the most important factors that contributed to a decision not to get tested for a possible HIV-infection or in any case to postponing getting tested for a long time. Even to this day, a stigma can be considered socially inexpedient (Roodenburg, 1999).

The consequences of stigmatization can be very far reaching and pertain to three different levels. To begin with, there are the social consequences for stigmatized people. They often lose their relationships with their friends, family 
and/or partner (Bos, Kok \& Dijker, 2001; Herek, 1999), and as it is very difficult for them to build up new social contacts, they soon lapse into social isolation. Second, there are the psychological consequences. People who are stigmatized experience it as a painful process that calls up negative emotions like fear, depression and animosity. People with HIV are often seen as promiscuous and are reproached for not having been careful in their choice of partners (Chesney $\&$ Smith, 1999). Third, there are the consequences of stigmatization on the health of those who are affected. The loss of interpersonal relationships means a drop in the potential number of people who can offer them support; this can have a negative impact on their health.

\section{Social environment}

The social environment in which Dutch MSM live can also influence their HIVtesting behavior. Its impact on that behavior can manifest itself through a number of different mechanisms. One's subjective convictions about the accepted social norms, values and expectations in relation to HIV-testing are an example of this. The standards and values that are supported within the social environment can have an important influence on behavior. When one is subjectively convinced that getting tested is not accepted within the social community or not considered to be of importance, this can have a negative influence on one's HIV-testing behavior and lead to non-testing.

Having no one in one's social environment who has been tested for HIV may also contribute to one's decision not to get tested. In general, people are thought to more easily adopt and actually carry out the behavior that they often observe in their social environment (Kok et al., 1996). The low percentage of Dutch MSM who have been tested for HIV so far may contribute in this way to an individual's decision not to get tested.

\section{HIV-testing policy in the Netherlands}

Since 1999, the Netherlands has had an active HIV-testing policy, the most important goal of which is to actively offer testing to those who belong to a group that is at risk of becoming infected with HIV and to inform them about the pros and cons of getting tested for HIV. Prior to the introduction of this new policy, however, there had been a more reserved policy in relation to HIVtesting. In those days, for example, educational campaigns did not actively promote testing for HIV. Explanations as to why Dutch MSM haven't been getting tested can be seen in this light. It is possible that Dutch MSM are generally still somewhat hesitant about getting tested because until now they have always seen more drawbacks than benefits. Moreover, the active testing policy may not in fact be active enough, in that it hasn't been possible to reach 
the desired target group(s) sufficiently or that the active policy is not being translated appropriately into effective educational campaigns that encourage HIV-testing among Dutch MSM.

\section{METHODS}

This section describes the methods and setup of the present study. To conduct this study, we opted for a qualitative investigation, since it is one of the first in the Netherlands that looks specifically at determinants of non-testing for HIV among MSM. Having the greatest possible explorative capacity was therefore considered important.

\section{Data collection}

For the collection of research data, we used individual, semi-structured indepth interviews. The most important feature of this type of interview is that the various topics to be discussed during the interview are already determined in advance. It is up to the interviewer to decide the sequence in which to broach these topics, however. He/she can adjust this on the basis of his/her perception of what seems most appropriate within the context of the interview. It is also possible within this type of interview to get the person being interviewed to provide more detailed information on a particular topic by asking supplementary questions. The central theme of each interview was why the subject had thus far never been tested for HIV and what his most important reasons for that were. During the first part of the interview, the subjects were asked a number of questions concerning their personal details, sexual preference and partner status. A variety of other questions in this part of the interview aimed at finding out which sexual techniques the subjects practiced. Subsequently they were asked about their use of condoms and/or other preventive measures. A few examples of questions that were asked during the first part of the interview are given in Table 3.

Table 3. Examples of questions that were asked during the first part of the interview

"How would you describe your own sexual preference?"

"Do you currently have a steady partner"

"Which sexual techniques do you use with your partner"

"Do you always take precautions when you have sex with your partner(s)? For example, do you use condoms?" 
During the second part of an interview, more specific questions were asked about the various reasons the subject had for not getting tested for HIV. These questions were based on the various possible explanations that were introduced in the discussion on the theoretical framework and had to do with knowledge, risk perception, fear and emotions in relation to an HIV-test, stigmatization, social environment and the current HIV-testing policy in the Netherlands.

Table 4 contains a few examples of questions that were asked during this part of the interview.

Table 4. Examples of questions asked during the second part of the interview

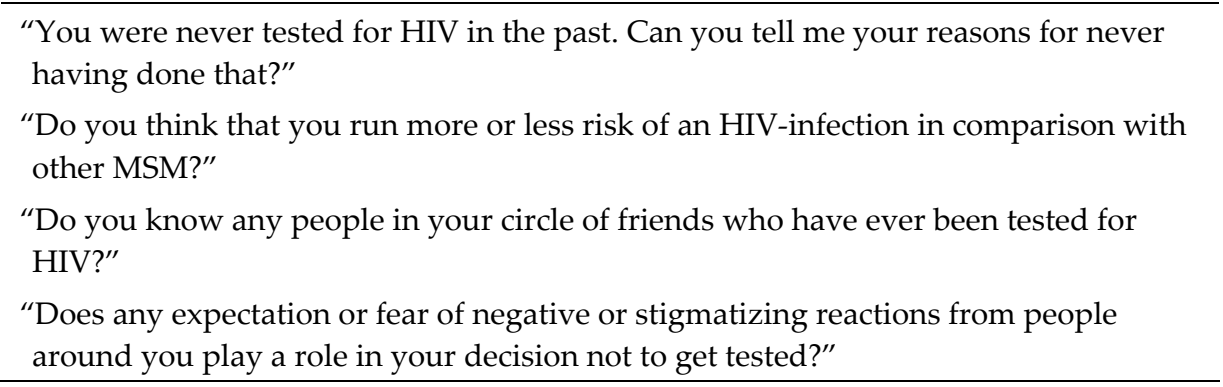

It is important to note that the subjects were also encouraged during the interview to talk spontaneously about anything they considered to be relevant within the context of the present study.

\section{Recruitment}

To be able to answer our central research question, we recruited a total of 32 MSM who matched the criteria we had established for participation in the study. Each participant should:

- as yet never have been tested for HIV;

- identify himself as gay or bisexual;

- have a steady partner or recent casual contacts.

During the recruitment phase, we also made sure the total sampling would include approximately equal numbers of men who were below 30 and above 30 years of age and likewise of men who had a steady partner and those who did not. A total of 25 men were recruited in Maastricht using three different strategies. First, potential participants were sought by means of leaflets and posters placed at local agencies such as the municipal health authority (GGD) and at the local chapter of the Dutch advocacy group for gay and bisexual men and women (COC), as well as in bars and discos for gay and bisexual men. These leaflets and posters contained a brief description of the nature and setup 
of the present study and an appeal to those who were interested to contact the project leader by telephone or e-mail. If the interested caller met the criteria for participation in the study, an appointment was made with him for an interview. In the second strategy, gay and bisexual men who could potentially want to take part in the study were actively canvassed at set times in the bars and discos in Maastricht that cater to them. Specifically, men who were in the bar or disco at that moment were asked if they were interested in taking part. Those who were interested were first evaluated in terms of the selection criteria and, if they satisfied those, later contacted by telephone to make an appointment for an interview. The third and final way we recruited subjects was to ask those who were taking part in the study if they would ask within their circle of friends if anyone else was interested in participating. The remaining seven participants were all recruited in Rotterdam with the help of the local health authority (GGD) there.

All participants were individually interviewed by one of five female interviewers who had all been given an extensive introduction to the topic in advance and through their earlier training possessed the necessary skills for conducting interviews. We chose to use female interviewers because research has shown that they are quicker at winning the confidence of the person being interviewed when the discussion involves a sensitive topic like sexuality (Ingham, Vanwesenbeeck \& Kirkland, 1999). The interviews lasted approximately one to two hours at most and were recorded on audiotape with the subject's written permission.

Prior to the interview, each subject was informed about the nature and purpose of the present study. They were also ensured that any information they might provide during the interview would be treated as strictly confidential and processed anonymously. At that point, every subject signed a statement of permission, indicating that they were participating in the study on a voluntary basis and were aware that they could terminate their participation in the study at any time. Following the interview, the participants received 75 euros' worth of gift certificates as compensation for their time.

\section{Subjects}

All 32 men who decided to take part in the present study were Dutch citizens. Thirty-one men described their sexual preference as homosexual and one man indicated that he was bisexual. Seventeen men were younger than 30 years old and seven of those had a steady partner. The average age in this subgroup was 23 years (range 20-29). The other 15 men were all older than 30 and seven of them had a steady partner. The average age in this subgroup was 38 years (range 30-54). The average age for the total sample was 30 years (range 20-54). In terms of the subjects' level of education, 25 men had received higher 
education, while seven had received a form of lower education. The data pertaining to the subjects' current living situation and their religious convictions (if any) are shown in Tables 5 and 6, respectively.

Table 5. Religious conviction of study participants $(\mathrm{N}=32)$

\begin{tabular}{ll}
\hline Religious conviction & $\mathbf{N}$ \\
\hline Catholic & 12 \\
Reformed & 1 \\
None & 17 \\
Other & 2 \\
\hline
\end{tabular}

Table 6. Current living situation of study participants ( $\mathrm{N}=32)$

\begin{tabular}{ll}
\hline Living situation & $\mathbf{N}$ \\
\hline Allone & 22 \\
Together (with partner or roommate) & 8 \\
With parents & 2 \\
\hline
\end{tabular}

\section{Data analysis}

To facilitate the analysis of the data collected for this study, the audio recordings were first typed out in their entirety as interview transcripts. Each interview transcript was then analyzed thematically using the specialized software QSR-NVIVO 1.3. Once the research data had been analyzed in this way, the audio recordings were destroyed, so that only the analyzed transcripts remained.

The thematic analysis can best be described as a process of selecting and encoding information. The encoding was done using themes selected on the basis of relevant theories. In that way, the information in each interview transcript could be selected and coded under the appropriate theme, for example: risk perception. In the same way, any information that was not relevant within the theoretical framework of the present study was deleted from the research data. The thematic analysis of the interview transcripts ultimately provided a database in which all relevant information was coded and grouped according to the theoretical framework. The ultimate results and the conclusions we draw from them in the present study are based on this structured database. 


\section{RESULTS}

In this section we describe the results of the present study. To begin with, we will focus on the sexual behavior reported by the subjects. We then consider in greater depth their various reasons for not getting tested for HIV.

\section{Sexual behavior}

\section{Men under $\mathbf{3 0}$ years of age: partner status and behavior}

Ten of the 17 men in this subgroup reported having no steady partner at the time of the study. Most of them said that they had occasionally had steady relationships in the past, and all of them reported having had one or more casual contacts in the recent past. The remaining seven men did have a steady partner at the time of the study. A small minority of those subjects said that they had also already had one or more steady relationships in the past. None of the men with a steady partner indicated that they also had casual sexual contacts outside their current steady relationship.

All of the men reported that they usually had oral sex with casual contacts. Most of them indicated that a condom was not always used in that case, but that care was always taken not to come in each other's mouth. Anal sex turned out to be a sexual technique used less frequently with casual contacts: a minority of the subjects reported having had anal sex occasionally with a casual contact. A small number of those men said they had not always used a condom during anal sex and that they had occasionally had unprotected anal sex with casual contacts.

"In the past six months I've had about four casual contacts that I had both anal and oral sex with... I didn't always use a condom, but I did always ask them about their past and I trusted that they were being honest."

(20 years old, no steady partner)

Anal and oral sex with the steady partner were reported. Most of the men indicated in that regard that they rarely if ever used a condom. The most important reason that most of them gave for this was that they had already been having a steady monogamous relationship with their partner for a longer period and that they trusted that their partner had not had any sexual contacts outside this relationship. A small number of men also indicated that ejaculation sometimes occurred in each other's mouth.

"I have had a steady partner three times in the past... In my last relationship I also had anal sex with my partner, but we avoided coming in each other."

(28 years old, steady partner) 


\section{Men over 30 years of age: partner status and behavior}

Eight of the 15 men from this subgroup indicated that they had no steady partner at the time of the study. Most said that they had already had one or more steady relationships in the past, and all of them reported having had one or more casual contacts in the recent past. The remaining seven men had a steady relationship at the time of the study and a number of them indicated that they had already had one or more steady relationships in the past as well. A number of men said that they also had casual sex contacts aside from their steady partner, but that they had made clear agreements about this with their partner.

"Besides that, we (my boyfriend and I) both occasionally have sex with others, and we both know about it... We go to the bathhouse every once in a while or otherwise have our friends and contacts. And we've made agreements about that: about things that we don't do with each other, so also not with others."

(41 years old, steady partner)

"We may be married, but you don't want to have the same thing for lunch everyday. We agreed on that from the very beginning once we started living together. He felt the need to play around with somebody else once in a while, and so did I."

(33 years old, steady partner)

The sexual techniques that nearly all of the subjects used with casual contacts were both anal and oral sex. A small number of them reported always having had protected sex with casual contacts, for both anal and oral sex. They also said that no one ever ejaculated in the other's mouth during oral sex. The remaining men indicated that they had also occasionally had unsafe sex with casual contacts, both unprotected anal sex and oral sex involving ejaculation in each other's mouth.

"I have anywhere from one to three casual contacts per month... Anal sex, yes, that happens sometimes too, and also oral sex, but then without anybody coming in the other's mouth. Unfortunately I almost never use condoms when I have sex with a casual contact. I know it's wrong, but what can I do?"

(54 years old, no steady partner)

The sexual techniques used with a steady partner turned out to be both anal and oral sex, and a condom was seldom used in either case. Most of the men reported that they didn't consider the use of condoms to be necessary because 
they had already been in a steady relationship for a longer period of time. Furthermore, a number of men indicated that it sometimes happened that they came in the other's mouth.

\section{Reasons for not getting tested for HIV}

In this subsection, we report the various reasons that the subjects mentioned for not getting tested for HIV. Any striking differences (as revealed in the interviews) between younger and older men, or between those with a steady partner and those without one, are mentioned explicitly.

\section{Knowledge}

As we hope to have made clear in the discussion of the theoretical framework, knowledge is an important condition that must be met before a certain behavior can be carried out. During the interviews, a variety of questions were asked to determine whether or not the subjects had sufficient knowledge about HIVtests, about HAART and about the testing-treatment argument in that connection. When questions were asked about a number of different aspects involved in an HIV-test, it became evident that most of the men had some general knowledge about HIV-tests. Most of them reported knowing that an HIV-test involved having blood drawn and that one had to go to the GGD, the hospital or one's family doctor to have that done. However, when asked more specific questions having to do with the cost of an HIV-test, the anonymity of the test results or the testing procedure, most of the men were unable to give clear answers to these. Many of those interviewed indicated for example that they didn't know exactly how much an HIV-test cost. In that connection, most of the subjects said they had actually figured that an HIV-test was entirely free. Nor did most of those interviewed know precisely what the procedure was that an HIV-test involves. The only thing they knew for sure was that they would need to have blood drawn for an HIV-test.

"Yeah, you can go to your doctor or to the GGD, and you can also have it done at the hospital... I don't really know what the testing procedure is: they draw blood and then you just wait until the result comes... I think they give you the result over the telephone, but I'm not exactly sure how it works... Beyond that, I think it all happens anonymously and that it doesn't cost anything... At least I'm assuming that it's free."

(25 years old, no steady partner)

One of the most important arguments that led to the shift towards an active HIV-testing policy in the Netherlands in 1999 was the development and the use of HAART for the treatment of those who were infected with HIV. The 
treatment of HIV came up at several points during the interviews, making it possible to determine how aware the subjects were of this method of treatment. Most of them reported having heard of "a combination therapy" but that they weren't familiar with the name HAART and otherwise didn't know anything about it. A small number of those interviewed indicated that they did know what HAART was because they had come into contact with the term through their education or work or because they knew someone who was being treated with HAART.

The use of HAART for treating people with an HIV-infection eventually led to the testing-treatment argument, which in concrete terms means that it is important to determine someone's seropositive status as quickly as possible so that an effective treatment with HAART can be started early on. Most of those interviewed indicated that they were not familiar with this argument, nor were they aware that it was so important to find out as quickly as possible if someone might be HIV positive.

"HAART? No, to be honest I really don't know anything about it... That [testingtreatment] argument is new to me too, but you are making it sound awfully positive. So what about the possible side effects, for example, and how does it actually work? What kind of therapy is it actually?"

(44 years old, no steady partner)

"I wasn't aware of the argument, but I would guess it really is true. Your immune system is probably a bit stronger at an early stage and your body can take a bit more and that means that you would remain better for a longer period if those AIDS medicines work properly..."

(20 years old, no steady partner)

In addition, a small number of men indicated that they found it odd that they knew so little about HAART and the related testing-treatment argument.

"I had actually never hear of it, of that argument... I think it's a little strange that there hasn't been any attention given to this in the media, since knowing about it makes it worth getting tested before it's too late."

(29 years old, no steady partner)

Although most of those interviewed thought the testing-treatment argument was a reasonable one for getting tested sooner, many of them also thought that it did not apply directly to themselves, for example because they claimed to have run little risk of becoming infected with HIV in the past. 


\section{Risk perception}

It appeared from the interviews that most subjects assessed their chances of becoming infected by HIV to be very slight. Most of them thought they had run or ran little if any risk of an HIV-infection. It also appeared that, when asked about a relative risk assessment, a large number of the subjects thought they ran less of a risk of becoming infected with HIV than other MSM.

"I'd say I'm more apt to run less of a risk of becoming infected with HIV than other MSM. When I look around me and see what's going on, I think, geez, they're just going at it like a bunch of rabbits."

(29 years old, no steady partner)

"I'd estimate the chance that I'm infected with HIV to be very small because I've never had unsafe sex. At least, there's no way I can have it, I know that for sure, and I don't think I'm going to be in situations where I could get it."

(24 years old, no steady partner)

"I would say there's zero chance that I myself am infected with HIV...because I figure that when I'm having sex with my partner, it's just the two of us. I'm assuming he isn't still having sex with others... I think I did occasionally run a risk of an HIV-infection in the past by not caring about anything when I was having promiscuous sex, for example by not using a condom during anal sex... If I compare myself with other gay men, I think I run less of a risk because I at any rate don't have any other contacts aside from my partner... "

(39 years old, steady partner)

The most important consequence of the low assessment that most of the subjects made of their risk of becoming infected with HIV was that they did not consider the necessity of their having an HIV-test to be very great.

"I would get tested if I had the feeling that I had run a real risk and I'm sure about it, so that the test could give me enough of a guarantee that I don't have it. I would do it if that were the case, but I don't have that feeling, so..."

(25 years old, no steady partner)

"One of the most important reasons why I still haven't been tested is that I'm convinced that I don't have it, because I've run practically no risk."

(21 years old, steady partner) 
For most of the men, the low risk they perceived was therefore one of the most important reasons for not getting tested for HIV. Interestingly, the subjects gave a number of different arguments when asked why they estimated their level of risk to be so low. We were struck by the fact that the men who had a steady partner usually indicated that they considered themselves to be at very low risk of an HIV-infection because they had a steady relationship and had no sexual contacts aside from their steady partner. Moreover, they also indicated that they trusted their partner and assumed that he, too, had had no sexual contacts outside the relationship. Men who had no steady partner indicated that they perceived themselves to be at very low risk because they had usually had safe sex. Most of those men said they had nearly always used a condom during anal sex and never let their sex partners ejaculate in their mouth during oral sex.

"The kinds of things I do now when I'm with others, sexually speaking, preclude a number of risks."

(46 years old, no steady partner)

When they did mention having had unsafe sex, most of those who were interviewed indicated that this only happened the first time or only incidentally. Some also indicated that they had had unsafe sex just once with a good friend or someone they knew well and who they were quite sure was not infected with HIV. In addition, a number of the older men said that they had occasionally run a risk of becoming infected with HIV in the past, but that they were convinced that they were not infected. The reason they gave for this was that they still felt healthy or that, by means of some other strategy, they were under the impression that they were not HIV positive.

"Yes, as I see it, I run little risk... I think it should have become obvious after a number of years if anything were wrong. We more or less kept to the nine-month rule when we started our relationship... and after I had run a risk with that one guy, if nothing turned out to be wrong in one way or another nine months later, then you can basically assume that nothing was wrong..."

(39 years old, steady partner)

\section{Fear}

Despite the fact that most of the subjects appeared to be convinced that they had run very little if any risk of an HIV-infection, the majority of them nevertheless retained a degree of uncertainty about what they referred to as that "very small chance" of having become infected with HIV. Indeed, as they indicated during the interviews, a sense of fear was another important reason 
for them not to get tested for HIV. This feeling of fear had primarily to do with a possible positive test result.

"My first reaction is one of fear... that I wouldn't want to know if the result of the test is bad... that is really the most important thing: my fear of the result."

(28 years old, steady partner)

"The idea of an HIV-test also makes me a little scared, especially the result of the test, if it were positive...and the consequences of that."

(33 years old, steady partner)

"The idea of an HIV-test gives me this sort of vague feeling, fear. Fear of that very small chance that I'll turn out to be positive after all, and of the mega-major consequences of that result, as I see it. There is only a very small chance, but if that's the case..."

(24 years old, no steady partner)

The fear that many of the men reported having of a positive test result has a lot to do with the fact that they estimated the consequences of such a result to be so great. Most of the subjects indicated that if they tested positive, that would radically change their lives.

"Most of all, I'm worried that the result will be positive. If it were positive, that would change everything all at once. Like your partner might also be infected, so then you're both going to be infected. Which ultimately means, as long as they don't find a cure, that you are going to die from it - and probably a lot earlier than you'd thought. That means that your whole life that you'd more or less charted out for yourself - everything you had in mind for yourself and that you wanted - that that's not going to happen."

(21 years old, steady partner)

A number of men said they considered a positive test result to be a sort of death sentence.

"If you are told that you have HIV, you're basically being told that you are going to die in a couple of years. That's how I see it now."

(25 years old, no steady partner)

"My main reason for not getting tested is basically the fear. It's really scary... It's like death is just around the corner."

(44 years old, no steady partner) 
Besides their fear of a positive test result, those who were interviewed also turned out to have anxiety about HIV itself. A large number of men indicated that when they were confronted with HIV in their immediate surroundings, for example by meeting someone who was HIV positive, this gave them feelings of anxiety.

"If I'm confronted with someone who has HIV or AIDS, yes, that makes me afraid. I met or saw someone with AIDS once, and...I was really afraid. I didn't know where to look. That made me feel so stupid..."

(23 years old, no steady partner)

In addition to the fear of a positive test result and their anxiety about HIV itself, various different men indicated that the period between the actual test and the announcement of the result was another source of anxiety. They told, for example, how a number of their friends had gotten tested for HIV and that those friends had found the wait to be highly stressful. This made the subjects even more anxious about that waiting period, and it made them afraid.

"I hadn't actually thought about it before, but those weeks between the test and the result, that must be really stressful. I know a number of people who got tested and who were completely stressed out during that period... Their experience has made me even more scared of those weeks in between.

(28 years old, steady partner)

In their answers to the questions about stigmatization, nearly all of the men indicated that they were not afraid of that. According to them, their decision about whether or not to get tested for HIV was in no way influenced by any fear of being stigmatized.

\section{Social environment}

At various points during the interviews, the subjects were asked questions about their social environment in general and about the gay scene in particular. A number of questions in this connection related specifically to the subjects' perception of the current standards and values with regard to an HIV-test. In their answers, most of the men indicated that they had the idea that their wider circle of friends generally thought positively about an HIV-test and that this was also the case within the gay community at large. Most of the subjects said their own attitude towards an HIV-test was very positive and that the same was true of their attitude towards those who get tested for HIV. They indicated for example that they had a lot of respect for such men and considered it to be a very sensible thing to do. 
"I have a lot of respect for men who get tested for HIV."

(44 years old, no steady partner)

A number of the questions were asked in order to find out if HIV-testing is currently a "hot topic" and whether their social environment in any way encourages people to get tested. Many of those who were interviewed indicated that while HIV itself is a very current topic within the gay community, HIVtesting is rarely ever discussed. It's not exactly avoided as a topic, but most of the men indicated that it is discussed sporadically and then only with good friends or with one's partner.

"HIV-testing: I don't really think it gets talked about much or that people think about it so much, so it's not exactly a hot topic. But it's generally thought to be a good thing and smart to do."

(28 years old, steady partner)

That also became clear when the subjects were asked how many of their good gay friends they knew for sure had ever been tested for HIV. The answer most of the men gave to this question was that they didn't exactly know. Some also said that if they did know, it wasn't something they discussed much with them.

"I don't know about any of my good gay friends whether or not they've ever been tested for HIV. It's very possible that they have, but I just don't have any idea about whether they have gotten tested or not... That's just because we've never talked about it."

(29 years old, no steady partner)

"I've never heard whether any of the acquaintances and good friends that come over to visit us have ever been tested."

(33 years old, steady partner)

"I do know a number of people who have been tested, probably about ten, and they all told me that openly too... But otherwise I haven't ever really discussed it with them, like about how they experienced it or how they felt when they did it, but more about the actual details... It's just not really something that I do my best to remember or that I'm all that interested in."

(24 years old, no steady partner)

Most of the men also indicated that they didn't have the idea that, for example, their friends or others in their social environment thought they (i.e. the subjects) 
ought to get tested for HIV at some point. Moreover, most of the subjects said that their social environment wouldn't influence their decision not to get tested for HIV. It is nevertheless striking that a small number of men indicated that they though it would be better if more people from their circle of friends would get tested for HIV. According to those subjects, that would make it much easier for them to do the same.

"It would be better if you had a whole lot of people in your circle of friends who would say, yeah, we're going get tested for HIV. I think it would make you more inclined to do it too."

(21 years old, no steady partner)

\section{HIV-testing policy in the Netherlands}

From the interviews it turned out that only a very small minority of the men were aware of the fact that the Netherlands currently has an active HIV-testing policy. When they were told about what this policy entailed, most of the subjects said that they had hardly noticed anything of it. They indicated for example that they couldn't think of a single educational campaign in which HIV-testing was encouraged or that mentioned where they could go to get tested if they wanted to do that.

"I think the current standpoint in the Netherlands is basically that HIV-testing is free... but I wouldn't know how they offer or recommend HIV-testing. One way or another they've managed to miss me..."

(29 years old, no steady partner)

"I can't think of any recent information campaign that promotes HIV-testing. Do they exist?"

(20 years old, no steady partner)

"I don't see any active testing policy whatsoever. I do see services, but no policy. If you ask me it's as if the government isn't really interested in whether or not people get tested."

(41 years old, steady partner)

In addition, a number of men reported that they thought that this policy didn't go far enough. In their view, for example, it shouldn't just stop at the active promotion of testing. People should regularly offer MSM the opportunity to get tested for HIV. 
"Offering HIV-testing by means of a leaflet and information campaigns is not exactly offering it actively. If you ask me, actively offering HIV-testing would be what the GGD did at a certain point with the hepatitis vaccination: they simply set up a little office in a bar and you could just walk in."

(23 years old, no steady partner)

\section{Mr. Right}

One reason that various different subjects gave for not having been tested was that they had yet to meet their "prince on a white horse". They considered an HIV-test as something you should do together with your steady partner once you've already been together for a while and have decided that you want to stay together in a relationship. In that sense, an HIV-test is seen as a sort of symbolic deed that will cement the relationship. Moreover, if the test result were negative, that would allow you to have unprotected sex with your partner within that relationship without having to worry about HIV and a possible infection.

"For one thing, it's that I still haven't found my Mr. Right, and if I do find him, then I'd do anything... I would say: okay, let's go ahead and do it now... And I'd prefer that we would do it together, because otherwise there's really no point.

(44 years old, no steady partner)

"I think I'd be more apt to get tested if I had a steady partner and you want to be sure about things and you want to have sex without a condom and you just want more freedom. I could imagine that I'd be more likely to get tested in that case."

(21 years old, no steady partner)

Moreover, a large number of the men who had a steady relationship at the time of the interview said they would definitely get tested for HIV if their current relationship would break up and they would start a new relationship.

\section{Barriers to testing}

A small number of men mentioned during the interview that they didn't like needles and that, for them, the fact that it's still necessary to draw blood in order to have an HIV-test done is a reason for not getting tested. 
"I'm not really into needles. For me, that is really the main reason, because I absolutely can't stand that, so if they come up with some other way, that would be great... I would prefer to know if I have it, if I've run a risk or whatever, but I don't really think I have, but really the most important thing are those needles. That's what keeps me from doing it."

(39 years old, steady partner)

As mentioned earlier, few of the men knew precisely what costs are involved in an HIV-test. In this connection, a number of those interviewed indicated that whatever costs there might be could be a barrier for them in terms of getting tested for HIV.

"No, I don't actually have any idea what an HIV-test costs. Frankly I always thought they were free. Now I do remember that it costs something, but hopefully not too much, since that would be a reason for me not to do it."

(28 years old, steady partner)

A number of men also indicated that it was a question of lack of time and nonchalance. They see that as another reason why they still haven't been tested for HIV. It turned out that they had indeed often thought about getting tested for HIV, but that for one reason or another they just postponed it or simply never got around to actually doing it.

"I've often thought that I really should do it at some point, but that still hasn't happened due to the most stupid reason: I just don't have time. I think I've really got to do it soon, but I basically never get around to it."

(21 years old, no steady partner)

\section{DISCUSSION AND CONCLUSIONS}

In this section we discuss the results in light of the theoretical framework described earlier in this chapter. To begin with, we were struck by the low level of up-to-date factual knowledge that most of those who were interviewed had in relation to HIV-testing. This is evident from the fact that most of them were unable to say much more about an HIV-test than where they could have it done and that it involved having blood drawn. Most of the subjects said they knew nothing about how much an HIV-test costs, about the procedure involved in such a test and about precisely how anonymous the test results were. In fact, remarkably few of the men turned out to be concerned about the aspects of anonymity in connection with the testing procedure. Research conducted by 
Facente (2000) had shown this to be a barrier to doing an HIV-test. A large number of the respondents in Facente's study had already been tested for HIV at some point in the past, however, which implies that her respondents may well already have had negative experiences with respect to the anonymity of the procedure. As the subjects in the present study reported knowing little about the procedure, it is unlikely that they would be too concerned about one particular aspect of a procedure they were unfamiliar with in general.

The men who were interviewed also had a low level of knowledge in relation to HAART. This is evident from the fact that most of the men reported knowing nothing about this method of treatment or about the relatively good prospects it offers to those who are infected with HIV. Only a few of the men were familiar with the testing-treatment argument, which is closely related to the use of HAART by those who are infected with HIV, and most of the men indicated that they did not realize that it was important to diagnose an HIVinfection as quickly as possible in order to maximize the effect of the treatment.

Theoretically, the low level of knowledge about HIV-testing, HAART and the testing-treatment argument could be the result of inadequately detailed information campaigns or of the failure of such campaigns to reach the target group. On the basis of our findings, the latter can be seen as the most plausible explanation. It turned out for example that none of the men could recall an information campaign aimed specifically at HIV-testing.

In terms of risk perception, it is remarkable that most of the subjects considered themselves to be at low risk of becoming infected with HIV. Most of the men thought they had run little or no risk of an HIV-infection and therefore considered an HIV-test to be unnecessary. It must be said in this regard that, considering the kinds of behavior those men reported, a small number of the subjects were indeed correct in thinking they had run a low risk of infection with HIV. They consistently used a condom whenever they had anal sex and often during oral sex as well, and if they did not use a condom during oral sex, they made sure that they and their partners did not ejaculate in each other's mouth. Most of those who were interviewed reported having had risky sex at least once in the past, however. These men therefore mistakenly have the idea that they have run only a negligible risk, if any, of an HIV-infection. Unrealistic optimism, a phenomenon we described in the theoretical framework, characterizes the risk perception that most men have in relation to an HIVinfection. They consider themselves to be at low risk of an HIV-infection. What is more, they systematically estimate their own level of risk to be lower than that of other MSM.

It appeared from the interviews that two mechanisms lead many men to perceive themselves as being at low risk of an HIV-infection despite the 
objectively demonstrable risks they have taken in their behavior. First, most of them had failed to consider the cumulative effects of risky behavior when assessing their risk of contracting HIV. In other words, they had not taken into account that having unsafe sex on multiple occasions substantially increases the risk of being infected with HIV. Based on the subject's reported behavior, condoms were rarely if ever used for anal sex within a steady relationship and the partners regularly came in each other's mouth during oral sex. Moreover, regardless of their current partner status, many of the men had already had one or more steady relationships in the past in which they had had unprotected sex with their partner at the time.

Second, data from the interviews also support the idea that men who had run risks actively reasoned those risks away. Many of the subjects gave one or more reasons that in their view justified their low assessment of the risk they ran of an HIV-infection. For example, many of them indicated that they figured they ran no risk of an HIV-infection because they were in a steady relationship and trusted that their partner was not having any sexual contacts outside the relationship. Those who reported also having casual sex outside their steady relationship - these were primarily older men - had made agreements in that regard with their partner and trusted that those were being kept. The Monitor Study pointed out in this connection that partners often fail to live up to the agreements they make with each other. It turned out for example that in relationships where the partners had agreed always to use condoms with casual partners, $12 \%$ of the respondents nevertheless reported having had unprotected anal sex with casual partners (Hogeweg \& Hospers, 2000). A number of other reasons that especially the younger men mentioned to justify their low risk assessment were that they had only had unprotected anal sex a small number of times, that they had had unprotected anal sex once with a good friend or acquaintance whom they believed was not infected with HIV, or that they hadn't been sexually active for very long. Older men more often said that they still felt healthy and didn't think they had noticed any physical symptoms that could point to an HIV-infection.

In addition to knowledge and risk perception, fear also evidently has a negative impact on the HIV-testing behavior of Dutch MSM. Their sense of fear turned out to manifest itself on a couple of different levels. First, the interviews revealed that men were afraid of a possible positive test result, even when they had indicated earlier that they considered themselves at low risk of being infected with HIV. This feeling of fear had to do primarily with the major consequences that most of the men thought a positive test result would have for them. Many of them reported that their world would collapse in the event of a positive test result, that this would place a heavy burden on their future plans, 
and that the HIV-infection would ultimately lead to their death. Their lack of knowledge about the treatment of an HIV-infection with HAART, especially about the positive effects of HAART, probably plays an important role in their experience of anxiety. As mentioned earlier, this method of treatment is beneficial in terms of both the life span and quality of life of those who are infected with HIV. As a result, the prospects for people with HIV are such that the medical profession no longer considers an HIV-infection to be a terminal disease but rather a chronic illness. A second level on which the so often reported sense of fear manifested itself was HIV/AIDS itself. Most men indicated that they considered HIV/AIDS to be a horrible disease that called up a sense of anxiety whenever they were confronted by it.

In our discussion of the theoretical framework, we also suggested that one's fear of being stigmatized and the fear that one's test results could be used against him could have a negative impact on the HIV-testing behavior of Dutch MSM. In terms of the fear of being stigmatized, a very small minority indicated that this was indeed the case. Nearly all of the men said they were not afraid that they would be confronted with negative reactions from those around them if they turned out to be HIV positive and that this would certainly not play a role in their decision not to get rested for HIV. There are two possible explanations for this. First, it could be that one only becomes aware of stigmatization once he or she has entered into the situation of being HIV positive. Second, it is possible that the stigmatization of people with HIV/AIDS is less widespread in the Netherlands than in other countries. The latter hypothesis is supported by the findings of a recent study in which it turned out that the reactions of the Dutch public towards people with HIV/AIDS are moderately positive (Bos et al., 2001). In terms of the fear that one's test results could be used against him, remarkably few of those who were interviewed mentioned experiencing this. Once again, this is probably due to their low level of knowledge about the procedure involved in HIV-testing.

Another behavior determinant mentioned in the theoretical framework as having a potentially negative impact on one's inclination to get tested for HIV was the social environment. The results show that the influence of the social environment on one's not getting tested for HIV primarily has to do with the lack of any substantial support and encouragement in terms of getting tested. In the first place, many of the men reported that HIV-testing was seldom talked about and in any case not a regular topic of conversation. In other words, HIVtesting turned out not to be an issue. Second, and closely related to this, most of the subjects indicated that their friends or acquaintances had never pointed out to them that it might be a good idea for them to get tested for HIV. The interviews also revealed that, according to most of the men, the current 
standards and values within their social environment with respect to an HIVtest were not such that getting tested was either frowned upon or considered unimportant. In addition, most of the subjects indicated that also within the gay community at large, getting tested for HIV-test was seen as sensible. Moreover, many of the men said they had respect for those people who actually did get tested. Once again, it should be pointed out that the results with respect to the role of the social environment can in part be seen in connection with the lack of information campaigns. As a result of that lack, the idea of getting tested is not being brought to everyone's attention sufficiently, it is hardly a topic of discussion, and too little use is being made of the mechanism whereby the support and encouragement one receives from one's circle of friends with regard to getting tested for HIV can have positive effects.

The current HIV-testing policy in the Netherlands also appears to have a role in the failure of Dutch MSM to get tested for HIV. An important initial finding was that hardly any of the subjects knew about the current, active HIVtesting policy in the Netherlands and few had any idea about what that policy entails. It is also striking in this connection that especially the older men never referred to the fact that HIV-testing used to be discouraged, let alone that they knew that things had changed in that regard. In other words, people are hardly if at all aware of the current HIV-testing policy. This isn't surprising, however, since the interviews revealed that none of the subjects could remember for example an educational campaign that specifically encouraged getting tested for HIV.

Most of the men were likewise unfamiliar with the testing-treatment argument, which is closely connected to the development and application of HAART. The interviews also revealed that many of the subjects were unaware of how important it is, in terms of this method of treatment, to discover someone's seropositive status as quickly as possible. This is remarkable, especially when one considers that this was one of the most important arguments for switching to an active HIV-testing policy in the Netherlands. In general, we can conclude in relation to the HIV-testing policy that too little effective information is available that focuses specifically on the HIV-test, on getting tested for HIV, and on HAART along with the testing-treatment argument.

Another interesting finding that emerged from the interviews was that a number of the men said they had not yet been tested for HIV because they still hadn't met the "love of their life". Moreover, many of those who had a steady partner indicated that they would get tested for HIV if their current relationship were to end and they would start a new one. It remains to be seen whether or not they will in fact get tested once they find themselves in a new steady 
relationship, since there were plenty of interviewees who had already been in numerous steady relationships in the past but had nevertheless still not been tested. Similar findings emerged from an Australian study by Lupton et al. (1995). Their explanation for this was that an HIV-test was gaining an evergreater symbolic value as a confirmation of a relationship or as a sign of purity. This explanation may also hold for the men who mentioned this in the present study.

In summary, the results of our study lead us to characterize the situation as follows. Among the group of MSM who have still never been tested for HIV, there is an extremely low level of knowledge about the current testing policy, about the HIV-test itself and about the procedures it involves. In addition, this group also has a sense of anxiety about having an HIV-test done and especially about the consequences of a positive result. Part of that fear can be considered ungrounded, however, certainly now that major advances have been booked in the treatment of those who are infected with HIV. Meanwhile, while the majority of these men have in fact run risks, they tend to reason away those risks. In this context it is interesting to note that one can in fact get away with reasoning away the risks since neither the educational campaigns nor one's social environment brings to one's attention the benefits of having an HIV-test done after one has run risks. In the event that new educational activities are developed in this area, the content of the information will need to focus on the above-mentioned aspects that are related to non-testing. These aspects would furthermore need to be approached in an integrated rather than an isolated manner, based on scientific insights about behavior and behavioral change. This will be a difficult but highly challenging task. 


\section{CHAPTER THREE}

Social-cognitive determinants of HIV-testing intentions

This chapter has been published as:

Mikolajczak, J., Hospers, H.J., \& Kok, G. (2006). Reasons for not taking an HIVtest among untested men who have sex with men: an Internet study. AIDS and Behavior, 10, 431-435. 


\section{INTRODUCTION}

Throughout the course of the AIDS epidemic, men who have sex with men (MSM) have been one of the groups at highest risk for HIV-infection in Western countries (UNAIDS, 2003). The current availability of more effective Highly Active Antiretroviral Therapy (HAART) for HIV-infected individuals provides strong arguments in favor of active promotion of HIV-testing among risk groups, including MSM. Early detection of HIV-infection allows adequate monitoring of an individual's health status, proper treatment initiation, and creates opportunities for education of newly diagnosed individuals with respect to treatment, care and support. Also, early detection allows HIVinfected individuals to better prepare for treatment (Chadborn et al., 2005).

In addition to treatment benefits, a meta-analysis on the effects of HIVtesting and counseling on sexual risk behavior showed that finding out being HIV-infected was associated with a significant reduction in subsequent sexual risk behavior whereas finding out being HIV-negative did not lead to an increase in sexual risk behavior (Weinhardt et al., 1999).

With respect to the uptake of HIV-testing, there is great variation in the proportion of MSM ever tested for HIV in Western countries. In some countries like Switzerland (Dubois-Arber et al., 2002; Moreau-Gruet et al., 2001;), and Spain (Pérez et al., 2002) HIV-testing rates among MSM of approximately $80 \%$ have been reported. In MSM samples in Australia (National Centre in HIV Social Research, 2003) and the USA (Mills et al., 2001; Webster et al., 2003) rates of over $90 \%$ have been observed. In other Western countries, such as the Netherlands and Scotland, HIV-testing rates among MSM are substantially lower. In a recently conducted Scottish survey, an HIV-testing percentage of $50 \%$ among MSM was found (Sigma Research, 2005). In the Netherlands, MSM HIV-testing rates have traditionally been the lowest in Europe. In 1994, only $33 \%$ of MSM were ever tested (Bochow et al., 1994). More recent studies among MSM in the Netherlands show that this number has somewhat increased since 1994, with approximately $55 \%$ of Dutch MSM now reporting ever having taken an HIV-test (Hospers et al., 2003; Hospers et al., 2005). Thus, a significant proportion of MSM in the Netherlands remains unaware of its serostatus, thereby not only missing out on the abovementioned benefits in case of HIVinfection but also continuing to place others at risk for HIV-infection through unprotected sex. With respect to the latter, a recent Dutch study showed that among MSM who were unaware of their HIV-status, 13\% reported unprotected anal intercourse (UAI) with their last casual sex partner (Hospers et al., 2005).

Given the low HIV-testing rates among MSM in the Netherlands and a recent change in the Dutch HIV-testing policy, - from a strategy that discourages HIV-testing to active promotion of HIV-testing among risk groups 
- interventions are needed that aim at motivating untested MSM to take an HIV-test. The development of such preventive interventions is ideally a planned activity (Kok, 1999; Kok et al., 2004), based on psychosocial theories of behavior and behavior change, as well as on empirical evidence (Bartholomew et al., 2001).

A recent interview study among 33 Dutch untested MSM provided insight regarding factors that contribute to not taking an HIV-test (Mikolajczak et al., 2004). Adequate knowledge about the current Dutch HIV-testing policy (i.e. that testing is now encouraged), HIV-testing procedures, and specific aspects of taking an HIV-test (i.e. costs for taking a test) appeared to be limited among respondents. Also, perceived risk of being HIV-infected was low, although a vast majority of respondents did report sexual risk behavior. Fear for detrimental consequences for their life and their future after finding out being HIV-infected was also reported by many respondents as a reason for not taking an HIV-test. In addition, it also became clear that HIV-testing was usually not openly supported or encouraged in respondents' social environment and that it was hardly ever talked about with others (i.e. friends).

The present chapter reports on the findings of a large scale quantitative Internet-based survey among Dutch MSM, which was set up to corroborate our previous qualitative findings on the one hand, and to identify the social cognitive determinants of HIV-testing on the other hand. In doing the latter, the behavioral determinants in Ajzen's Theory of Planned Behavior (TPB) (Ajzen, 1991) were assessed to predict the intention of untested at-risk Dutch MSM to take an HIV-test. TPB postulates that the intention to take an HIV-test is the most proximal predictor of actually doing so. Intention in its turn is determined by attitude, self-efficacy and social norms with respect to taking an HIV-test. Ajzen's TPB variables were supplemented with additional behavioral determinants such as knowledge about HIV-testing, perceived risk of HIVinfection, talking about HIV-testing with others, and fear of taking an HIV-test, based on the findings from our qualitative study.

\section{METHODS}

For the purpose of the present study, an interactive online questionnaire was developed and hosted on the website of the largest Dutch chat site for MSM (www.chatboy.nl). Visitors of the Chatboy-website were invited to complete this questionnaire. 


\section{Questionnaire}

The interactive online questionnaire asked for demographic information, sexual risk behavior in the AIDS era and social cognitive variables related to HIVtesting. Demographic variables of interest were age, educational level, cultural background, sexual attraction, HIV-testing, HIV-status and steady partner status of respondents. Sexual risk behavior in the AIDS era was measured by identifying respondents' estimated total number of casual and/or steady partners in the previous 20 years, engagement in anal intercourse with these partners, and engagement in unprotected anal intercourse (UAI) with these partners. Most of the social cognitive determinants of interest were measured with multiple items, which were subjected to reliability analysis to allow item summation, given a sufficient reliability coefficient ${ }^{1}$.

Ajzen's TPB variables were operationalized as follows:

- the direct attitude towards taking an HIV-test was measured with four items. Example: "I consider taking an HIV-test to be ...", measured on a five-point scale (very unwise-very wise), alpha $=.72$.

- twelve attitudinal beliefs with respect to taking an HIV-test were included on the basis of our previous qualitative findings. Of these, seven items made up a scale that reflected perceived advantages of taking an HIV-test. Example: "If I take an HIV-test, I can timely initiate treatment", measured on a five-point scale (totally disagree-totally agree), alpha $=.59$. The remaining five items made up a scale that reflected perceived disadvantages of taking an HIV-test. Example: "If I take an HIV-test, others will easily assume that I have had unprotected sex", measured on a five-point scale (totally disagree-totally agree), alpha $=.51$.

- subjective social norms were measured by two items. The first item, "Do you think your good friends would approve you taking an HIV-test", was measured on a five-point scale (surely not-surely so) with one additional option (I don't know) which was recalculated to the mean. The second item, "Do you think your good friends think that you should take an HIV-test", was measured on a five-point scale (surely not-surely so) with one additional option (I don't know) which was also recalculated to the mean.

- A scale of respondents' self-efficacy with respect to taking an HIV-test and the different steps involved was made up of eight items. Example: "I consider waiting for the test results for a couple of days to be ... ", measured on a fivepoint scale (very difficult-very easy), alpha $=.83$.

- intention to take an HIV-test was measured by three statements. Example: "I am planning to take an HIV-test", measured on a five-point scale (totally not applicable-completely applicable), alpha $=.96$.

\footnotetext{
${ }^{1}$ Since all scales measuring the social cognitive variables in the present study were self-constructed,
} a reliability coefficient of .50 was considered as the lower limit criterion for sufficiency 
The additional social cognitive determinants were operationalized as follows:

- three items made up a scale that measured how much respondents had ever talked about HIV-testing. Example: "How much have you ever spoken about taking an HIV-test with your good friends", measured on a five-point scale (never-very often), alpha $=.84$.

- two qualitatively different scales were constructed to assess respondents' knowledge about HIV-testing. The first scale, measuring factual knowledge about HIV and HIV-testing consisted of 14 items. However, insufficient internal consistency (alpha $=.49$ ) prevented item summation and subsequent inclusion of this scale in the statistical analyses. None of the items displayed a significant correlation with intention. A second scale, which measured perceived knowledge about HIV-testing, was made up of seven items. Example: "How much do you know about the purpose of early detection of HIV-infection", measured on a five-point scale (very little-very much), alpha $=.86$.

- perceived risk for HIV-infection was measured with one question: "What do you think your chance of being HIV-infected is?", measured on a seven-point scale (impossible-very great chance).

Finally, 15 reasons for not taking an HIV-test were presented to untested respondents only, who were asked to rate to the importance of these 15 reasons in their decision not to take an HIV-test. Example: "I have never taken an HIVtest because a positive result would turn my life upside down", rated on a fivepoint scale (very unimportant-very important).

\section{Procedure}

Uploaded to a secure website, the interactive online questionnaire was only accessible via three links located on the Chatboy website: a button placed on the homepage, a profile of a chat room visitor nicknamed Chatboy^study, and a click-on banner in the chat box itself.

\section{Enrollment}

Statistics logged by our Internet server showed that the opening page of the online questionnaire was visited 10804 times during the enrolment period of 29 days. The opening page contained information about the purpose and the background of the study, and invited chatters to complete the questionnaire. Chatters could proceed to the introduction page of the questionnaire by clicking the "enter"-button, which $69 \%$ (7513) of the initial visitors did.

On this page, participants were provided with answering instructions as well as a "continue"-button that led to the first question. Nearly 95\% (7127) of the participants who arrived at the introduction page continued to the first question. Of these, approximately 4319 completed the questionnaire and submitted their answers. Thus, $57 \%$ of all chatters who arrived at the 
introduction page, and $61 \%$ of those who continued on to the first question completed the questionnaire. This figure is comparable to the response rates of other paper-and-pencil and Internet-based MSM surveys in the Netherlands (Hospers et al., 2005; Hospers et al., 2003).

\section{Data quality}

The dataset, containing 4319 records, was subject to a profound cleaning process. This consisted of checking for multiple submissions from the same IPaddress, submissions with an unrealistically short completion time relative to the number of questions that had to be answered, and logical inconsistencies in answers that participants provided on different questions (for example, reporting a smaller total number of casual partners than the number of casual partners with whom they practiced anal intercourse). These checks resulted in exclusion of 126 cases. Due to an error in the programming code, the answer of the first 162 respondents on one item was not saved to the data file which led to deletion of these records. A routing error led to the loss of critical information of another 199 respondents which were also deleted from the data file. After performing the above described procedures, the cleaned data file contained unique records of 3832 respondents. Of these, 2205 respondents (57\%) indicated that they had ever taken an HIV-test (171 HIV-positive; 2034 HIV-negative). The remaining 1627 untested respondents (43\%) comprised the final sample for the following analyses on determinants of not testing for HIV.

\section{Statistical analysis}

Given the large sample size in all analyses, differences were tested using a pvalue of .01 .

\section{RESULTS}

Mean age of the sample $(\mathrm{N}=1627)$ was 33 years $(\mathrm{SD}=10.72$; range 14 to 76$)$. A majority of the respondents $(78 \%)$ indicated that they were either exclusively or mostly attracted to other men (referred to as gay men in the remainder of this article), while a substantial group (22\%) indicated that they were also attracted to women (referred to as bisexual men in the remainder of this article). Of respondents, $48 \%$ had completed some form of higher education (university, college, or high school at a higher level), whereas $52 \%$ had completed some form of lower education (elementary school, vocational training, or lower-level high school). Most respondents (90\%) had a Dutch cultural background, $4 \%$ a Dutch/non-Dutch background (e.g. Dutch/Antillean), and 6\% a non-Dutch background. A majority of the respondents (56\%) reported unprotected anal 
intercourse (UAI) with another man since becoming sexually active with men. Of these, $31 \%$ with casual partners, $28 \%$ with steady partners and $41 \%$ with both casual and steady partners. This group of respondents ( $\mathrm{N}=908)$ makes up the at-risk group for HIV-infection. The remaining 719 respondents $(44 \%)$ reported no UAI and make up the no-risk group for HIV-infection. These two risk groups did not differ on demographics. However, with respect to sexrelated variables, a higher proportion of respondents in the at-risk group indicated being gay $\left(89 \%\right.$ versus $\left.65 \% ; \mathrm{X}^{2}(1)=134.75, \mathrm{p}<.001\right)$, and to have a steady relationship with a man $\left(60 \%\right.$ versus $\left.40 \% ; X^{2}(1)=35.54, p<.001\right)$ compared to respondents in the no-risk group. Also, a higher number of lifetime casual partners was significantly associated with a higher likelihood to be classified in the at-risk group ( $\mathrm{OR}=1.02$ for the effect of 10 more casual partners, $\mathrm{p}<.001,99 \% \mathrm{CI}$ for $\mathrm{OR}=1.01-1.03)$. No such association was found with respect to lifetime steady partners.

Next, the importance of reasons underlying the decision not to test, and differences in importance between the at-risk group and the no-risk group were assessed. As can be seen in Table 1, only the top 4 of the 15 reasons for not taking an HIV-test yielded a score above the scale mean, indicating relevance in the decision not to test for HIV.

Interestingly, these four reasons were also the ones that discriminated between risk groups. Respondents in the no-risk group appraise the fact that they "...have never been at risk for HIV-infection" and they "...never had unprotected sex" as the most important reasons for not taking an HIV-test. Respondents in the at-risk group considered "...because a positive result would turn my life upside down", and "...because I am afraid of the consequences of a positive test result" as the most important reasons for not taking an HIV-test. Two additional reasons (reason 6 and 12) also discriminated between respondents in both risk groups (see Table I). However, since the scores of these items was below the scale mean, their relevance in respondents' decision not to take an HIV-test can be considered limited. 
Table 1. Mean scores of the importance of 15 reasons for not taking an HIV-test, comparing untested at-risk and no-risk respondents (five-point scale, 1=very unimportant, $5=$ =very important)

\begin{tabular}{|c|c|c|c|c|c|}
\hline I have never taken an HIV-test ... & $\begin{array}{c}\text { Total } \\
\text { group } \\
(\mathrm{N}=1465)\end{array}$ & $\begin{array}{c}\text { No-risk } \\
\text { group } \\
(\mathrm{N}=652)\end{array}$ & $\begin{array}{l}\text { At-risk } \\
\text { group } \\
(\mathrm{N}=813)\end{array}$ & $\mathrm{F}$ & $p<$ \\
\hline $\begin{array}{l}\text { 1. because I think I have never been at } \\
\text { risk for infection }\end{array}$ & 3.45 & 3.80 & 3.16 & 85.86 & .001 \\
\hline $\begin{array}{l}\text { 2. because a positive result would } \\
\text { turn my life upside down }\end{array}$ & 3.39 & 3.14 & 3.60 & 34.36 & .001 \\
\hline $\begin{array}{l}\text { 3. because I have never had } \\
\text { unprotected sex }\end{array}$ & 3.29 & 3.94 & 2.78 & 279.04 & .001 \\
\hline $\begin{array}{l}\text { 4. because I am afraid of the } \\
\text { consequences of a positive test } \\
\text { result }\end{array}$ & 3.01 & 2.75 & 3.22 & 35.31 & .001 \\
\hline $\begin{array}{l}\text { 5. because I don't like talking about } \\
\text { my sex life with a doctor or nurse }\end{array}$ & 2.78 & 2.71 & 2.83 & 2.10 & ns \\
\hline $\begin{array}{l}\text { 6. because I would rather not know } \\
\text { whether I am infected }\end{array}$ & 2.56 & 2.28 & 2.77 & 39.13 & .001 \\
\hline $\begin{array}{l}\text { 7. because I would rather not have } \\
\text { counseling before and after the test }\end{array}$ & 2.50 & 2.48 & 2.51 & .14 & ns \\
\hline $\begin{array}{l}\text { 8. because I don't expect a lot of } \\
\text { support and understanding of my } \\
\text { friends if I would do it }\end{array}$ & 2.44 & 2.43 & 2.45 & .03 & ns \\
\hline $\begin{array}{l}\text { 9. because I don't expect a lot of } \\
\text { support and understanding of my } \\
\text { friends when I turn out HIV+ }\end{array}$ & 2.35 & 2.38 & 2.33 & .57 & ns \\
\hline $\begin{array}{l}\text { 10. because I would rather not talk } \\
\text { about it with my partner }\end{array}$ & 2.16 & 2.21 & 2.11 & 1.89 & ns \\
\hline $\begin{array}{l}\text { 11. because I am sure that the current } \\
\text { medicines still have too many side } \\
\text { effects }\end{array}$ & 2.13 & 2.11 & 2.15 & .35 & ns \\
\hline $\begin{array}{l}\text { 12. because I have not yet met the } \\
\text { "right guy" }\end{array}$ & 2.08 & 2.25 & 1.95 & 15.80 & .001 \\
\hline $\begin{array}{l}\text { 13. because I do not know where I can } \\
\text { get tested }\end{array}$ & 2.07 & 2.13 & 2.02 & 2.21 & ns \\
\hline $\begin{array}{l}\text { 14. because there are no good } \\
\text { medicines and you can't do } \\
\text { anything about it }\end{array}$ & 2.06 & 2.02 & 2.09 & .93 & ns \\
\hline $\begin{array}{l}\text { 15. because I am afraid of blood and } \\
\text { needles }\end{array}$ & 1.81 & 1.82 & 1.81 & .00 & ns \\
\hline
\end{tabular}

Only respondents with no missing data on all 15 reasons were included in this analysis $(\mathrm{N}=1465)$

For the following analyses, only untested at-risk respondents were selected. In order to predict their intention to take an HIV-test, a sequential multivariate 
regression analysis was conducted with intention to take an HIV-test as the dependent variable. Close inspection of the assumptions for regression analysis led to a square root transformation of the dependent variable to improve homoscedasticity of residuals. No outliers were identified and no other assumptions of regression analysis were violated. A number of respondents had missing values on one or more of the (social cognitive) variables which resulted in 733 cases that were included in the regression analysis.

In the first step of the regression analysis, Ajzen's TPB variables were entered as predictors of intention. As can be seen in Table II, direct attitude and subjective social norm contributed significantly to the prediction of respondents' intention to take an HIV-test $\left(\mathrm{R}^{2}=.26\right)$. Their respective regression coefficients indicate a positive association with intention to take an HIV-test. In the second step of the analysis, additional social cognitive variables were introduced in the regression model by means of the stepwise forward procedure. Of these, only perceived risk of HIV-infection, and talking about HIV-testing contributed significantly to the prediction of the dependent variable, increasing the amount of explained variance to $28 \%$. As can be seen in table II, a higher perception of risk for HIV-infection and a higher score on the talking variable are associated with a higher intention to take an HIV-test.

Contrary to other TPB-determinant studies (Armitage and Connor, 2001), the level of explained variance in our regression model is substantially lower, which prompted further exploratory analyses. In order for additional variables to be included in the regression model, a significant correlation with intention was set as criterion. This led to the selection of nine additional variables. Of these, 6 originated from the 15 reasons for not taking an HIV-test: "I don't know where I can take an HIV-test" ( $\mathrm{r}=.17, \mathrm{p}<.001)$; "I have never had unprotected $\operatorname{sex}^{\prime \prime}(\mathrm{r}=-.11, \mathrm{p}<.01)$, "I have never been at risk for infection" $(\mathrm{r}=-.23, \mathrm{p}<.001)$; “I don't like talking about my sex life with a doctor or nurse" $(\mathrm{r}=.12, \mathrm{p}<.01)$; "A positive test result would turn my life up-side-down" ( $\mathrm{r}=.10, \mathrm{p}<.01)$; "I am afraid of the consequences of a positive test result" $(\mathrm{r}=.12, \mathrm{p}<.01)$. The three remaining additional variables that had a significant correlation with respondents' intention were demographic in nature: age $(r=-.28, p<.001)$; sexual orientation $(\mathrm{r}=-.15, \mathrm{p}<.001 ; 0=$ gay, $1=$ bisexual $)$ and reported risk with casual partners $(\mathrm{r}=.11, \mathrm{p}<.01)$. The latter variable reflected the significantly lower intention among untested at-risk respondents who never had UAI with casual partners compared to respondents who did report UAI with casual partners $(\mathrm{F}(1,731)=8.49, \mathrm{p}<.01)$. No such difference was found with respect to reported UAI with steady partners.

Of the six reasons for not taking an HIV-test, two had additional predictive value: "I don't know where I can get tested" which was positively 
associated with intention, and "I have never been at risk for HIV-infection" which was negatively associated with intention (see Table II). In addition, the effect of risk perception in the second model was partialled out after inclusion of the new variable which reflected the subjective risk for HIV-infection. Furthermore, two of the three demographic variables, namely age and sexual orientation, also added significantly to the prediction of respondents' intention. As can be seen in Table II, older respondents and bisexuals have a lower intention to take an HIV-test. The final regression model explained $37 \%$ of the variance in intention (see Table 2).

Table 2. Pearson correlations (r), standardized regression coefficients $(\beta)$ and levels of significance of the predictors of the intention to take an HIV-test among untested at-risk Dutch MSM $(\mathrm{N}=733) .{ }^{*}(\mathrm{p}<.01),{ }^{* *}(\mathrm{p}<.001)$

\begin{tabular}{|c|c|c|c|c|c|}
\hline \multirow[t]{2}{*}{ Predictor } & \multicolumn{5}{|c|}{ Model } \\
\hline & \multirow[b]{2}{*}{$r$} & I & II & III & IV \\
\hline & & \multicolumn{4}{|c|}{$\beta$} \\
\hline Direct attitude & $.31^{* *}$ & $.27^{* *}$ & $.29^{* *}$ & $.27^{* *}$ & $.24^{* *}$ \\
\hline Perceived advantages & $.18^{* *}$ & .08 & .08 & .08 & .05 \\
\hline Perceived disadvantages & .01 & .05 & .03 & .05 & .04 \\
\hline Approval of good friends when testing & $.11^{*}$ & .03 & .03 & .03 & .00 \\
\hline Good friends think you should get tested & $.41^{* *}$ & $.37^{* *}$ & $.32^{* *}$ & $.28^{* *}$ & $.29^{* *}$ \\
\hline Self-efficacy & $-.09^{*}$ & -.08 & -.08 & -.06 & -.03 \\
\hline Perceived risk for HIV-infection & $.18^{* *}$ & & $.12^{*}$ & .06 & .06 \\
\hline Talking about HIV-testing & $.15^{* *}$ & & $.11^{*}$ & $.13^{* *}$ & $.13^{* *}$ \\
\hline I don't know where I can get tested & $.17^{* *}$ & & & $.12^{* *}$ & $.13^{* *}$ \\
\hline I have never been at risk for HIV-infection & $-.23^{* *}$ & & & $-.15^{* *}$ & $-.13^{* *}$ \\
\hline Age & $-.30^{* *}$ & & & & $-.21^{* *}$ \\
\hline Sexual orientation ( $0=$ gay, $1=$ bisexual) & $-.15^{* *}$ & & & & $-.10^{*}$ \\
\hline $\mathrm{R}^{2}$ & & .26 & .28 & .31 & .37 \\
\hline$F_{\text {change }}$ & & $42.66^{* *}$ & $11.79^{* *}$ & $15.33^{* *}$ & $30.23^{* *}$ \\
\hline
\end{tabular}

In order to determine which items underlying the significant predictors discriminated between respondents, two intention groups were created based upon respondents' score on the intention variable. The first group consisted of respondents who scored below the scale mean, reflecting a negative intention to 
take an HIV-test (low intenders, $\mathrm{N}=396$ ). The second group consisted of respondents who scored above the scale mean, reflecting a positive intention to take an HIV-test (high intenders, $\mathrm{N}=180$ ). The remaining 157 respondents were not included in this analysis since their intention score was exactly the scale mean, reflecting a neutral position towards taking an HIV-test. Table 3 summarizes the results of the comparison of significant predictors between both intention groups.

Table 3. Comparison of respondents with a low versus high intention to take an HIV-test on significant predictors (if applicable at item-level $(\mathrm{N}=576)$ )

\begin{tabular}{|c|c|c|c|c|}
\hline Predictor & $\begin{array}{l}\text { Low } \\
\text { intention }\end{array}$ & $\begin{array}{c}\text { High } \\
\text { intention }\end{array}$ & $F / X^{2}$ & $\mathrm{p}<$ \\
\hline \multicolumn{5}{|l|}{$\begin{array}{l}\text { Direct attitude: "I consider taking an } \\
\text { HIV-test to be" }\end{array}$} \\
\hline very unimportant - very important & 3.35 & 4.10 & 63.01 & .001 \\
\hline very bad - very good & 3.92 & 4.51 & 58.65 & .001 \\
\hline very wise - very unwise & 4.03 & 4.73 & 76.27 & .001 \\
\hline very pleasant-very unpleasant & 2.47 & 2.55 & .49 & ns \\
\hline $\begin{array}{l}\text { Subjective social norm:" Do you think } \\
\text { your good friends think you should take } \\
\text { an HIV-test" }\end{array}$ & 2.58 & 3.49 & 101.80 & .001 \\
\hline \multicolumn{5}{|l|}{$\begin{array}{l}\text { Talking about HIV-testing: "How often } \\
\text { have you ever talked about HIV-testing } \\
\text { with ..." }\end{array}$} \\
\hline good friends & 1.80 & 2.09 & 15.72 & .001 \\
\hline someone who has already been tested & 1.67 & 1.98 & 15.25 & .001 \\
\hline others & 1.49 & 1.56 & 1.26 & ns \\
\hline $\begin{array}{l}\text { I have never been at risk for HIV- } \\
\text { infection }\end{array}$ & 3.44 & 2.84 & 26.10 & .001 \\
\hline I don't know where I can get tested & 1.76 & 2.18 & 12.36 & .001 \\
\hline Age & 35.32 & 27.84 & 69.83 & .001 \\
\hline \multicolumn{5}{|l|}{ Sexual orientation } \\
\hline$\%$ gay & 86 & 94 & $X^{2}(1)=7.64$ & .01 \\
\hline
\end{tabular}


Table 3 shows that three attitude items discriminate between high and low intenders. High intenders consider taking an HIV-test to be significantly more important, better and wiser compared to low intenders. High intenders also scored significantly higher on subjective social norm. With respect to talking about HIV-testing, two of three items discriminated between high and low intenders, reflecting high intenders to have talked about HIV-testing significantly more than low intenders, both with good friends and someone who had already taken an HIV-test. Low intenders rated not being at risk for HIV-infection significantly higher than high intenders. Contrary to low intenders, high intenders rated not knowing where to get tested significantly higher. Low intenders were significantly older than high intenders. Also, the high intention group comprised a significantly higher proportion of gay men compared to the low intention group (see Table 3).

\section{DISCUSSION AND CONCLUSION}

The present study provides important and relevant empirical input for future development of prevention activities aimed at motivating Dutch MSM to take an HIV-test. In the present Internet-sample of MSM, $42 \%$ of respondents never took an HIV-test. Among untested respondents, different reasons for not taking an HIV-test were found and social cognitive determinants of at-risk respondents' intention to take an HIV-test were identified.

With respect to reasons for not taking an HIV-test, four reasons - which were previously identified in our qualitative study - were also found in the present study. In addition, the present results also show that untested at-risk respondents' reasons for not taking an HIV-test are qualitatively different from untested no-risk respondents' reasons. Reasons reflecting low perceived risk for HIV-infection appear more important in no-risk respondents' decision not to test, whereas reasons reflecting fear of taking an HIV-test and the perceived detrimental consequences of an HIV-positive test result are more important for at-risk respondents.

With respect to identifying the structure of social cognitive determinants underlying HIV-testing, results in the present study show that three social cognitive determinants have a significant contribution in the prediction of untested at-risk respondents' intention to take an HIV-test: attitude, subjective social norm, and talking about HIV-testing. The regression model that contained these predictors accounted for $28 \%$ of the variance in respondents' intention to take an HIV-test. Exploratory analyses, which were prompted by this relatively low amount of explained variance, identified four additional 
variables that added significantly to the prediction of intention. The final regression model - containing seven predictors - accounted for $37 \%$ of the variance. Although the addition of variables increased the level of explained variance to what is usually found in comparable behavioral determinant studies (i.e. Armitage and Conner, 2001), it should be noted that the final model contains two demographic variables: age and sexual orientation. This is not in line with theory, since it is to be expected that their effects are reflected through the cognitive determinants that make up intention (Ajzen, 1991). One explanation for the presence of the effects of demographics might be that an important social cognitive determinant was not measured. Another explanation might be that within the social cognitive determinants measured, one or more specific aspects related to age or sexual orientation was not well captured. The fact that bisexuals have a lower intention to take an HIV-test than gay men do, might for example be related to many bisexuals believing that HIV-testing will be an open sesame to revealing their bisexuality to their partner. With respect to age, lower intention to take an HIV-test among older MSM might be related to a large time lag between their last sexual risk behavior and the present, compared to younger MSM, which may make HIV-testing less salient. Or, the absence of clinical symptoms may have led older MSM to believe that they are not HIVinfected. However, such beliefs were not included in the present study, leaving these explanations hypothetical and subject to future research.

Based on the present findings, several recommendations for future interventions to promote HIV-testing can be made. Part of the intervention should focus on establishing a positive attitude towards HIV-testing by providing arguments that support the importance of HIV-testing and stressing that it is a wise and good thing to do. In addition, substantial attention should be devoted to the establishment of a social norm that reflects general acceptance of taking an HIV-test. This in turn might also contribute to HIV-testing becoming less of a taboo and subject to more discussion, an aspect that should be part of future interventions as well. Untested at-risk respondents' low perceived risk for HIV-infection points to the necessity for future interventions to focus on establishing adequate perception of risk. Specific attention should also be devoted to counteract the effect of fear, which might not only become more intense as a result of establishing adequate perceptions of risk for HIVinfection, but was an important reason for not taking an HIV-test among at-risk respondents as well. Fear reduction might be accomplished by providing relevant arguments that counter the perceived detrimental consequences of taking an HIV-test and emphasize the (health) advantages of doing so.

To motivate untested at-risk Dutch MSM to take an HIV-test, adequate methods and strategies should be selected from theories of behavior change 
(Bartholomew et al., 2001). In addition to the recommendations made above, future research might clarify which (aspects of) social cognitive determinants were not captured in the present study. Along with the present findings, clarification thereof will also contribute to the development of effective theoryand evidence based interventions. 


\section{CHAPTER FOUR}

A qualitative study of environmental factors related to HIV-testing 


\section{INTRODUCTION}

For a long time, HIV-testing has not been actively promoted in the Netherlands which was reflected in its official policy on HIV-testing. It was not until the introduction of Highly Active Antiretroviral Therapy (HAART) in 1996 that a change in the Dutch HIV-testing policy was initiated and a shift from discouraging towards active promotion of HIV-testing was accomplished (Gezondheidsraad, 1999; VWS, 2003; Mikolajczak, van Kesteren, Hospers \& Kok, 2004). The strongest argument for this shift was the availability of a sufficient medical alternative (HAART) for individuals who found out that they were HIV-positive. The renewed HIV-testing policy focuses on promoting HIV antibody testing among high-risk groups for HIV-infection, men having sex with men (MSM) being one of the most important ones.

Despite the change in the Dutch HIV-testing policy, testing rates are still relatively low among MSM in the Netherlands as compared with other Western countries. Recent studies among Dutch MSM indicate that approximately 55\% have ever taken an HIV-test (Hospers, Dörfler \& Zuilhof, 2003). In Australia on the other hand, HIV-testing rates among MSM are substantially higher. In addition, it should be noted that not only has a high percentage of Australian MSM ever taken an HIV-test, a large number of HIV-negative MSM have been tested for HIV within the last 6 months. Table 1 provides an overview of recently reported HIV-testing rates among MSM in six large cities in Australia.

Table 1. HIV-testing rates among Australian men who have sex with men

\begin{tabular}{lcccc}
\hline City & \multicolumn{3}{c}{$\%$ of men ever tested } & \% of HIV- negative men tested within \\
& HIV+ & HIV- & Total & 53.2 \\
\hline Sydney (2002) & 15.5 & 78.0 & 93.5 & 48.2 \\
Melbourne (2004) & 8.5 & 77.1 & 85.6 & 50.9 \\
Brisbane (2002) & 6.8 & 81.0 & 87.8 & 51.0 \\
Adelaide (2003) & 5.3 & 82.4 & 87.7 & 40.8 \\
Canberra (2003) & 5.1 & 79.8 & 84.9 & 44.0 \\
Perth (2002) & 3.4 & 75.9 & 79.3 & \\
\hline
\end{tabular}

Source: Gay Community Periodic Surveys (NCHSR)

Given the overall (health) advantages of finding out one's HIV-positive status, i.e. proper monitoring and adequate treatment initiation; and the positive effect 
of finding out one's serostatus on sexual risk behaviour, there is reason to argue that more Dutch MSM should (regularly) take an HIV-test. However, in order to initiate behaviour change among a large group of at-risk MSM, of whom a large proportion has never taken an HIV-test, a profound understanding of behavioural determinants at the individual but also at the environmental level is required.

A small-scale qualitative study into reasons for not taking an HIV-test (Mikolajczak et al., 2004), followed by a large-scale quantitative study on determinants of not taking an HIV-antibody test has already been carried out (Mikolajczak, Hospers \& Kok, 2006; 2007). The knowledge that has been acquired in both studies provides relevant input for the development of intervention programs that are aimed at motivating Dutch MSM to uptake HIVtesting. As stated before, environmental factors have to be taken into account as well when behaviour change is to be accomplished (Bartholomew, Parcel, Kok \& Gottlieb, 2006).

Given the substantial difference in HIV-testing rates among MSM in the Netherlands and Australia, a qualitative study into environmental factors related to HIV-testing was undertaken in Sydney. The basic idea for this study was to learn from the Australian situation and to find out to what extent it would be possible to take the Australian findings into account when designing an intervention that is aimed at promoting (regular) HIV-testing among MSM in the Netherlands. Therefore, individual in-depth interviews were carried out with individuals who have been involved in the fight against HIV/AIDS in Sydney, Australia as a policy maker, a prevention and/or education worker, or a sexual health specialist or general practitioner. In addition, whenever the opportunity came about, gay men themselves were asked about their experience(s) with (regular) HIV-testing.

This chapter of the thesis reports on the work carried out during a three months working visit at the National Centre in HIV Social Research (NCHSR) in Sydney. It is an impression and description of the interviews that were carried out, supplemented with information from relevant written documents.

\section{POLICY MAKERS}

In 1985, the HIV antibody test, developed in the United States, became available in Australia. From this moment on, a blood test could tell whether or not one was infected with the HIV-virus. The first official HIV-testing policy in New South Wales was developed by the AIDS Council of New South Wales (ACON) in the first year after the HIV antibody test became available. The initial advice that was given to gay men was not to get voluntarily tested for HIV. The main 
reason for this advice was based on the fact that at that moment in time, there was no treatment for HIV-infection available. Therefore, finding out that you were HIV-positive was considered useless since it would not have any advantage at an individual level. Besides the fact that no sufficient medical alternative was available for HIV-positive individuals at that moment in time, there were other factors that contributed to this initial advice in the first HIVtesting policy:

1. Fear of widespread discrimination of HIV-positive individuals, given that HIV/AIDS mainly hit the gay community whose members were already exposed to acts of discrimination because of their sexual orientation.

2. It was unclear whether people's test results were confidential. In these early days for example, no specific laws or regulations were available to protect the confidentiality of HIV-test results.

3. It was unclear whether you could still get certain types of insurance if you turned out to be HIV-positive.

In a sense, this first official policy on HIV-testing was political and ideological in nature (and strikingly similar to the Dutch policy in the 1980s). Given that there were many uncertainties that surrounded HIV-testing and the consequences for gay men if they found out that they were HIV-positive, such issues first had to be dealt with before HIV-testing could be openly supported policy-wise.

Along with the development of the first HIV-testing policy, an educational policy was developed and disseminated in the gay community. The educational message focused on promoting consistent safe sex through condom use. The recommended guideline in this educational policy was to assume that everybody was HIV-positive including oneself. This way, two targets were accomplished at once. First of all, people were motivated to comply with a strategy that protected them from getting an HIV-infection while still being sexually active, namely: having safe sex through consistent condom use. Secondly, by disseminating this guideline an attempt was made to overcome the need to take an HIV-test: by always using a condom when having sex with men, you could neither get infected yourself nor could you infect someone else with the virus. The "condom use"-message was widely communicated during this period of time and several campaigns that focused on the promotion of consistent condom use were developed and implemented. 
Some examples of such campaigns are:

- The "RUBBA ME" campaign (1985)

- It's Black \& White ... condomwise (1986)

- If it's not on, it's not on (1988)

- Several educational booklets containing information about HIV/AIDS and how to prevent HIV-infection

In addition, this educational policy also recognized that an HIV-infection was not something only gay men could acquire. It recognized that an HIV-infection could hit everybody and that everybody was involved in the fight against HIV/AIDS.

The advice not to take a voluntary HIV-test remained at the core of the official HIV-testing policy until the end of the 80's, beginning of the 90's when a call for change was finally accepted and made. Already in 1987 for example, a discussion paper on AIDS Antibody Testing, that emphasized the importance of HIV-testing among risk groups for HIV-infection was written and circulated. Not much later, the initially discouraging HIV-testing policy was revised and shifted towards a policy that focused on active promotion of HIV-testing among MSM. This shift came about due to several different reasons:

- Prophylaxis and more importantly AZT treatment was now available which could slow down the progression of HIV-infection

- Very straightforward anti-discrimination and anti-stigmatization laws that protected the rights of HIV-positive individuals were worked on (or already implemented)

- A registration system that guaranteed the confidentiality of HIV-testing results was set-up whereby anonymous HIV-testing was made possible

- Since the introduction of the HIV antibody test in 1985, a relatively large number of gay men had already been taking (regular) HIV-tests

From this point on, the HIV-testing policy also explicitly states that HIV-testing is for free in Australia. Taking an HIV-test might cost a patient a consultation session with the general practitioner but this is refunded through a MEDICARE system, thus making the actual testing for free.

This renewed HIV-testing policy also provided the basis for the first national HIV-testing policy that was written and published in 1992 which also stated that HIV-testing should be actively promoted among (MSM). 


\section{Australian National HIV-testing policies}

- 1992: the first policy was actually not much more than a very detailed document on what had been going on in the gay community with regard to HIV-testing. It consisted of a description of all the different places where MSM could get tested for HIV, the safety procedures that had to be taken into account and a description of the different steps in the process of taking an HIV-test.

- 1998: the National HIV-testing policy that was written and published in 1998 was actually a review and an update of the 1992 policy. The main changes in this renewed policy had to do with the pre- and posttest counselling guidelines. The term pre-test counselling for example was replaced with the term HIV-test discussion. This change was accomplished mainly by the influence of doctors and GP's who now considered HIV to be a chronic and thus manageable disease and did not want to keep on suggesting that HIV was still something exceptional.

- currently: the 1998 policy is subject to review at the moment and the main focus again lies on changing the counselling procedures. One of the ideas is to only go through standard post-counselling if the HIV-test result is positive. Another reason for the current revision is to see if more (risk) groups should be encouraged to uptake (regular) HIV-testing. Finally, another important aspect of this review has to do with the integration of testing for HIV and other sexually transmissible infections (STI).

The Australian National HIV-testing policies that have been written since 1992 rely on a set of basic principles with regard to HIV-testing that have remained unchanged since then:

1. Voluntary HIV-testing with counselling and confidentiality is fundamental

2. HIV-testing should be of the highest possible standard

3. HIV-testing is accessible to those at highest risk for HIV-infection

4. HIV-testing is critical to determining the extent and location of HIVinfection in the community

It is important to note that the HIV-testing policies are embedded in the Australian National HIV/AIDS Strategy which provides a broader framework for the response to the HIV/AIDS epidemic in Australia.

\section{GAY COMMUNITY AND GAY COMMUNITY ORGANIZATIONS}

Contrary to what would be expected given the initial official advice in the first HIV-testing policy in New South Wales, immediately after the introduction of 
the HIV-test a relatively large number of gay men took an HIV antibody test anyway. The general attitude in the gay community at this moment in time can best be characterized as "regardless of the official advice of community organizations, I want to get tested and I want to know whether I am infected with the virus or not". This was reflected in the outcome of the first large behavioural research study that was carried out in 1987 (Sendziuk, 2003). Besides questions on sexual behaviour and other related issues, respondents were also asked whether they had ever taken an HIV-test. The results showed that at that moment in time, about $70 \%$ had taken an HIV-test. Another illustration that many gay men got tested for HIV despite the advice not to do so is reflected in the many members of community organizations such as ACON who were tested for HIV (despite the advice in the policy they wrote themselves). More than once, this period in time has been referred to as a somewhat schizophrenic period in which HIV-testing occurred anyway among gay men despite the advice not to do so for reasons that have been cited above. In order to explain and understand this somewhat peculiar reaction within the gay community with regard to voluntary HIV-testing in these early days after the introduction of the HIV antibody test, it is important to take into account a set of factors.

First of all, it is important to realize that in the beginning of the 80's, the gay community in Australia was mainly restricted to Sydney and Melbourne. It seems fair to state that Sydney in particular was the place to be for Australian gay men which resulted in a large and fairly well organized gay community in Sydney. The presence of a great amount of gay press, dealing with all sorts of specific gay-related topics, was one of the consequences thereof. In the early 80 's, a lot of attention in the gay press was inevitably dedicated to HIV/AIDS since this new disease, which had already taken epidemic forms in the United States, affected gay communities in particular. The consistent focus on HIV/AIDS and the amount of attention that was given to it contributed to a very high level of awareness on this topic within the gay community. Many gay men realized that they might have been exposed to HIV because they had had unprotected anal intercourse, which was identified as the main route for HIVinfection among gay men. In combination with the introduction of the HIV antibody test in 1985, which got a lot of attention in the gay press as well, this contributed to gay men simply wanting to know what their serostatus was because they considered it to be very important with respect to the future planning of their lives. If they were HIV negative, they could stick to the plans that they had envisioned (for example career wise), whereas if they turned out to be HIV-positive a lot would change. Among other things, preventing other men from becoming infected then became a relevant issue for many men. 
Although fear of being HIV-positive was a common emotion at this moment in time in the gay community, apparently it never stopped men from getting tested and finding out what their serostatus was.

Another factor that has to be taken into account is the precedent of a relatively large group of HIV-tested MSM that was created as a result of "The Sydney AIDS Prospective Study". Participants, who had been enrolled in this study in the years before HIV-testing was possible, were asked to give blood samples that were subsequently tested for a number of STI as part of the study. Once the HIV antibody test was introduced in 1985, researchers had blood samples available from a very large group of gay men which made it possible to generate epidemiological data on the spread of HIV in Sydney. All participants were therefore asked whether they agreed on having their blood samples tested for HIV antibodies as well and most of them consented. As a result, a large group of gay men was tested for HIV in a relatively short period of time after the introduction of the test. In addition, a relatively large proportion of the respondents turned out to be HIV positive.

A factor also to be taken into account is that in the early 80 's, most gay men in Sydney visited a relatively select number of doctors or general practitioners who worked in the "gay area" of Sydney (Taylor Square, Oxford Street). Most of these doctors were either gay themselves or were known in the gay community as gay-friendly with a high caseload of gay men in their practice. These doctors were very much involved with the gay community, most of them were part of it themselves, and were supportive towards gay men when they requested an HIV-test. In addition, a majority of gay men were familiar with the idea of getting tested for infectious diseases on a regular basis, since that had been the main strategy to fight the STI-epidemics(s) among gay men in the 1970's.

At the end of the 1980's, the development and introduction of AZT treatment for HIV-infected individuals provided an additional, important factor that contributed to a significant increase in (regular) HIV-testing among gay men. With the introduction of AZT treatment, a medical argument that supported HIV-testing among gay men was now available and led to the so called "testing-treatment"-argument. Given this new form of treatment it now became very important for gay men to get tested on a regular basis since it provided the only opportunity to get access to treatment if they were HIVinfected. At the same time, a large amount of men who had been diagnosed HIV-positive had their so called "second coming-out" - meaning that they openly talked about their HIV-positive status - partly because they had to if they wanted to take up AZT treatment and partly because some key figures (high profile gay men) in the gay community who were HIV-positive set the 
example by disclosing their status. Soon thereafter, People Living with HIV/AIDS - a community organization that represented HIV-positive individuals and advocated on their behalf - originated and became a partner in the fight against HIV/AIDS. As a community organization, they had a great impact on the development of the anti-discrimination laws that protected the rights of HIV-positive individuals and they fought for access to AZT treatment for all HIV-positive individuals (this was actually driven by a group of HIVpositive individuals who named themselves ACT UP). As a community organization, it also provided a network that HIV-positive individuals could connect with for information and support. This in turn was reassuring for other gay men and an incentive to get tested because they could see there was a community they could rely on if they turned out to be HIV-positive.

One could state that the gay community and its various organizations have always been involved in the fight against HIV/AIDS and played a central role in it. In general, the Australian response to HIV/AIDS is best characterized as a partnership approach between affected communities, governments, and medical, scientific and health care professionals. All of the interviewees acknowledged that this has been the key ingredient in the successful fight against HIV/AIDS in Australia. It was also acknowledged that the choice for this model in the early days of the HIV/AIDS epidemic in Australia was the result of a having the right people at the right place at the right moment in time. As a result however, a great part of the current achievements with regard to HIV/AIDS and HIV-testing in particular can be ascribed to the gay community itself.

\section{PREVENTION AND EDUCATION}

In prevention and education, HIV-testing was not actively promoted until the late 1980's/ beginning 1990's. As stated previously, the official policy at that moment in time advised gay men not to take an HIV-test because there was no treatment available. The prevention and education activities in that time period were focused on motivating condom use. Some examples of such campaigns are:

- $\quad$ The "RUBBA ME" campaign (1985)

- It's Black \& White ... condomwise (1986)

- If it's not on, it's not on (1988)

By communicating the educational message to assume everybody was HIVpositive including yourself, the need for consistent condom use was reinforced. 
With the introduction of AZT treatment for HIV-positive individuals, the socalled testing-treatment argument emerged. This was a very strong incentive for gay men to get tested for HIV, since HIV-testing was the only way to find out whether they were HIV-infected which in turn would provide them with access to treatment and an opportunity to save their life. Along with the development of an HIV-testing policy that shifted from the advice not to take an HIV-test to promoting HIV-testing among gay men, prevention and education activities now focused on promoting HIV-testing as well. The availability of AZT treatment and the need for early detection of one's HIVinfection to gain access to treatment and treatment benefits were used as educational messages in prevention activities targeted at gay men. It is important to note that at the same time, the promotion of consistent condom use to prevent HIV-infection remained unchanged.

Unlike in the Netherlands, the introduction of HAART in 1996 hardly introduced new arguments in the context of HIV-testing in Australia. The testing-treatment argument was already well established in Australia at the end of the 80's beginning of the 90's with the introduction of AZT treatment. However, it did cause prevention and education activities to focus even more consistently on the importance of consistent condom use. This was mainly enforced by the observation that the availability of better treatment (HAART) induced some form of "AIDS optimism" among gay men which has been proposed as an explanation for observed reductions in consistent condom use. An example of such a campaign:

- Poster with an image of a condom and lube and the following slogan: "of all the combination treatments, this (image) remains the most effective"

In addition, the availability of HAART led to the development of information booklets that contained the most recent information about HIV/AIDS, the new treatments that were available and the implications thereof:

- HIV: tests and treatments, now more choices than ever before! (1997)

- LIFE. HIV drugs: tips on making treatment easier (1998)

Until now, HIV/AIDS related prevention and education activities are mainly focused on a combination of both the promotion of consistent condom use to prevent HIV-infection on the one hand, and the promotion of regular HIVtesting on the other hand.

It should be noted that one of the most recent changes in prevention and education activities has to do with the integration of HIV and other STI's that are common among gay men, such as syphilis and gonorrhoea. This is reflected in the broader focus of recent prevention and education activities: 
- The promotion of consistent condom use to prevent HIV-infection and some STIs

- The promotion of regular sexual health screening which includes HIVtesting and STI-testing

An example of such a campaign:

- I picked someone up last night ... and something (2004)

Besides communicating educational messages that motivated gay men to get (regularly) tested for HIV and promoted the use of consistent condom use to prevent HIV-infection, a great amount of effort in prevention and education was spent on campaigns that focused on:

- Anti-discrimination of HIV-positive individuals

- The responsibility of both HIV-negative and HIV-positive individuals in the fight against HIV/AIDS in Australia

- Harm reduction practices such as the use of Post-exposure Prophylaxis (PEP) after recent exposure to risk for HIV-infection, or strategic positioning

It is important to note that community organizations such as ACON (AIDS Council of New South Wales), AFAO (Australian Federation of AIDS Organizations), PLWHA (People Living with HIV AIDS) and many more have been responsible for the development and implementation of prevention and education campaigns in Australia. This is a logical result of the nature of Australia's partnership model in the fight against HIV/AIDS and the strong belief in community based health education.

\section{SEXUAL HEALTH SPECIALISTS AND GENERAL PRACTITIONERS}

When HIV/AIDS was first diagnosed in Australia in 1982, the majority of sexual health specialists and general practitioners were convinced that the traditional model of infectious diseases control, based on widespread testing, was to be applied to HIV/AIDS as well. It had proven to be a valid model in the late 1970 's and the beginning of the 80's to fight such infectious diseases like syphilis or gonorrhea among gay men and is called "the test and contain model for transmissible disease control". Although this model had proven its value in the past, it soon became clear that it was hardly applicable to HIV/AIDS. The main reason being that unlike other infectious diseases that can be relatively easily transmitted, HIV-infection turned out to be much harder to contract since 
transmission of HIV among gay men mainly occurs when HIV-negative men are exposed to the blood or semen of an HIV-positive sex partner. As a result however, sexual health specialists and general practitioners have always been in favor of HIV-testing among gay men which created a supportive environment. As pointed out before, a relatively small group of sexual health specialists and general practitioners who worked in the gay area in Sydney were initially confronted with gay men's requests to take an HIV-test. The fact that many of these sexual health specialists or general practitioners were gay themselves, also contributed to a supportive attitude towards HIV-testing among gay men who wanted to get tested for HIV in the early days after the introduction of the HIV-test.

The introduction of AZT treatment for HIV-positive individuals at the end of the 1980's, introduced the testing-treatment argument. More men got tested for HIV in the following years and more general practitioners - also outside the traditional gay area in Sydney - were confronted with HIV/AIDS. To update their knowledge about HIV/AIDS, a booklet called "Could it be HIV" was developed and disseminated among all general practitioners.

AZT treatment provided a medical argument that was used by sexual health specialists and general practitioners to support the benefits of early detection of HIV-infection with respect to the availability and efficiency of treatment. Although initially, early detection of HIV-infection led to early treatment initiation, it soon became clear that monitoring the levels of viral load and CD4 cells was a better strategy since treatment initiation turned out to be more efficient when the critical thresholds for viral load and CD4 cells were crossed. Over the following years, HIV treatments kept improving and ultimately led to the development and application of HAART (which led to the acceptation of the testing-treatment argument in the Netherlands).

Since the end of the 1980's, when a treatment for HIV first became available, sexual health specialists and general practitioners have taken up a pro-active approach with respect to HIV-testing which has remained unchanged over the years. Sexual Health specialist and general practitioners that were interviewed all confirmed that HIV-testing has always been, and still is, very high on their agenda. Currently, in most cases, gay men visiting their sexual health specialist or a general practitioner will request an HIV-test themselves. In this case, an assessment of their sexual risk behaviour and a pretest discussion will be conducted. The pro-active approach of sexual health specialists and general practitioners with respect to HIV-testing is reflected in their offer to gay men of an HIV-test. According to the sexual health specialists and general practitioners that I interviewed, several cues trigger them to make 
this offer to a gay man if he did not make the request to take an HIV-test himself:

- When he has clinical symptoms that are associated with HIV-infection

- When behavioral risk assessment indicates exposure to risk for HIVinfection

- When he requests STI-testing

- When the information in his medical file indicates that it has been long time since he had his last test

The STIGMA guidelines are the latest set of guidelines with regard to HIV- and STI-testing that have been developed and implemented in daily practice. The core line of the STIGMA guidelines states that all men who have had any type of sex with another man in the previous year should be offered a sexual health screen (HIV-test and necessary STI-tests) at least once a year. When a man is highly sexually active (multiple casual partners or sex on premises venues) more frequent testing may be indicated.

These guidelines do not only call upon a pro-active approach of sexual health specialists and general practitioners to offer gay men an HIV-test but also to offer gay men STI-tests. Nowadays, sexual health specialists and general practitioners offer STI-testing if the assessment of the patient's sexual risk behaviour indicates risk for infection. An observed decrease in STI-testing and recent STI epidemics of syphilis and gonorrhea among gay men contributed to the development of these guidelines. Nowadays, HIV-testing and STI-testing is offered to gay men as a sexual health screen. According to the doctors that I interviewed, most gay men comply with this offer and take this so-called "sexual health screen". If gay men don't comply with this offer, doctors will try to motivate them to do so eventually by talking about the risks for STI-infection among sexually active gay men and the possible health consequences. It is important to note however that the decision whether or not to take the tests ultimately lies within gay men themselves.

\section{HISTORY AND THE CURRENT SITUATION: WHAT CAN WE LEARN?}

The basic idea for the present study on environmental factors with regard to HIV-testing among gay men in Australia was to pick up important lessons that may assists the development of effective prevention campaigns aimed at motivating Dutch MSM to take an HIV-test. With a recent shift in the Dutch HIV-testing policy towards active promotion of HIV-testing among MSM a unique opportunity presented itself to learn from a country that has succeeded 
in establishing high HIV-testing rates among MSM. The study carried out in Sydney - interviewing policy makers, prevention and education workers, sexual health specialists and general practitioners, and talking to gay men themselves provided a better understanding of:

- The historical dynamics underlying the current situation with regard to HIV-testing among MSM in Australia (Sydney in particular)

- The current situation with regard to HIV-testing among MSM in Australia

The previous parts of this report provided a brief overview of the Australian history with regard to HIV-testing among MSM and a sketch of significant (historical) dynamics that contributed to the establishment of the current situation. Some aspects, such as the early choice for a partnership approach in the fight against HIV/AIDS and the strong belief in community based health education, find their origin in a specific historical context which can not be (easily) recreated and transferred to the Netherlands. Some of the decisions that were taken in the early days of HIV/AIDS and the availability of the HIV antibody test are the result of having the right people at the right place at the right moment in time. The Netherlands has its own history in its fight against HIV/AIDS, where other decisions have been made over time.

With respect to HIV-testing among MSM, the current Australian situation can be considered a desirable situation that we have to try to move towards in the Netherlands as well. The following paragraphs contain specific findings and lessons with regard to environmental factors that have to be taken into account if long-term behavioural change among Dutch MSM with regard to HIV-testing is to be accomplished. Some of the factors are not directly linked with HIVtesting specifically but have a broader scope. Other factors however are directly linked with HIV-testing and the current situation in Australia.

\section{Recognizing the importance of HIVIAIDS}

One of the most salient aspects of the Australian response to HIV/AIDS, besides the partnership approach, is the recognition by the Commonwealth Government and the State Governments that the fight against HIV/AIDS has always been and still is a top priority in public health. Not only is this reflected in the several National HIV/AIDS Strategies and the HIV-testing policies that have been developed over the years, it is also reflected in the amount of financial support that Australian governments provide to community organizations to ensure the continuity of their activities. In addition, the Australian situation shows that the involvement of gay community organizations is a key element in the fight against HIV/AIDS. 


\section{Develop a National HIV-testing policy}

Over the years, several HIV-testing policies - embedded in the National HIV/AIDS Strategies - have been developed in Australia. Currently, the HIVtesting policy that was developed and adopted in 1998 (ANCARD \& IGCARD) still provides the formal framework and describes all relevant aspects with regard to HIV-testing. As is stated in the National HIV-testing Policy, the guiding principles for HIV-testing should continue to be:

- Voluntary testing with counselling and confidentiality is fundamental to Australia's HIV/AIDS response

- Testing should be of the highest possible standard

- Testing is accessible to those at risk of HIV-infection

- Testing policy is critical to determining the extent and location of HIVinfection in the community

Although a policy document in itself does not motivate MSM to take a (regular) HIV-test, it does provide a formal framework which clearly outlines all the necessary conditions at the different levels involved, which need to be fulfilled in order for a decision to promote HIV-testing among MSM to be successfully translated in practice.

\section{Involvement of gay community organizations}

As has been pointed out before in this report, gay community organizations can be given credit for a lot of the achievements that have been made in the fight against HIV/AIDS in Australia. The fact that most MSM in Australia have ever been tested for HIV and a large proportion of tested MSM has been tested within the last 6 months (see table 1) is no exception to that. It seems clear that community organizations can be trusted and are well able to provide prevention and education for their respective members. However, as stated before, it is important to ensure their activities by means of sufficient government funding. In addition, partnership, support and collaboration among gay community organizations themselves should be encouraged.

\section{Involvement of HIV-positive men in prevention and education}

The origination and involvement of the HIV-positive's community organizations has contributed largely to the accomplishment of several important issues: the development and implementation of strong antidiscrimination laws that protected the rights of HIV-positive individuals being one example. In addition, targeting HIV-positive individuals in prevention and education activities, supported the establishment of the idea that both HIVpositive and HIV-negative men have a responsibility in the fight against HIV/AIDS and should be supportive to each other. 


\section{Establish a widely supported social norm with regard to (regular) HIV-testing}

During the interviews that I carried out and the talks that I had with numerous gay men during my stay in Sydney, it soon became clear that within the gay community a deeply entrenched social norm with regard to (regular) HIVtesting has been established. Gay men consider HIV-testing to be something that is part of being a responsible gay man. By taking an HIV-test, they take care and responsibility for their own health and the health of other gay men. The fact that HIV-testing is widely supported within the gay community in Australia has resulted in what can be labelled an "HIV-testing culture". A large proportion of gay men in Sydney have taken up a strategy of regular testing for HIV which means they go for a test every 6 or 12 months.

\section{A pro-active approach of doctors: offering an HIV-test}

The important role of sexual health specialists and general practitioners in offering gay men an HIV-test has been acknowledged by all the interviewees. Sexual Health specialist and general practitioners that I interviewed all confirmed that HIV-testing has always been, and still is, very high on their agenda. The STIGMA guidelines advice sexually active gay men to take a "sexual health screen" at least once a year and call upon a pro-active approach from sexual health specialists and general practitioners.

\section{The testing treatment argument: HAART}

Contrary to Australia, the introduction of AZT treatment for HIV-positive individuals did not lead to a change in the HIV-testing policy in the Netherlands. Whereas AZT treatment led to the emergence of the so-called "testing-treatment" argument, this only happened in 1996 in the Netherlands with the introduction of HAART and ultimately led to a change in the Dutch HIV-testing policy. Given the widely acknowledged benefits of HAART for quality of life and life expectancy of HIV-positive individuals, the testingtreatment argument should be appropriately communicated in future prevention campaigns that are aimed at motivating Dutch MSM to take a (regular) HIV-test. At the same time, one should be very careful not to create a sense of "HIV-optimism" among MSM when communicating the benefits of treatment with HAART.

\section{Sexual risk and HIV-testing}

Although sexual risk behaviour remains the most important route of HIV transmission among MSM, the guidelines for HIV-testing (STIGMA) and the message that is now central in all prevention and education activities related to HIV-testing among MSM is much broader. As pointed out before, the core line states: 
All men who have had any sex with another man in the previous year should be offered at least once a year:

- HIV serology

- Syphilis serology (including a TPHA, TPPA or EIA test)

- Pharyngeal culture for gonorrhoea

- Anal culture or NAAT for gonorrhoea and NAAT for chlamydia

- Clinical indicators for anal tests include:

- Any anal sex with casual partners

- Any unprotected anal sex

- Any anal symptoms (bleeding, itching, pain)

- HIV-positive

- Past history of gonorrhoea

- Contact with any STI

- Request for a test

- First catch urine NAAT for Chlamydia

- Hepatitis A serology, and Immunise if negative

- Hepatitis B serology, and Immunise if negative

\section{Monitoring of the gay community: behavioural research}

Regular monitoring of gay communities by means of behavioral research studies performed by institutes such as the National Centre in HIV Social Research (NCHSR) and the National Centre in HIV Epidemiology and Clinical Research (NCHECR) allows gay community organizations such as ACON, AFAO, PLWHA and others to develop and implement prevention and education activities that are based on recent and relevant behavioral data. Longterm behavioral monitoring allows researchers to pick up subtle changes on a variety of relevant variables such as condom use, HIV-testing, sexual practices, HIV-status and many more. Feeding this information back into the gay community organizations, then allows them to take these findings into account in their prevention and education activities. This is another good example of what the partnership approach which characterizes Australia's response to HIV/AIDS has contributed to. In the absence of long-term monitoring studies, such subtle changes would go unnoticed and good opportunities calling for specific prevention and education campaigns would go lost.

\section{Free HIV-testing and other "practical" aspects of taking an HIV-test}

Some practical aspects of taking an HIV-testing have largely contributed the establishment of facilitating conditions and an enabling environment with regard to HIV-testing in Australia:

1. HIV-testing is for free in Australia. The actual testing is funded by money that the National Government provides the State Governments with. In 
some cases (depending on the type of health insurance people have), people will have to pay for the consultation session with the doctor or sexual health specialist. However, this is refunded by the healthcare system (MEDICARE)

2. confidentiality of HIV-test results is guaranteed by means of a code-system that is applied to someone's blood sample when it is send out to a laboratory and a set of public health laws that protect HIV-test information. An HIV-test only requires an individual to provide 4 initials, which can be randomly chosen, and his date of birth. That way laboratories performing the actual tests can never track the identity of the individual whose blood has been tested (positive). HIV-test information in one's medical file, kept by the sexual health specialist or general practitioner is also legally protected.

3. HIV-test results are only provided by the sexual health specialist or general practitioner during a consultation session with the patient. HIV-test results are never provided over the phone. The doctors that I interviewed all confirmed this because of the opportunity for proper counseling and education.

\section{CONCLUSION}

Both the Netherlands and Australia have their own history in their fight against HIV/AIDS. An historical view of this fight and the dynamics that contributed to certain decisions to be taken, help clarifying the underlying processes that explain the observed differences between the current situations in both countries. The most remarkable difference, which was the most important reason for my visit to Sydney, is reflected in the HIV-testing rates among MSM in both countries (see table 1).

By interviewing policy makers, prevention and education workers, sexual health specialists and general practitioners and gay men themselves, I got a better understanding of the Australian history and acquired relevant knowledge about environmental factors that have contributed (and still do) to the establishment of such high HIV-testing rates among MSM in Australia. These factors should be taken into account during the development of interventions aimed at promoting HIV-testing among Dutch MSM. Along with a better understanding of individual (cognitive) factors that contribute to not taking an HIV-test among Dutch MSM - which we now have and also provides relevant input for the development of such interventions - the efficiency of such interventions should be optimal. 


\section{CHAPTER FIVE}

A systematic review of the effects of HIV-testing on sexual risk behavior 


\section{INTRODUCTION}

HIV-testing and counseling serves a specific form of prevention which is usually referred to as secondary prevention. The rationale underlying voluntary counseling and testing (VCT), is that early detection of HIV-infection allows for a timely and more efficient way to treat this particular health problem. Moreover, in the case of HIV-infection, VCT might also contribute to primary prevention in the sense that finding out one's HIV-status, could lead to safer sexual behavior so that infecting others or becoming infected oneself is prevented. This systematic review contributes to answering the question whether VCT leads to safer sexual behavior. It builds on the existing evidence from previous reviews and a meta-analysis on this topic. In this sense, it can be considered a systematic state-of-the-art update of the available literature on the effects of VCT on sexual risk behavior.

In some Western countries like Australia or the United States, the introduction of the HIV-antibody test in 1985 served as a starting point for widespread VCT programs targeted at people at-risk for HIV-infection, such as men who have sex with men (MSM) (Chamot, Coughlin, Farley \& Rice, 1999; Valdiserri, 1997; Van de Ven, Prestage, Knox \& Kippax, 2000). In other Western countries, for example the Netherlands, such programs did not make up the cornerstone of their HIV-prevention policy until the introduction of Highly Active AntiRetroviral Therapy (HAART) as a treatment for HIV-infected individuals in 1996. In this so-called pre-HAART era, HIV-prevention activities in these countries were primarily focused at the promotion of consistent condom use and safe sex whereas HIV-testing was advised against in most cases. These countries' HIV-prevention policy was based on the conviction that knowing one's seropositive status was not beneficial at the individual level given the absence of adequate treatment. In addition, it was not clear what the effect of finding out one's serostatus on subsequent sexual behavior was (Mooij, 2004).

The introduction and application of HAART in Western countries gave rise to new arguments in favor of secondary prevention activities in the field of HIV/AIDS-prevention. Most importantly, HAART provides adequate treatment for HIV-infected individuals. Although HIV-infection remains incurable and HAART can have negative side-effects such as diarrhea, fatigue, lypodystrophy (body fat redistribution), and strict adherence to the therapy can restrain the patient's daily life, the overall health advantage of HAART is now widely acknowledged and reported on (Chadborn, Baster, Delpech, Sabin, Sinka, Rice \& Evans, 2002). In addition, the urge for active promotion of VCT programs in Western countries is encouraged from the observation that 
treatment with HAART is more effective when one's HIV-positive status is detected at an early stage, allowing adequate monitoring and optimal treatment initiation (Higgins, Galavotti, O’Reilly, Schnell, Moore, Rugg \& Johnson, 1991). Contrary to Western countries, treatment availability and options are still limited in most developing countries, where VCT is primarily applied in the context of sexual risk reduction among serodiscordant (both partners having a different HIV-status) heterosexual couples in a steady relationship.

Besides a positive impact on the health status of the HIV-positive individual as a result of timely treatment initiation, early detection of one's serostatus might also contribute to changes in sexual risk behavior. Since HIV is an infectious disease, which can be transmitted through unsafe sexual behavior, it is important to explore whether this is the case. Over the past years, two reviews (Higgins et al., 1991; Wolitski, MacGowan, Higgins \& Jorgensen, 1997) and one meta-analytic review (Weinhardt, Carey, Johnson \& Bickham, 1999) on the effects of VCT on sexual risk behavior have been published. Higgins and her colleagues (1991) concluded that with respect to MSM, a dramatic reduction of sexual risk behavior occurred during the 1980s. However, due to methodological issues in most of the studies included in their review, they pointed out that the evidence regarding the effects of VCT on sexual behavior remained inconclusive. The review by Wolitski and his colleagues (1997) was based on articles published between 1990 and 1996. With regard to MSM, they also found evidence of risk-related behavioral change but, in line with Higgins et al (1991), were unable to find clear evidence pointing in the direction of VCT as being the critical factor leading to changes in sexual risk behavior. Based on a meta-analytic review of 27 published studies between 1985 and 1997, Weinhardt and his colleagues (1999) concluded that VCT is effective in reducing sexual risk behavior among individuals who find out that they are HIV-positive. Their findings also showed that after VCT, HIV-negative individuals did not change their sexual behavior more than untested individuals.

Within the present context of treatment availability (HAART) in Western countries, it is important to find out whether the findings in previous reviews (Higgins et al., 1991; Wolitski et al., 1997) and meta-analysis (Weinhardt et al., 1999) remain valid. By systematically reviewing relevant journal articles published between 1996 and 2005, the present study aims to update the available empirical evidence on the relationship between VCT and sexual risktaking behavior. In addition, it also seeks to find out whether the introduction and application of HAART has caused a change in the pattern of results that emerged from the previous studies on this topic, all of which have been conducted in the pre-HAART era. 


\section{METHODS}

For the purpose of the present review, a computer-based search of Psycinfo, Medline and ERIC was conducted, using a search string that combined relevant keywords: (((HIV-testing or HIV testing or HIV-test or HIV test or HIV antibody test or HIV antibody testing or seroconversion) and (sexual behavior or sexual behaviour or sexual behavior change or sexual behaviour change) and (counseling or counseling)) and $(P Y>1996))$ ). All articles generated in this search, were subsequently screened on the basis of their title and abstract and selected if they met all of the following criteria:

1. Published in a peer-reviewed journal after 1996

2. Compared a group of HIV-positive individuals with a group of HIVnegative individuals (i.e., between subjects comparison) or compared individuals before and after notification of their HIV-status (i.e., within subjects comparison)

3. Measured any of the following sexual behaviors during a specific period:

a. Unprotected (insertive or receptive) anal intercourse (UAI) or unprotected vaginal intercourse (UVI)

b. Consistency in condom use during sexual intercourse

c. Number of sexual partners

The reference list of selected articles from the electronic search, were scanned for additional publications that were also included in the present review if all of the abovementioned criteria were met. The process of searching and selecting relevant studies according to the above mentioned inclusion criteria, resulted in 13 studies that were included in the present review. The main findings of these studies with regard to the central research question are outlined in the next paragraph. More details of the studies included in the present review and a description of the findings are also summarized in Table 1.

\section{RESULTS}

A number of studies provide empirical evidence supporting the hypothesis that VCT results in safer sexual behavior, either through increased consistent condom use and/or a reduction in the number of sexual partners. A recent longterm follow-up study among 963 serodiscordant (both partners having a different HIV-status) heterosexual Zambian couples (Allen, Meinzen-Derr, Kautzman, Zulu, Trask, Fideli, Musonda, Kasolo, Gao \& Haworth, 2003) showed that participants reported an average increase in condom use after joint 
VCT, which was maintained for at least one year. Beneficial effects of a malefocused VCT program on condom use, among both serodiscordant and seroconcordant (both partners having the same HIV-status) heterosexual couples have been reported by Roth, Steward, Clays, van der Straten, Karita \& Allen (2001). The rate of sexual intercourse without condoms was significantly decreased at the one-year follow-up assessment in couples where one or both partners were HIV-positive. The Voluntary HIV-1 Counseling and Testing Efficacy Study Group (2000) reported evidence of a positive relationship between VCT and subsequent sexual risk reduction among heterosexual individuals and couples. Findings from their randomized (multi-site) trial showed that receiving VCT resulted in a significantly greater decline in reported unprotected intercourse with non-primary partners, than only receiving health information. In addition, both HIV-infected men (individual) and HIV-infected women (individual) reported significantly greater reductions in unprotected intercourse than uninfected men or women. The same pattern of results was obtained for couples enrolled in their study. A positive association between repeated HIV-testing and counseling on the one hand, and (sexual) risk reduction among male heterosexuals on the other hand, was reported by Bentley, Spratt, Shepherd, Gangakhedkar, Thilikavathi, Bollinger \& Mehendale (1998). Mekonnen, Sanders, Aklilu, Tsegaye, Rinke de Wit, Schaap, Wolday, Geskus, Coutinho \& Fontanet (2003) found evidence of sexual risk reduction in a recently conducted cohort study among male Ethiopian factory workers receiving VCT and health education. MacGowan, Brackbill, Rugg, Swanson, Weinstein, Couchon, Scibak, Molde, McLaughlin, Barker \& Voigt (1997) reported a reduction in high risk sexual behavior among injecting drug users (IDU) after receiving a positive HIV-test result. In their study, HIV-positive participants had significantly fewer sex partners without using a condom over the follow-up period, and HIV-positive participants were five times more likely than other participants to always use condoms. A study conducted by Deren, Beardsley, Tortu \& Goldstein (1998) also showed that VCT led to safer sexual behavior among IDU's. Although all study participants reported a reduction in sexual risk behavior, the reported reduction from baseline to follow-up was significantly greater for HIV-positive study participants. Dilley, Woods, Sabatino, Lihatsh, Adler, Casey, Rinaldi, Brand \& McFarland (2002) found that among HIV-negative MSM, HIV-testing combined with a counseling approach focusing on a person's self-justifications after recent high-risk sexual behavior, was effective in reducing subsequent unprotected anal intercourse (UAI) over a 12-month period. When HIV-testing was combined with standard counseling, this long term reduction of UAI was not achieved. Kotranski, Semaan, Collier, lauby, Halbert \& Feighan (1998) found that VCT had a positive impact on 
reducing (sexual) risk behavior among out-of-treatment drug users, but found no additional effect of an enhanced counseling intervention on sexual risk reduction. A similar pattern of results was obtained by Inciardi, Surrat, Kurtz \& Weaver (2005). In their study, evidence suggested that VCT lead to a reduction of sexual risk behavior among HIV-positive female commercial sex workers (CSW). No additional effect of an enhanced counseling intervention on sexual risk reduction was found. Six months after VCT, HIV-positive CSW were more likely to have decreased their sexual risk behavior than HIV-negative CSW, regardless of the intervention (standard versus enhanced) they had participated in.

Four studies provide no clear empirical support for the hypothesis that VCT leads to sexual risk reduction. Ickovics, Grigorenko, Beren, Druley, Morrill \& Rodin (1998) tested the hypothesis that VCT would lead to safer sexual behavior among heterosexual women. Over an 18 month period, sexual behavior of 106 women who tested HIV-negative was compared with a group of 54 women who did not get tested. Although tested women initially reported a decrease in risky sexual behavior compared to untested women, ultimately both groups returned to the same (baseline) levels of sexual risk, indicating limited long-term effects of VCT on reducing sexual risk behavior in their research population. A study conducted by George, Green \& Murphy (1998) showed that receiving an HIV-negative test result during VCT did not increase the risk of acquiring new STD's in the next year. A cohort study conducted by Clark, Brasseux, Richmond, Getson \& D'Angelo (1998) among 149 HIVnegative adolescents showed neither a reduction in HIV risk behaviors nor a decrease in STD's after VCT, over a 2 year period. 
Table 1. Summary and overview of the studies included in the present systematic review, in alphabetic order

\begin{tabular}{|c|c|c|c|c|c|}
\hline Study & Location & Design & $\mathrm{N}$ & Population and comparison & Main findings \\
\hline $\begin{array}{l}\text { Allen et al., } \\
\text { (2003) }\end{array}$ & $\begin{array}{l}\text { Lusaka, } \\
\text { Zambia }\end{array}$ & $\begin{array}{l}\text { L; VCT at baseline; } \\
\text { follow-up at } 3 \\
\text { months, } 6 \text { months, } 9 \\
\text { months and } 12 \\
\text { months }\end{array}$ & 963 & $\begin{array}{l}\text { Within subjects (serodiscordant } \\
\text { heterosexual couples) comparison } \\
\text { of sexual behavior and condom } \\
\text { use. Between group comparison } \\
\text { (with a sample of } 66 \\
\text { seroconcordant HIV-negative } \\
\text { couples) of sexual behavior and } \\
\text { condom use. }\end{array}$ & $\begin{array}{l}\text { Frequency of sex in discordant couples did not } \\
\text { change after VCT. However, the proportion of } \\
\text { contacts with a condom increased from } 3 \% \\
\text { before VCT to }>80 \% \text { afterwards. This increase in } \\
\text { condom use remained stable through a } 12 \\
\text { month follow-up period among discordant } \\
\text { couples. Seroconcordant negative couples, } \\
\text { followed for } 12 \text { months reported condom use in } \\
\text { only } 28 \% \text { of their sexual encounters. }\end{array}$ \\
\hline $\begin{array}{l}\text { Bentley et al., } \\
\text { (1998) }\end{array}$ & Pune, India & $\begin{array}{l}\mathrm{L} ; \mathrm{VCT} \text { at baseline; } \\
\text { follow up at } 3,6,12, \\
18 \text { and } 24 \text { months }\end{array}$ & 1628 & $\begin{array}{l}\text { Within subjects (HIV-negative } \\
\text { heterosexual men) comparison of } \\
\text { sexual behavior and condom use } \\
\text { before and after VCT. }\end{array}$ & $\begin{array}{l}\text { Continued VCT among study participants was } \\
\text { positively associated with reductions in (sexual) } \\
\text { risk behaviors. A sizable reduction in the } \\
\text { number of men visiting CSW was found: } 63 \% \text { at } \\
\text { baseline versus } 23 \% \text { at } 24 \text { month follow-up, } \\
\text { along with a significant increase in condom use } \\
\text { among men who continued visiting CSW. }\end{array}$ \\
\hline $\begin{array}{l}\text { Clark et al., } \\
(1998)\end{array}$ & $\begin{array}{l}\text { Washington } \\
\text { DC, USA }\end{array}$ & $\begin{array}{l}\mathrm{L} ; \mathrm{VCT} \text { at baseline; } 1 \\
\text { year follow-up }\end{array}$ & 149 & $\begin{array}{l}\text { Within subjects (HIV-negative } \\
\text { adolescents) comparison of } \\
\text { condom use and STD rate before } \\
\text { and after VCT. }\end{array}$ & $\begin{array}{l}\text { VCT had no significant effect on sexual risk } \\
\text { behavior: no reduction in STD rate, and } \\
\text { inconsistent condom use was found after VCT, } \\
\text { indicating no changes in sexual risk behavior as } \\
\text { a result of VCT. }\end{array}$ \\
\hline $\begin{array}{l}\text { Deren et al., } \\
\text { (1998) }\end{array}$ & $\begin{array}{l}\text { East } \\
\text { Harlem, } \\
\text { New York, } \\
\text { USA }\end{array}$ & $\begin{array}{l}\mathrm{L} ; \mathrm{VCT} \text { at baseline; } \\
\text { advanced or standard } \\
\text { referrals during } \\
\text { posttest counseling; } 6 \\
\text { months follow-up }\end{array}$ & 541 & $\begin{array}{l}\text { Within and between subjects } \\
\text { comparison of sexual behavior } \\
\text { among out-of treatment drug } \\
\text { users in two intervention } \\
\text { conditions (standard vs. } \\
\text { enhanced). }\end{array}$ & $\begin{array}{l}\text { HIV-positive and HIV-negative participants in } \\
\text { both intervention conditions reported } \\
\text { reductions in risk behavior over time. HIV- } \\
\text { positive individuals report significantly greater } \\
\text { reductions in sexual risk behavior from baseline } \\
\text { to follow-up than HIV-negative participants. }\end{array}$ \\
\hline
\end{tabular}




\begin{tabular}{|c|c|c|c|c|c|}
\hline $\begin{array}{l}\text { Dilley et al., } \\
\text { (2002) }\end{array}$ & $\begin{array}{l}\text { San } \\
\text { Francisco, } \\
\text { USA }\end{array}$ & $\begin{array}{l}\text { RCT; HIV-testing at } \\
\text { baseline; one of } 4 \\
\text { types of counseling at } \\
\text { baseline; } 6 \text { months } \\
\text { follow-up; } 12 \text { months } \\
\text { follow-up }\end{array}$ & 248 & $\begin{array}{l}\text { Between group (HIV-negative } \\
\text { MSM) comparison of the effect of } 4 \\
\text { different types of counseling ( } 1 \\
\text { standard counseling condition, } 3 \\
\text { enhanced counseling conditions) } \\
\text { on subsequent sexual risk } \\
\text { behavior. }\end{array}$ & $\begin{array}{l}\text { At the } 6 \text { months follow-up session, the } \\
\text { proportion of subjects reporting UAI decreased } \\
\text { in all } 4 \text { counseling conditions. At the } 12 \text { months } \\
\text { follow-up session, a reduction in reported UAI } \\
\text { was only found in the } 3 \text { enhanced counseling } \\
\text { conditions but no longer in the standard } \\
\text { counseling condition. The largest decrease in } \\
\text { UAI at } 12 \text { months follow-up was found in the } \\
\text { so-called "self-justification counseling } \\
\text { intervention". }\end{array}$ \\
\hline $\begin{array}{l}\text { George et al., } \\
(1998)\end{array}$ & $\begin{array}{l}\text { Paddington, } \\
\text { London }\end{array}$ & $\begin{array}{l}\text { VCT at baseline; } 1 \\
\text { year follow up }\end{array}$ & 228 & $\begin{array}{l}\text { Between subjects (genitourinary } \\
\text { clinic visitors) comparison of STD } \\
\text { rate before and after VCT. }\end{array}$ & $\begin{array}{l}\text { Testing negative for HIV was not associated } \\
\text { with an increase in subsequent risk of acquiring } \\
\text { an STD (i.e., increased sexual risk behavior). }\end{array}$ \\
\hline $\begin{array}{l}\text { Ickovics et al., } \\
\text { (1998) }\end{array}$ & USA & $\begin{array}{l}\mathrm{L} ; \mathrm{VCT} \text { at baseline; } 5 \\
\text { follow-up sessions } \\
\text { over a } 18 \text { month } \\
\text { period }\end{array}$ & 138 & $\begin{array}{l}\text { Between subjects (tested HIV- } \\
\text { negative women versus untested } \\
\text { women) comparison of sexual risk } \\
\text { behavior. }\end{array}$ & $\begin{array}{l}\text { VCT had limited effects on sexual behavior } \\
\text { change. After } 18 \text { months, the level of sexual risk } \\
\text { behavior in both groups was equal to the level } \\
\text { reported at baseline. VCT does not appear to } \\
\text { have a long-term effect on sexual risk behavior } \\
\text { among seronegative women. }\end{array}$ \\
\hline $\begin{array}{l}\text { Inciardi et al., } \\
(2005)\end{array}$ & $\begin{array}{l}\text { Florida, } \\
\text { USA }\end{array}$ & $\begin{array}{l}\text { L; VCT at baseline; } \\
\text { random assignment to } \\
\text { one of two } \\
\text { intervention } \\
\text { conditions (standard } \\
\text { counseling } \\
\text { intervention versus } \\
\text { enhanced counseling } \\
\text { intervention); } 3 \\
\text { months follow-up }\end{array}$ & 407 & $\begin{array}{l}\text { Between subjects (HIV-positive } \\
\text { versus HIV-negative female CSW) } \\
\text { comparison of (sexual) risk } \\
\text { behavior before and after VCT. }\end{array}$ & $\begin{array}{l}\text { HIV-positive women appear to be } 1.9 \text { times } \\
\text { more likely to have decreased their frequency of } \\
\text { unprotected sex and } 2.2 \text { times more likely to } \\
\text { have decreased their number of sex partners } \\
\text { than HIV-negative women. The enhanced } \\
\text { counseling intervention was not more effective } \\
\text { in reducing sexual risk behavior than the } \\
\text { standard counseling condition. }\end{array}$ \\
\hline
\end{tabular}




\begin{tabular}{|c|c|c|c|c|c|}
\hline $\begin{array}{l}\text { Kotranski et al., } \\
\text { (1998) }\end{array}$ & $\begin{array}{l}\text { Philadelphi } \\
\text { a, USA }\end{array}$ & $\begin{array}{l}\mathrm{L} ; \mathrm{VCT} \text { at baseline ; } \\
\text { additional enhanced } \\
\text { intervention for one } \\
\text { half of the } \\
\text { participants } \\
\text { (random); } 6 \text { moths } \\
\text { follow-up }\end{array}$ & 417 & $\begin{array}{l}\text { Between subjects (enhanced versus } \\
\text { standard counseling intervention) } \\
\text { and within subjects (out-of- } \\
\text { treatment drug users) comparison } \\
\text { of (sexual) risk behavior before } \\
\text { and after VCT. }\end{array}$ & $\begin{array}{l}\text { Results show that at the } 6 \text { month follow-up, } \\
\text { overall, a lower proportion of individuals } \\
\text { reported engaging in unprotected vaginal sex } \\
\text { and fewer sexual partners. The additional } \\
\text { enhanced counseling intervention was not more } \\
\text { effective in reducing (sexual) risk behavior } \\
\text { among participants than the standard } \\
\text { intervention. }\end{array}$ \\
\hline $\begin{array}{l}\text { MacGowan et } \\
\text { al., (1997) }\end{array}$ & $\begin{array}{l}\text { Massachuse } \\
\text { tts and } \\
\text { Connecticut } \\
\text {, USA }\end{array}$ & $\begin{array}{l}\text { L; } 5 \text { interviews for } \\
\text { each participant: } \\
\text { baseline, } 1 \text { month, } 3 \\
\text { months, } 6 \text { months, } 12 \\
\text { months; HIV-testing } \\
\text { and counseling at } \\
\text { each interview, } \\
\text { methadone treatment }\end{array}$ & 1053 & $\begin{array}{l}\text { Within subjects and between } \\
\text { subjects comparison of sexual risk } \\
\text { behavior in the } 30 \text { days preceding } \\
\text { each follow-up interview among } \\
\text { sexually active participants only } \\
(n=690) \text {. }\end{array}$ & $\begin{array}{l}\text { HIV counseling, knowledge of an HIV-positive } \\
\text { test result and remaining in a methadone } \\
\text { maintenance treatment program (MMTP) was } \\
\text { associated with reductions in sexual risk } \\
\text { behaviors. }\end{array}$ \\
\hline $\begin{array}{l}\text { Mekonnen et al., } \\
(2003)\end{array}$ & $\begin{array}{l}\text { Addis } \\
\text { Ababa, } \\
\text { Ethiopia }\end{array}$ & $\begin{array}{l}\text { C; VCT at baseline; } 4 \\
\text { follow-up sessions } \\
\text { with including } \\
\text { (repeat) VCT }\end{array}$ & 921 & $\begin{array}{l}\text { Between subjects (male factory } \\
\text { workers) comparison of sexual } \\
\text { risk behavior. }\end{array}$ & $\begin{array}{l}\text { Changes in sexual risk behavior and a reduction } \\
\text { of STD over time were found. Between the first } \\
\text { and the fourth follow-up session, a significant } \\
\text { decline in the proportion of males reporting } \\
\text { recent casual sex }(17.5 \%-3.5 \%) \text {, sex with CSW } \\
(11.2 \%-0.75 \%) \text { and genital discharge }(2.1 \% \text { - } \\
0.6 \%) \text { was found. }\end{array}$ \\
\hline $\begin{array}{l}\text { Roth et al., } \\
(2001)\end{array}$ & $\begin{array}{l}\text { Kigali, } \\
\text { Rwanda }\end{array}$ & $\begin{array}{l}\mathrm{L} ; \mathrm{VCT} \text { at baseline; } 1 \\
\text { year follow-up }\end{array}$ & 684 & $\begin{array}{l}\text { Within subjects and between } \\
\text { subjects comparison of condom } \\
\text { use among heterosexual couples. }\end{array}$ & $\begin{array}{l}\text { Findings showed an increase in condom use } \\
\text { among serodiscordant couples of whom the } \\
\text { male partner received HIV-test results for the } \\
\text { first time (proportion regular condom users was } \\
5 \% \text { before testing and counseling and } 65 \% \text { at } \\
\text { one year follow-up). Findings also showed an } \\
\text { increase in condom use among discordant and } \\
\text { concordant positive couples who had }\end{array}$ \\
\hline
\end{tabular}


previously been tested and counseled

(proportion regular condom users was 29\% before testing and counseling and $62 \%$ at one year follow -up). A relatively smaller increase in condom use among concordant negative couples was found.

\begin{tabular}{|c|c|c|c|c|}
\hline $\begin{array}{l}\text { The Voluntary } \\
\text { HIV-1 } \\
\text { Counseling and } \\
\text { Testing Efficacy } \\
\text { Study Group } \\
(2000)\end{array}$ & $\begin{array}{l}\text { Kenya, } \\
\text { Tanzania, } \\
\text { Trinidad }\end{array}$ & $\begin{array}{l}\text { L; VCT or basic health } \\
\text { information at } \\
\text { baseline }-7 \text { months } \\
\text { follow-up with VCT - } \\
13 \text { months follow-up } \\
\text { with VCT }\end{array}$ & 3706 & $\begin{array}{l}\text { Within subjects and between } \\
\text { subjects comparison of sexual risk } \\
\text { behavior before and after either } \\
\text { VCT or offering basic health } \\
\text { information among heterosexual } \\
\text { individual or couple participants. }\end{array}$ \\
\hline
\end{tabular}

Findings support the efficacy of VCT in

promoting behavior change. Reductions in unsafe sexual behavior among respondents who received VCT were found. HIV-positive individuals reported a significantly greater reduction in unsafe sex than HIV-negative individuals.

$\mathrm{C}=$ cohort study; $\mathrm{CSW}=$ commercial sex worker(s); IDU=injecting drug users; $\mathrm{L}=$ longitudinal design; MSM=men who have sex with men; $\mathrm{RCT}=$ randomized control trial; $\mathrm{STI}=$ sexually transmitted infection; VCT=voluntary counseling and HIV-testing 


\section{DISCUSSION AND CONCLUSION}

\section{Discussion}

Evidence regarding a potential positive effect of VCT on subsequent sexual risk behavior has long been inconclusive and unclear. It was only until Weinhardt et al. (1999) published their meta-analytic review, that more clarity could be given. Their meta-analysis showed that VCT had a positive effect on sexual risk behavior among HIV-positive individuals, in the sense that individuals receiving a positive HIV-test result, reported a significantly greater reduction in subsequent sexual risk behavior than HIV-negative or untested individuals. This was reflected in an increase in regular condom use and/or a reduction in the number of sexual partners. Based on the findings in the present study, in which articles published after 1996 - the start of the so-called HAART era - on the effect of VCT on sexual risk behavior have been reviewed, their conclusions still appear to stand. The most compelling evidence for sexual risk reduction after VCT can be found in studies focusing on serodiscordant couples (Allen et al., 2003; Roth et al., 2001; The Voluntary HIV-1 Counseling and Testing Efficacy Study Group, 2000). Additional empirical support for the hypothesis that VCT leads to subsequent sexual risk reduction is provided in a recently conducted meta-analysis of high-risk sexual behavior among persons aware and unaware of their HIV-infection (Marks, Crepaz, Walton Senterfitt \& Janssen, 2005). Results from this study show that individuals, who find out that they are HIV-positive, subsequently reduce their levels of sexual risk behavior. Also, it was found that HIV-positive individuals who become aware of their HIV-status, subsequently reduce their level of sexual risk behavior more than HIV-positive individuals who remain unaware of their HIV-status. It must be noted, that in spite of the evidence in favor, some of the studies included in the present review were unable to demonstrate a (longterm) reduction of sexual risk behavior after VCT (Ickovics et al., 1998; George et al., 1998; Clark et al., 1998). However, despite a lack of clear empirical support for VCT having a positive effect on subsequent sexual risk reduction, no empirical evidence for VCT having a negative effect on sexual risk behavior (i.e., an increase in sexual risk behavior after VCT) was found in these studies either.

An important remark that must be made with respect to the conclusions as they were drawn by Weinhardt et al. (1999) has to do with the interpretation of "HIV-positive individuals becoming safer". Closer inspection of the studies reviewed in the present paper and additional empirical evidence from studies focusing on sexual behavior among MSM (Dodds, Mercey, Parry \& Johnson, 2003; Elford, Bolding \& Sherr, 2002; Hickson, Weatherburn \& Reid, 2002; Hickson, Weatherburn, Reid \& Stephens, 2003; Hospers, Kok, Harterink \& de Zwart, 2005, National Centre in HIV Social Research, 2003) shows that the 
reported frequency of unprotected anal intercourse (UAI) is considerably higher among HIV-positive individuals compared to HIV-negative individuals. For example, in a recently conducted Internet-based study among Dutch MSM, $39 \%$ of HIV-positive MSM reported UAI with their last sex partner, compared to $15 \%$ of HIV-negative and 13\% of untested MSM (Hospers et al., 2005). When taking into account serosorting, $28 \%$ of HIV-positive MSM, $15 \%$ of HIVnegative MSM and 13\% of untested MSM reported UAI with their last sex partner (i.e., with unknown HIV-status). Such findings call for more specific interventions aimed at (maintaining) sexual risk reduction after finding out ones HIV-status to be developed and implemented. The development of such interventions should ideally be a planned activity (Kok, 1999) and interventions should be based on psychosocial theories and empirical evidence in order for successful behavior change to be achieved (Bartholomew, Parcel, Kok \& Gottlieb, 2006). Future research should focus on finding out the psycho-social determinants underlying (maintained) sexual risk reduction, more specifically in the context of finding out ones HIV-status.

\section{Conclusion}

The outcome of the present systematic review leads to the conclusion that empirical evidence supports active promotion of VCT. Besides widely acknowledged secondary prevention effects, there is a relatively clear primary prevention effect related to VCT: individuals who find out they are HIVpositive become safer and individuals who find out they are HIV-negative do not become less safe. In the fight against HIV/AIDS, future HIV-prevention activities should therefore focus on active promotion of VCT. In addition, effective interventions aimed at reducing sexual risk behavior or maintaining sexual risk reduction after finding out one's HIV-status, should be developed and used. Such interventions, systematically developed on the basis of theory and empirical evidence, could be implemented as part of the post-test counseling session in the process of VCT. 


\section{CHAPTER SIX}

Developing a theory- and evidence-based Internet intervention

This chapter will be published as:

Mikolajczak, J., Kok, G., \& Hospers, H.J. (2008). Queermasters: developing a theory- and evidence-based Internet HIV-prevention intervention to promote HIV-testing among men who have sex with men (MSM). Applied Psychology: an international review, in press. 


\section{INTRODUCTION}

In this chapter of the thesis, the systematic development of an Internet intervention to promote HIV-testing among men who have sex with men (MSM) is described. The development of the program was based on the Intervention Mapping (IM) protocol, a process that consists of six consecutive steps to systematically develop health promotion programs using theory, empirical evidence from the literature, and additional evidence from research. Each of the six steps in the IM process comprises a set of tasks to be carried out by the program planner(s), ultimately resulting in a number of clear end products that are needed for the next step (Bartholomew, Parcel, Kok \& Gottlieb, 2006; Kok, Schaalma, Ruiter, van Empelen \& Brug, 2004).

In the present article, we do not provide the results of the evaluation of the effects of our intervention but focus on its systematic development. Traditionally, the health promotion literature has consisted largely of descriptive studies on psychosocial determinants of behavior, of theory driven frameworks for intervention evaluation (Sidani \& Sechrest, 1999; Chen, 1990), and of evaluation studies reporting on the effectiveness of a program. However, what is often not or only briefly provided in such evaluation studies is a detailed description of how theory and evidence are used to systematically develop the program: how determinants are linked to methods for behavior change, and how the latter are operationalized in terms of a practical strategy (Michie \& Abraham, 2004). Insufficient information on the development and the content of any health promotion program not only poses limits to adequate program evaluation (Sidani \& Sechrest, 1999), but also to conducting metaanalytic reviews of intervention effectiveness in the future (Abraham \& Michie, 2007). Recently, more publications have described the development of programs for primary prevention purposes, such as safe sex in different (high) risk populations for HIV-infection (Kok, Harterink, Vriens, de Zwart \& Hospers, 2006; van Empelen, Kok, Schaalma \& Bartholomew, 2003) , stress management among adolescents (Kraag, Kok, Abu-Saab, Lamberts \& Fekkes, 2005), and (safe) sex education for HIV-positive MSM (van Kesteren, Kok, Hospers, Schippers \& de Wildt, 2006). Fewer publications described the development of programs for secondary prevention purposes aimed at early detection through screening, such as cervical cancer screening (Hou, Fernandez \& Parcel, 2004). The present article is another example of such a description, now in the area of HIV-testing.

In the first step of IM, prior to the actual development of our program, we conducted an extensive needs assessment to find out whether the need for a program to promote HIV-testing among MSM existed and, if so, what the program should address (Bartholomew et al., 2006; Green \& Kreuter, 2005). In 
the second step, we identified desired behaviors and environmental conditions that would reduce the health problem identified in the previous step. The end products of step 2 are matrices of change objectives, i.e., program blueprints that identify what and who should change as a result of our program. In the third step, we linked change objectives to practical strategies derived from theoretical methods for behavior change. The end product of step 3 is a list of theoretical methods for behavior change, theoretical parameters of use for each of these methods, and practical strategies to be applied in the fourth step, which includes program development. The end product of step 4 is the actual program or intervention. In the fifth and the sixth step of IM, the large-scale implementation of the program, as well as the process and effect evaluation of the program was prepared. The end products of these last two steps in IM are a detailed plan for future adoption and implementation of the program on the one hand and an extensive plan for effect- and process-evaluation of the program on the other hand. Empirical and theoretical evidence was systematically searched for and applied, to ground the decisions we made throughout the application of IM for the development of our program (Bartholomew et al., 2006; Kok et al., 2004).

\section{IM step 1: needs assessment}

The first step in IM is commonly referred to as the needs assessment, and consists of collecting, analyzing and interpreting available data that may contribute to program planning and development (Bartholomew et al., 2006, chap. 5). An important aspect we had to clarify first, was whether the need for a program that focuses on promoting HIV-testing among MSM actually existed. The current availability of more effective treatment for HIV-infected individuals, called Highly Active AntiRetroviral Therapy (HAART), provides strong arguments in favor of active promotion of HIV-testing aimed at early detection of HIV-infection (in Western countries). Early detection of HIVinfection allows for better preparation for treatment among newly diagnosed individuals, adequate monitoring of an individual's health status, proper treatment initiation, and creates opportunities for education with respect to treatment, care and support (Chadborn et al., 2005). Whereas initially, HIVtesting was not actively promoted in the Netherlands, it is now actively promoted among individuals at high risk for HIV-infection. In Western countries, including the Netherlands, MSM are a key target group for HIVprevention activities, since they continue to be at high risk for HIV-infection (UNAIDS, 2003).

The Netherlands' revised HIV-testing policy called for effective health promotion programs that would focus specifically at the promotion of HIV- 
testing among MSM. Furthermore, the need for such a program was fostered by the observation that the uptake of HIV-testing among MSM in the Netherlands was, and still is, substantially lower than it was in most other Western countries. In some of these countries, HIV-testing rates among MSM of $80 \%$ and higher are observed (Mikolajczak, Hospers \& Kok, 2006), while in the Netherlands, the most recent large-scale $(\mathrm{N}=4194)$ Internet-based survey among MSM showed that only $60 \%$ of the participants had ever taken an HIV-test, indicating that a substantial proportion of MSM in the Netherlands remain unaware of their serostatus (Hospers, Dörfler \& Zuilhof, 2006). As a consequence, HIV-infected men miss out on the above mentioned benefits of treatment. In addition, a substantial amount of these men also continue to place other men at risk for HIV-infection through unprotected anal intercourse (UAI). Thus, HIV-testing should be promoted among MSM in the Netherlands, and the need for a program that focuses on the promotion thereof clearly exists.

To find out which aspects our health promotion program should address, we conducted two studies to gather a thorough understanding of both the personal (social-cognitive) correlates - referred to as determinants in the remainder of this article - that underpin the relevant risk behavior of not taking an HIV-test among MSM, and the environmental conditions or external determinants that contribute to it. Guided by the available literature on the topic, we first set up a small-scale qualitative study into reasons for not taking an HIV-test among 32 untested Dutch MSM (Mikolajczak, van Kesteren, Hospers \& Kok, 2004). Findings from this qualitative study indicated that not taking an HIV-test could be related to a variety of factors. Adequate knowledge about the Dutch HIV-testing-policy, HIV-testing procedures, and specific aspects of taking an HIV-test such as the costs involved, appeared to be limited among study participants. In addition, the perceived risk of being infected with HIV was low, although the majority of respondents reported sexual risk behavior in the six months prior to the interview. The low perceived risk for HIV-infection may be the outcome of a defensive reaction in terms of cognitive dissonance reduction (Offir, Fisher, Williams, Fisher, 1993), as a result of the level of fear that is experienced by at-risk respondents when taking an HIV-test comes into play. This interpretation was fostered by the finding that most of these respondents indicated they feared detrimental consequences for their lives and their future if they would find out being HIV-infected. Taken together, high levels of fear associated with taking an HIV-test might lead atrisk respondents to reinterpret their past sexual behavior and the associated risks for HIV-infection. The fact that participants generated such reasons as: "I knew him for quite some time before we had sex and I knew his sexual history, so he must have been safe", to justify their low perceived risk for HIV-infection 
supports the interpretation of our findings in terms of cognitive dissonance reduction (Mikolajczak et al., 2004; Mikolajczak, Hospers \& Kok, 2006). Finally, our qualitative study also showed that HIV-testing was neither encouraged nor reinforced by respondents' social environment, and was hardly ever talked about with significant others (i.e., good friends).

Shortly thereafter, a large-scale Internet-based survey among MSM in the Netherlands was set up, to corroborate our qualitative findings on the one hand, and to extend our understanding of the determinants underpinning not taking an HIV-test on the other hand, by exploring additional determinants derived from social-cognitive theories, such as Ajzen's (1991) Theory of Planned Behavior (TPB). Results from this study showed that the intention to take an HIV-test in the near future, among at risk MSM in the study sample $(\mathrm{N}=733)$ could be predicted from a set of (social-cognitive) determinants, including their attitude towards taking an HIV-test, the perceived social norm concerning taking an HIV-test, and perceived behavioral control (or self-efficacy: Bandura, 1986) about taking an HIV-test, Additional predictors were specific knowledge about taking an HIV-test (i.e., where to get tested), their perception of risk for HIV-infection (i.e., have never been at risk for HIV-infection), and how much they had talked about HIV-testing with significant others (i.e., good friends) (Mikolajczak, Hospers \& Kok, 2007)

\section{IM step 2: matrices of change objectives}

At the beginning of this second step in IM, we further narrowed down the target group of our program to MSM who were sexually active with casual partners. In addition, the health promoting behavior for our target group was also elaborated upon and rephrased as: "MSM who are sexually active with casual partners take an HIV- and sti-test (referred to as regular Sexual Health Checkups ${ }^{2}$ in the description of our program: see IM step 4) at least once every year". The next task we had to carry out was to further specify the health promoting behavior in terms of performance objectives. These can be considered as preparatory or sub-behaviors for the target group, and were derived by answering the following question: "what do the participants of our program need to do to perform the health promoting behavior?" (Bartholomew et al., 2006, chap. 6). Performance objectives for the target group of our program are summarized in Table 1.

\footnotetext{
${ }^{2}$ Conform the Dutch current policy on hiv- and sti-testing, a sexual health checkup for MSM comprises the so-called "big-five": hiv, syphilis, gonorrhea, hepatitis B and chlamydia
} 
Table 1. Performance objectives for taking a regular HIV-test, for sexually active MSM with asual partners

1. Decide to be open-minded about HIV-testing

2. Become aware of a defensive reaction towards HIV-testing

3. Identify oneself as sexually active

4. Decide to take an HIV-test

5. Make an appointment for taking an HIV-test

6. Go to the test location for an HIV-test

7. Find out the result of the HIV-test

8. When HIV-negative: decide to take an HIV-test on a regular basis

Once performance objectives were defined and clearly formulated, we looked back at our findings concerning the (social-cognitive) determinants of taking an HIV-test. Of these, we selected determinants that we judged important for the purpose of our program on the one hand, and changeable on the other hand. Both our research findings in the studies discussed earlier (Mikolajczak et al., 2004, 2006, 2007), and the present scientific knowledge about behavioral determinants (Bartholomew et al., 2006, chap. 6; Glanz, Rimer \& Lewis, 2002) provided evidence we used to decide upon the importance and the changeability of the determinants in relation to the behavior we wanted to change. The determinants we selected for inclusion in our health promotion program, on the basis of the above described process, can be found in Table 2.

After selecting the determinants, we created matrices of change objectives by crossing the performance objectives (see Table 1) with each of the selected determinants (see Table 2). Next, we formulated change objectives and entered these in the cells of the matrix, at the intersection of each performance objective and the determinants. Change objectives take into account the target population, and actively and measurably express the necessary change(s) to be achieved at the determinant level, with respect to the performance objectives. For example: sexually active MSM with casual partners (target population) recognize the advantages (determinant: attitude) of taking a regular HIV-test (performance objective). Part of our matrix of change objectives, including more examples of change objectives, can be found in Table 3 . 
Table 2. Selected examples of importance (I) and changeability (C) of personal and external determinants of performance objectives

\begin{tabular}{|c|c|c|c|}
\hline Determinants & 1 & C & Evidence for importance \\
\hline \multicolumn{4}{|l|}{ Personal } \\
\hline Knowledge* & + & +++ & Precondition for positive attitude \\
\hline Risk perception* & +++ & + & $\mathrm{r}=.18<.001$ \\
\hline Attitude* & +++ & +++ & $\mathrm{r}=.31<.001$ \\
\hline Perceived social norm* & +++ & + & $\mathrm{r}=.41<.001$ \\
\hline Coping style & ++ & + & $\begin{array}{l}\text { Adaptive coping grants healthy } \\
\text { solutions }\end{array}$ \\
\hline Skills* & ++ & ++ & $\begin{array}{l}\text { Precondition for self-efficacy } \\
\text { improvement }\end{array}$ \\
\hline Self-efficacy* & ++ & ++ & $\mathrm{r}=.-09<.01$ \\
\hline \multicolumn{4}{|l|}{ External } \\
\hline Descriptive social norm* & +++ & + & $\mathrm{r}=.11<.01$ \\
\hline Social support* (other MSM) & +++ & + & Making healthy behavior easier \\
\hline Reinforcement* (health services) & +++ & + & Making healthy behavior easier \\
\hline
\end{tabular}

Note: Determinants marked with an * were included in our program.

Importance $=$ the strength of the evidence for the causal relationship between the determinant and behavior we want to change.

Changeability = the strength of the evidence that the proposed change can be realized by our program;

+ means: not very important, not easy to change; ++ means: important, changeable; +++ means: very important, very easy to change. Correlations (with intention to take an HIV-test) and levels of significance are based on the results from a report by Mikolajczak and colleagues (2007)

Table 3. Selected part of the matrix of change objectives for our health promotion program for sexually active MSM with casual partners

\begin{tabular}{llll}
\hline $\begin{array}{l}\text { Performance } \\
\text { objectives }\end{array}$ & Attitude & $\begin{array}{l}\text { Perceived social } \\
\text { norm }\end{array}$ & Reinforcement \\
\hline $\begin{array}{lll}\text { MSM decide to take an } \\
\text { hiv-test }\end{array}$ & $\begin{array}{l}\text { MSM recognize the } \\
\text { advantages of } \\
\text { taking an hiv-test }\end{array}$ & $\begin{array}{l}\text { MSM acknowledge } \\
\text { that other MSM } \\
\text { take an hiv-test }\end{array}$ & $\begin{array}{l}\text { Local health services } \\
\text { support hiv-testing }\end{array}$ \\
$\begin{array}{l}\text { When hiv-negative: } \\
\begin{array}{l}\text { MSM decide to take a } \\
\text { regular hiv-test }\end{array}\end{array}$ & $\begin{array}{l}\text { MSM express a } \\
\text { positive attitude } \\
\text { towards regular } \\
\text { hiv-testing }\end{array}$ & $\begin{array}{l}\text { MSM acknowledge } \\
\text { that other MSM } \\
\text { regularly take an } \\
\text { hiv-test }\end{array}$ & $\begin{array}{l}\text { Local health services } \\
\text { support regular hiv- } \\
\text { testing }\end{array}$ \\
\hline
\end{tabular}




\section{IM step 3: theoretical methods and practical strategies}

In the third step, the change objectives in our matrix were linked to practical strategies derived from theoretical methods for behavior change. A theoretical method is a general technique, derived from theory, to accomplish desired changes in the determinants of behaviors and environmental conditions. Modeling is an example of a theoretical method, derived from Bandura's (1986) Social Cognitive Theory (SCT), which can be applied to achieve a change in one's skills (Bartholomew et al., 2006, chap. 7),. A practical strategy is a specific application of a theoretical method, in ways that fit the target group of the program and the context in which it will be conducted, for example a video role model story. Based on theory and the available up-to-date literature on theoretical methods of behavior change (Bartholomew et al., 2006, chap. 7; Glanz et al., 2002), we identified and selected relevant methods for each of the determinants identified earlier (see IM step 2). An overview and a description of the methods we selected for our health promotion program can be found in Table 4.

Table 4. Selected examples of determinants, theoretical methods, theoretical parameters of use, and practical strategies

\begin{tabular}{|c|c|c|c|}
\hline Determinants & Theoretical method & Parameters of use & Strategy \\
\hline Knowledge & $\begin{array}{l}\text { Tailoring (Rimer \& } \\
\text { Kreuter, 2006) }\end{array}$ & $\begin{array}{l}\text { Information fits } \\
\text { characteristics of the } \\
\text { individual }\end{array}$ & $\begin{array}{l}\text { Tailored feedback, } \\
\text { "wheel of } \\
\text { knowledge" }\end{array}$ \\
\hline Attitude & $\begin{array}{l}\text { Arguments (Ajzen, 1991; } \\
\text { Tam \& Ho, 2005) }\end{array}$ & New arguments & "Statement game" \\
\hline Perceived social norm & $\begin{array}{l}\text { Visible expectations } \\
\text { (Ajzen, 1991) }\end{array}$ & $\begin{array}{l}\text { Positive expectations are } \\
\text { available in the } \\
\text { environment }\end{array}$ & $\begin{array}{l}\text { Virtual MSM } \\
\text { audience displays a } \\
\text { favorable norm }\end{array}$ \\
\hline Skills and self-efficacy & $\begin{array}{l}\text { Modeling } \\
\text { (Bandura, 1986) }\end{array}$ & $\begin{array}{l}\text { Identification with the } \\
\text { model, reinforcement, } \\
\text { skills and coping model }\end{array}$ & $\begin{array}{l}\text { Tailored video role } \\
\text { modeling story }\end{array}$ \\
\hline Risk perception & $\begin{array}{l}\text { Gain frame - loss frame } \\
\text { (Apanovitch, McCarthy } \\
\text { \& Salovey, 2003) }\end{array}$ & $\begin{array}{l}\text { More effective to use loss } \\
\text { frame for detection } \\
\text { behavior }\end{array}$ & $\begin{array}{l}\text { Tailored feedback in a } \\
\text { loss frame }\end{array}$ \\
\hline Reinforcement & $\begin{array}{l}\text { Organizational advocacy } \\
\text { (Bartholomew et al., } \\
\text { 2006, chap. 4; Fernández } \\
\text { et al., 2003) }\end{array}$ & $\begin{array}{l}\text { Effective advocacy skills, } \\
\text { timing and resources }\end{array}$ & $\begin{array}{l}\text { Negotiations with } \\
\text { health services }\end{array}$ \\
\hline
\end{tabular}

Since theoretical methods are derived from theory, parameters of use - i.e., conditions that have to be met in order for a method to have the desired effect have to be taken into account when translating the selected methods into 
practical strategies. For example, SCT (Bandura, 1986) states that modeling will only be effective when the following conditions are met from the perspective of the learner (i.e., program participant): identification with the model; perceiving the model as a coping model instead of a mastery model; reinforcement of the model; and demonstration of adequate skills to the learner.

In addition to meeting the theoretical parameters of use, all of our practical strategies had to be feasible in the specific Internet setting of our program. Rather than limiting our possibilities for the development of practical strategies, this allowed us to make use of more innovative strategies such as interaction with virtual relational agents and e-mail feedback. In addition, using the Internet for the delivery of our program allowed us to reach a large number of individuals from our target population in a relatively short period of time, and to personalize our program material to the individual characteristics of the program participants through computerized tailoring. All the strategies we generated and included in our program, covering all of the change objectives identified earlier (see IM step 2), can be found in Table 4 .

Another important task we carried out in this step of IM, was the creation of an extensive linkage group: a group of individuals and organizations that collaborate in the development of our health promotion program by lending their knowledge and expertise on the one hand, such as individuals from our target population and Internet experts, or being responsible for adoption and implementation of our program on the other hand, such as MSM service (field) organizations.

\section{IM step 4: program development}

Actual development of our program, in terms of program materials, scope, sequence and theme was realized in this fourth step of IM. The program was a website (http://www.queermasters.nl), or more specifically, a Rich Internet Application. The back-end consisted of a MySQL database; the front-end for the program users was a Flash application communicating with the MySQL backend in XML. We used a PHP/HTML front-end to access the MySQL database.

The general theme we chose for our health promotion program was: "Queermasters, the online gay health show". In consultation with our linkage group, it was considered a theme that fitted well with our target population. The concept of an online gay health show allowed us to include different rounds for different program components, virtual relational agents (Bickmore, Gruber \& Picard, 2005) in terms of a show master and his assistant, and a virtual MSM audience in the background representing a reference group, and expressing an injunctive social norm (Cialdini \& Goldstein, 2004). In addition, the current Dutch online HIV-test promotion program served as a control 
condition to allow effect evaluation of our program (see step 6 of IM). The scope of our program focused primarily on the advantages of regular sexual health checkups and the fact that most other MSM favor regular checkups, to motivate participants to take up regular sexual health checkups and consequently get tested for HIV. The scope of the program that served as the control condition focused on both risk information and risk communication to motivate participants to take an HIV- and an STI-test. In our program, we deliberately avoided the use of risk information and risk communication as means of motivating participants to take an HIV-test. This decision was taken on the basis of our qualitative (Mikolajczak et al., 2004) and quantitative (Mikolajczak et al., 2006) findings. Additional empirical evidence in support of our decision comes from the results of a study conducted by Lauby, Bond, Eroğlu and Batson (2006), which led the authors to conclude that increasing perceived risk for HIV-infection might not be a successful method to motivate (at-risk) individuals to take an HIV-test. An overview of the scope and sequence of our program and the control program, including the different strategies and program materials that we developed can be found in Table 5 .

The show master, a virtual relational agent (Bickmore et al., 2005) specifically designed to build and maintain a social-emotional relationship with the program participant, plays an important role in Queermasters. Participants first select their preferred show master out of three attractive, friendly looking and seemingly intelligent show masters. The selected show master then guides the different rounds in Queermasters, just like a "real" show master. Throughout the show, he poses questions (real speech in mp3-format), sometimes makes jokes, gives tailored feedback to the program participant and also sends e-mails upon request. In addition, he is able to wink, smile, and give thumbs-up or thumbs down; human-like features that were included in the showmasters' design to approximate human face-to-face interaction as closely as possible (see Figure 1 and Figure 2 for examples). 
Table 5. Scope and sequencing of Queermasters

\begin{tabular}{ll}
\hline Rounds & Strategies and materials \\
\hline \multirow{2}{*}{ Enrollment } & \multicolumn{1}{c}{ Start session 1} \\
& - banners on Dutch gay Web sites \\
& - banner, button and chat profile on www.chatboy.nl \\
& - advertisement in popular gay magazines \\
Round 1 & - picking favorite show master \\
& - informed consent \\
& - tailored questionnaire: demographics, sexual behavior and hiv-testing \\
& - e-mail registration \\
Round 2 & - tailored questionnaire: baseline measurement \\
& - randomization
\end{tabular}

\section{Experimental condition}

Round 3 - video: a new perspective on hiv- and sti-testing (knowledge, perceived social norm, advantages of regular sexual health checkups, attitude), tailored to age and steady partner status

- statement game: participants' opinion about advantages linked to regular sexual health checkups, opinion of men in the audience, tailored feedback on participants' opinion by show master, get extra e-mail information

Round 4 - wheel of knowledge: participants' knowledge, tailored feedback by show master

\begin{tabular}{|c|c|}
\hline \multicolumn{2}{|c|}{ Control condition } \\
\hline \multirow[t]{2}{*}{ Round 3} & - risk checklist \\
\hline & $\begin{array}{l}\text { - risk indicator: participants' assessment of personal risk for hiv- } \\
\text { infection versus professional assessment participants' risk for } \\
\text { hiv-infection }\end{array}$ \\
\hline Round 4 & $\begin{array}{l}\text { - outcome risk checklist and (hiv and/or sti) test recommendation, } \\
\text { possibility to acquire an explanation of the recommendation }\end{array}$ \\
\hline \multirow[t]{2}{*}{ Bonus } & $\begin{array}{l}\text { - immediate posttest: intention } \\
\text { - tailored link to website: detailed overview of test locations (address, } \\
\text { contact info, ...) in the Netherlands } \\
\text { - tailored link to website also send to mailbox }\end{array}$ \\
\hline & End session 1 \\
\hline \multirow[t]{2}{*}{ E-mail } & $\begin{array}{l}\text { - } 90 \text { days after finishing session } 1 \\
\text { - invitation to participate in session } 2\end{array}$ \\
\hline & Start session 2 \\
\hline \multirow[t]{2}{*}{ Follow-up } & - tailored questionnaire: follow-up measurement \\
\hline & End session 2 \\
\hline
\end{tabular}


Figure 1. Statement game: tailored dialogue between participant and show master (information between brackets only shown to participants involved in an ongoing steady relationship with another man)

\begin{tabular}{|c|c|}
\hline $\begin{array}{l}\text { On screen: taking a regular checkup } \\
\text { makes condom use unnecessary }\end{array}$ & $\begin{array}{l}\text { On screen: your opinion } \\
\text { - I agree } \\
\text { - } \quad \text { I disagree }\end{array}$ \\
\hline \multicolumn{2}{|c|}{ Show master: let's see what our men in the audience think of this } \\
\hline \multicolumn{2}{|c|}{$\begin{array}{l}\text { On screen: voting results from the men in the audience } \\
\quad 21 \% \text { agree } \\
\quad 79 \% \text { disagree } \\
\text { Show master: a large majority does not agree with this statement }\end{array}$} \\
\hline If answered I agree: & If answered I disagree: \\
\hline $\begin{array}{l}\text { Show master: leaving out condoms is not an } \\
\text { option; it remains the best way to protect you } \\
\text { from getting hiv or another sti. [Within your } \\
\text { steady relationship it might be an option, but } \\
\text { then you have to comply with a set of rules] }\end{array}$ & $\begin{array}{l}\text { Show master: indeed, leaving out condoms is } \\
\text { not an option; it remains the best way to protect } \\
\text { you from getting hiv or another sti. [Within your } \\
\text { steady relationship it might be an option, but } \\
\text { then you have to comply with a set of rules] }\end{array}$ \\
\hline
\end{tabular}

Figure 2. Virtual Show Master provides Tailored Feedback in Real Speech (mp3-format) to Program Participant and offers Extra Information via E-mail

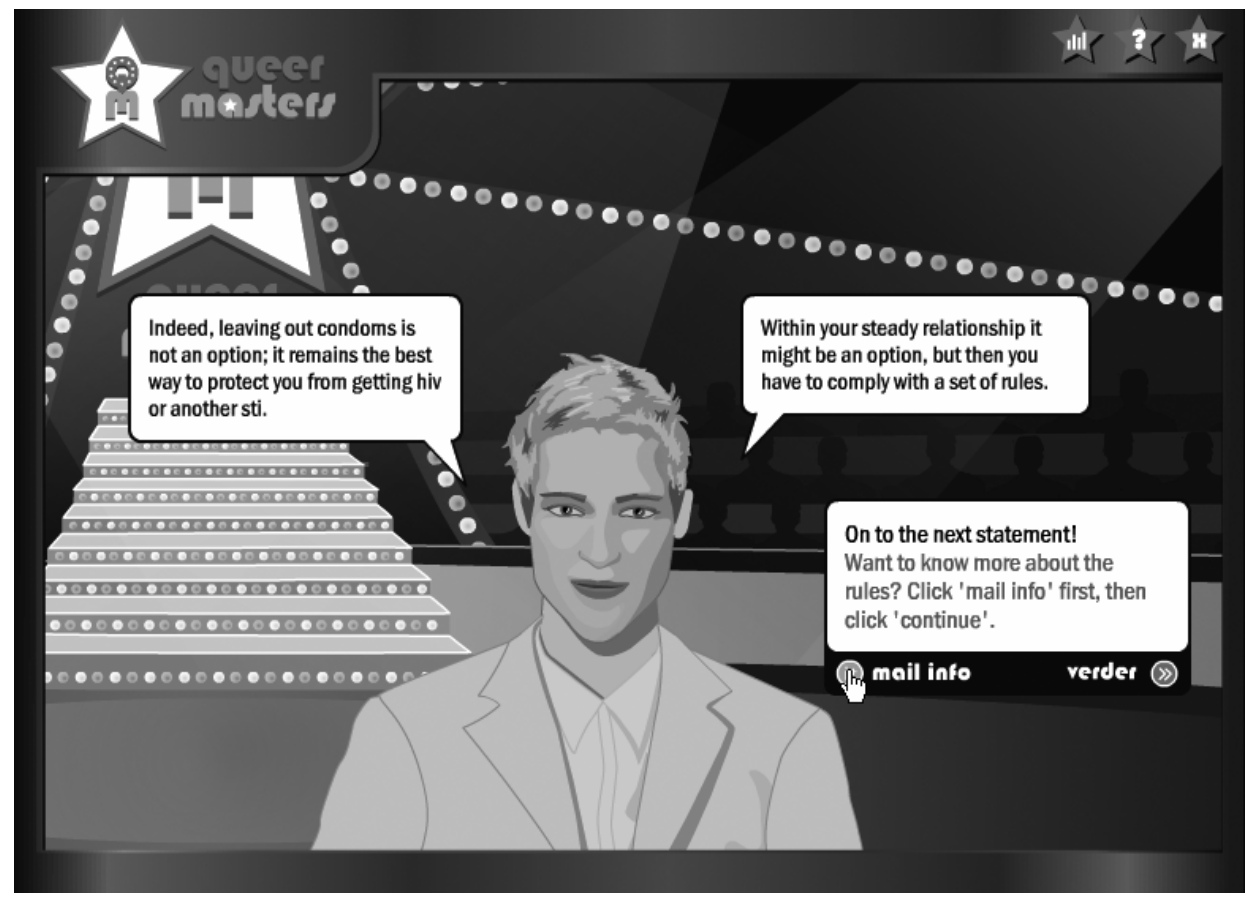

All our program material was developed in line with the parameters of use (see step 3), and covered all the change objectives (see IM step 2). As can be seen in 
Table 5, the video role model story, for example, was tailored to the characteristics of the participants (young versus old; steady partner versus no steady partner). In all four videos, a positive role model - already displaying the desired behavior of taking a regular sexual health checkup - talked about the advantages of taking a regular checkup and explained that his friends are supportive towards him taking these checkups. In addition, he listed several locations to go for a checkup.

All our program material was extensively pre-tested by a group of professionals (individuals working in the field of health promotion and Internet communication specialists), and by members from our target population.

\section{IM step 5: adoption and implementation}

To ensure that Queermasters would be continued after the development phase for as long as the need for our program exists, we anticipated both its implementation and adoption. With respect to the implementation of the program, Schorer - Gay and Lesbian Health Foundation Amsterdam - was the most important agent. They will get full control and management over the website after the evaluation.

\section{IM step 6: evaluation}

In the final step of IM, we planned the evaluation of our program in terms of effect and process evaluation. Effect evaluation allowed us to determine whether or not our program was successful in realizing its goals and objectives, compared to best (online) practice. Therefore, Queermasters was embedded in a randomized control trial design with a three months follow-up period (see Table 5). Achievement of the final goal of our program was evaluated by comparing the number of program participants that took an HIV-test after exposure to either the experimental or the control condition. In addition, the matrices of change objectives (see IM step 2) provided us with input for the effect evaluation at the level of determinants in terms of measurable change objectives. Process evaluation on the other hand, allowed us to determine why our program was or was not successful in achieving its goals and objectives.

\section{DISCUSSION}

The application of IM (Bartholomew et al., 2006; Kok et al., 2004) for the systematic development of an Internet health promotion program called "Queermasters", designed to motivate Dutch MSM to take an HIV-test, has been described in this article. The use of the Internet for the delivery of our program to MSM in the Netherlands provided us with some important 
advantages. First of all, it allowed us to reach a relatively large number of individuals from the target population in a relatively short period of time. Contrary to other mass media channels, such as television or billboards, another important advantage of Internet use is the possibility to adapt program material to the characteristics of the individual participants by means of computerized tailoring (de Vries \& Brug, 1999; Kroeze, Werkman \& Brug, 2006). For example, based on the demographic information gathered during the first round of Queermasters, such as age and steady partner status, we exposed program participants to one of four different versions of the video role model story. In addition, some of the feedback provided by the show master was given only to participants who had indicated that they were currently involved in a steady relationship with another man. Using computer tailoring in an Internet intervention thus reduces the traditional gap between mass communication and interpersonal communication. Finally, another advantage of the use of the Internet is the fact that people tend to be more open and honest in answering questions on sensitive topics, such as drug use or in our case HIV-testing (Turner, Ku, Rogers, Leidberg, Pleck \& Sonestein, 1998).

Over the past years, the use of the Internet for the delivery of health promotion programs has grown rapidly, and will most likely continue to do so. During the development of our program, the use of IM served as a necessary and helpful protocol to ensure the systematic use of theory and evidence. Consequently, our program's chances for being successful in achieving its ultimate goals and objectives will be maximized. The needs assessment, step 1 of the IM protocol, was particularly helpful in getting a better understanding of the health problem and its causes, both at an individual and an external level. During the second step, both the outcome of the needs assessment and additional evidence from theories of behavior, such as the Theory of Planned Behavior (Ajzen, 1991), provided us with direct input for building our matrices of change objectives. The fact that IM forced us to ground all of our decisions on theory and evidence ensured that during the third step of IM, the appropriate theoretical methods for behavior change were selected and consequently translated into practical strategies that fitted both our target group on the one hand, and the Internet setting of our program on the other hand. Another important aspect of this third step in IM, which contributes significantly to maximizing the chances of developing an effective program, comprises taking into account the theoretical consideration for use of the different methods selected. For example, modeling will most likely be less effective if not all the theoretical considerations for use - described earlier in this paper - are taken into account. During the different steps of IM, but particularly during the fourth and the fifth step, close collaboration with members from our target group and 
professionals proved to be very useful in developing our program. For example, members of our target group were not only consulted for extensive pre-testing of program material at the end of program development, but were consulted whenever we were unsure about any particular aspect of our program; for example, the name of our program: "Queermasters".

As a result of the thorough application of IM to the development of our health promotion program, we believe that we have maximized its chances for being succesfull in achieving its goals and objectives. Our belief is strengthened by the observation that both early (Kalichman, Carey \& Johnston, 1996; Mullen, Green \& Persinger, 1985) and more recent reviews of health promotion programs (Van Empelen, Kok, Van Kesteren, Van den Borne, Bos \& Schaalma, 2003) come to the conclusion that the quality of program planning is be the best predictor of successful achievement of a program's goals and objectives. Future evaluation of our program, which was anticipated on during its development, will allow us to ultimately answer the question whether or not our program has been successful in doing so and why. As such, we believe that the application of IM to the development of health promotion programs will continue to contribute significantly to the effectiveness of such programs in the future, also in the context of an Internet setting. In addition, we believe that the present article meets the recent request for more detailed descriptions of program development in the health promotion literature. Finally, it must be noted that the content of our health promotion program was developed specifically in a Dutch context. As such, this implies that our program can not be applied unconditionally in the context of another country or a different target population. Doing so would require program planners to redo the Intervention Mapping process to ensure adequate adaptation of our programs' content to meet up with the specific needs of the new context or target population. 



\section{CHAPTER SEVEN}

Evaluating the effects of the intervention

This chapter is currently in preparation for publication:

Mikolajczak, J., Van Breukelen, J.P., Kok, G., \& Hospers, H.J. (in preparation). Evaluating the effects of an online HIV-prevention intervention to promote HIV-testing among Men who have Sex with Men (MSM) 


\section{INTRODUCTION}

This paper describes the evaluation of the effects of a health promotion program that was developed to motivate Dutch Men who have Sex with Men (MSM) to take an HIV-test. Therefore, a new and systematically developed online intervention was compared to an existing online intervention in a RCT design. The development of the new intervention was guided by the Intervention Mapping protocol (Bartholomew, Parcel, Kok \& Gottlieb, 2006). This maximized that program development was systematically planned on the basis of available theory and evidence (Kok, Schaalma, Ruiter, Van Empelen \& Brug, 2004). The newly developed intervention was named Queermasters. To motivate MSM to take an HIV-test, Queermasters introduced the concept of regular Sexual Health Checkups (SHC) and focused primarily on the advantages thereof, and attempted to influence the perceived social norm towards taking such checkups among MSM participants. Conform the Dutch current policy on HIV- and STI-testing, a Sexual Health Checkup comprises a test for the so called "Big five": HIV, syphilis, gonorrhea, hepatitis B and chlamydia. An existing online intervention, which was used as a control condition in our intervention study, focused on both risk information and risk communication to motivate MSM to take an HIV and/or an STI-test. Contrary to the control intervention, Queermasters deliberately avoided the use of risk information and risk communication as a method to motivate MSM to get tested. This decision was taken on the basis of findings in our previous studies (Mikolajczak, Kok \& Hospers, 2007; Mikolajczak, Van Kesteren, Hospers \& Kok, 2004) which suggest that increasing perceived risk for HIV-infection may not be an effective means to motivate Dutch MSM to take an HIV-test. Increasing perceived risk for HIV-infection might lead to an increase in the level of fear that is experienced, which might consequently lead to a defensive reaction in which one attempts to reduce unpleasant feelings as quickly as possible - for example by denying the threat or avoiding information about past sexual risk behavior - in order to achieve a feeling a safety (Ruiter, Verplanken, De Cremer \& Kok, 2004). Further support for the decision not to apply risk communication as a method to motivate MSM to take an HIV-test in Queermasters was provided by Lauby, Bond, Eroğlu \& Batson (2006), who found that perceived risk for HIV-infection was not associated with increased HIV-testing. More details on the development of Queermasters are described and reported elsewhere (Mikolajczak, Kok \& Hospers, 2008).

The Netherlands' current HIV-testing policy (Gezondheidsraad, 1999; VWS, 2003), which focuses on the promotion of HIV-testing among individuals at high(er) risk for HIV-infection, prompted the development of an effective 
health promotion program that would focus specifically at the promotion of HIV-testing among MSM. Moreover, the need for such a program was, and still is, also fostered by the observation that a large proportion of MSM in the Netherlands are still unaware of their HIV-status. The most recent figures from a large scale online study among MSM in the Netherlands called "Monitoronderzoek 2007", show that $63 \%$ of the respondents ever took an HIVtest (Hospers, Dörfler, Zuilhof \& Nijman, 2007). Although this figure is slightly higher compared to the figure that was found one year before $(60 \%$ : Hospers, Dörfler \& Zuilhof, 2006), and is substantially higher than the figure that was found in the first wave of this study in 2000 (47\%: Hogeweg \& Hospers, 2000), it remains relatively low when compared to the figures that are reported in other Western countries. In Australia for example, behavioral studies among MSM that have been conducted over the past years consistently report HIV-testing rates of about $85 \%$ and more among MSM (NCHSR, 2005).

As a consequence of the relatively low HIV-testing rates among MSM in the Netherlands, it is likely that a substantial number of MSM are unaware of their HIV-infection. Consequently, these men miss out on the benefits that are related to treatment of HIV-infection with HAART nowadays. In addition, many of them may also continue to place their sex partners at risk for HIVinfection through sexual risk behavior. It is thus expected that the beneficial effects of motivating (more) MSM in the Netherlands to take an HIV-test are twofold. First of all, the health status of individual men who find out that they are infected with the virus can be monitored and treatment with HAART can be initiated at an adequate moment in time. As a result, the effectiveness of treatment with HAART is optimized. It should be noted that although HAART can have negative side-effects, the overall advantages of HAART and its positive effects on quality of life and life expectancy of HIV-infected individuals are currently widely acknowledged (Ives, Gazzard \& Easterbrook, 2001; Matic, Lazarus \& Donoghoe, 2006; Saunders \& Burgoyne, 2002). Second, it can be expected that men who find out that they are infected with the virus will significantly reduce their level of sexual risk behavior (Marks, Crepaz, Senterfitt \& Janssen, 2005; Weinhardt, Carey, Johnson \& Bickham, 1999), which in turn reduces the spread of the virus in the MSM population in the Netherlands. It is also noteworthy that the available evidence does not support the idea that finding out being HIV-negative leads to a significant increase in sexual risk behavior among MSM (Weinhardt et al., 1999).

Finding out whether or not an intervention is effective in achieving its goals and objectives is an important aspect of program development (Bartholomew et al., 2006). Therefore, both process- and effect-evaluation of Queermasters were conducted. Evaluation of the effects of our newly 
developed program was realized by comparing it with an existing online intervention on a number of relevant outcome variables. Process evaluation included a comparison of participants' overall rating of the intervention in which they participated (either the experimental or the control condition), and a set of evaluative questions concerning the intervention in which they participated. Interventions that require an intermediate user, for example a counselor, to apply an intervention to individuals from the targeted population (i.e. sexually active MSM in the Netherlands), also call for an evaluation of such aspects as adoption and implementation of the intervention. Inadequate adoption (deciding to use the intervention) and implementation (using the intervention as it was developed to be used) of an intervention, at the level of the intermediate user, might hinder the interventions' effectiveness (Bartholomew et al., 2006; Fleuren, Wiefferink \& Paulussen, 2004). However, since Queermasters was a pre-programmed piece of software which was delivered to individuals from the target population through the Internet, and required no intermediate user to do so, adequate adoption and implementation was ensured. Therefore, both aspects are not further considered in the remainder of this paper, and process-evaluation of our intervention focuses on an analysis of different indicators reflecting participants' opinions about and experiences with the intervention in which they participated.

The outcome of both types of evaluation will be discussed in the final section of this paper. Also, implications of the findings for future HIVprevention activities that focus on promoting HIV-testing among MSM in the Netherlands will be considered.

\section{METHODS}

\section{Participants}

Participants for our intervention study were enrolled both online and offline. Online recruitment was realized by placing banners on several large and popular Dutch MSM websites, and by placing a click-through button on the home page of the most popular Dutch MSM chat website (www.chatboy.nl), and by placing a chatter's profile in the Chatboy chatbox inviting visitors to participate. Offline recruitment was realized by placing advertisements in popular Dutch MSM press.

\section{Procedure}

During the 28 days online period of Queermasters, from the November 1, 2006 until November 28, 2006, a total of 5030 men started our program by completing the first question in the questionnaire. Of these, a number were 
excluded for further statistical analyses because they either did not meet the inclusion criteria ${ }^{3}$ for the intervention study $(\mathrm{N}=1018)$, did not complete all the questions on demographics ( $\mathrm{N}=1003)$, or lived in the city of Nijmegen ${ }^{4}(\mathrm{~N}=123)$. After deleting these records, the dataset that was used for statistical analyses to evaluate the intervention effects contained 2886 unique records. Of these, 1704 men $(59 \%)$ finished the questionnaire (that preceded randomization to experimental and control group), which included questions on demographics, a request for a valid e-mail address and a pretest measurement of Theory of Planned Behavior variables (TPB: Ajzen, 1991) including their intention to take an HIV-test within the next three months. After finishing this part of the program, these respondents were randomly assigned to either the experimental intervention condition or the control intervention condition. Of these, 1425 men $(84 \%)$ completed the intervention part including an immediate posttest measurement of their intention to take an HIV/STI-test within the next three months, and thereby finished the complete pretest of our intervention study.

Three months after finishing the first session of Queermasters, all 1425 men received an e-mail, in which they were invited to participate in a follow-up session. In total, 612 men reacted to our e-mail invitation and started with the follow-up session of Queermasters, which included the question whether or not they had taken an HIV and/or an STI-test during the past three months. Of the men that started the follow-up session of Queermasters, 529 men (86\%) completed it. Details on the flow of the number of participants in our intervention study can be found in Figure 1 .

\footnotetext{
${ }^{3}$ Inclusion criteria for the intervention study were: having had casual sex partners in the past six months, not being HIV-positive, and living in the Netherlands

${ }^{4}$ For the purpose of another evaluation study, participants living in the city of Nijmegen were not randomly assigned to one of two intervention conditions, but always assigned to the experimental intervention. Therefore, they are not included in the intervention study described in this paper
} 
Figure 1. Flowchart of Queermasters, including: the number of participants in the intervention study, an overview of the key activities conducted at various points in the study, and the different drop-out analyses (D.O.) that were conducted

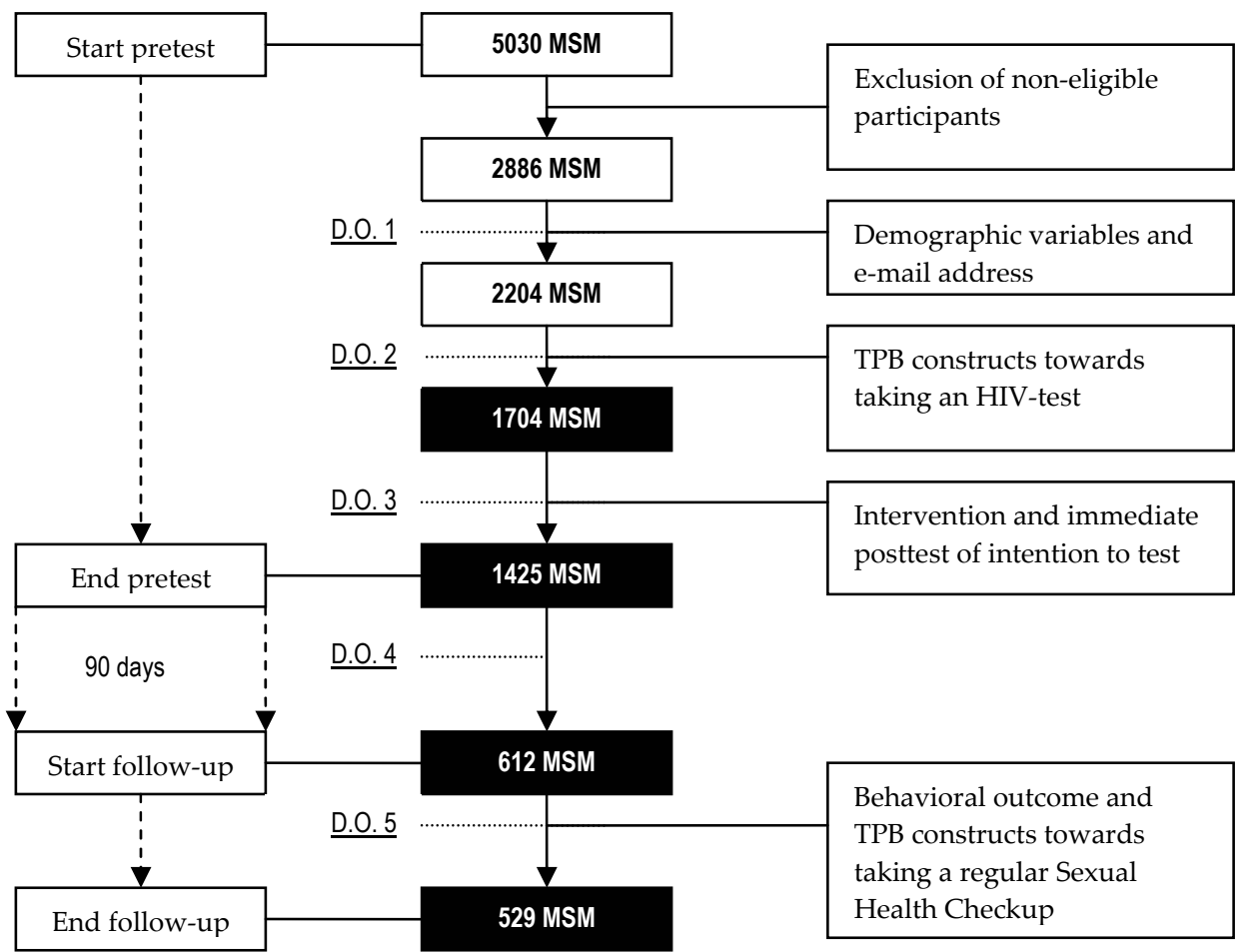

Note: black boxes concern the number of participants in the study after randomization to condition

\section{Materials}

For the purpose of our online RCT a Rich Internet Application (RIA), which can be considered a website application with the features and functionalities of a traditional desktop application, was developed and hosted on www.queermasters.nl. The back-end of our RIA consisted of a MYSQL database; the front-end for the users of our RIA was a Flash application.

The program that comprised the pretest in our intervention study consisted of two distinct parts. The first part contained an interactive questionnaire which asked for demographic information, a valid e-mail address and measurement of the different constructs of the Theory of Planned Behavior (TPB), of which some were used as a pretest measure of outcome variables of interest. Demographic variables of interest were age, educational level (recoded to $0=$ lower; 1 =higher), cultural background (recoded to $1=$ Dutch; $2=$ Dutch + 
other; $3=$ Non Dutch) , sexual attraction (recoded to $0=$ bisexual; $1=$ homosexual), HIV-testing history ( $0=$ never tested; $1=$ tested longer than nine months ago; $2=$ tested within the past nine months), STI-testing in past nine months $(0=$ no; $1=y e s)$, steady partner status ( $0=$ no; $1=y e s)$ and sexual risk behavior with casual partners in the last 6 months preceding the questionnaire (recoded to $0=$ no risk behavior; $1=$ =risk behavior). In addition, participants were asked to provide the first two numbers of their postal code and the name of the province in which they currently resided. The first question allowed us to calculate whether participants lived in an urban or a rural part ( $0=$ rural; $1=$ =urban) of the Netherlands, by applying the official criteria provided by the Dutch Central Bureau of Statistics (CBS). The second question allowed us to make a distinction between participants living in the "Randstad" and participants living outside this urban agglomeration in the West part of the Netherlands $(0=$ other; $1=$ Randstad). This distinction may be relevant in the context of promoting HIVtesting, given there are more testing facilities in the "Randstad" than in the rest of the Netherlands. An overview of the demographic features of MSM respondents at various points in the study is provided in Table 1.

After finishing the questions on demographic variables of interest, participants were asked to provide us with a valid e-mail address. For the purpose of our online RCT, this was necessary since participants were offered the option to receive extra information on certain topics later on in our program, for example during their intervention. In addition, a valid e-mail address was needed for us to be able to invite respondents to participate in a three month follow-up session of Queermasters.

After providing us with a valid e-mail address, participants were asked to fill in the questions on TPB constructs. Most of these constructs were measured using multiple items, which were subjected to reliability analysis to allow item summation and calculation of a mean score for each of the constructs (range 1 7), given a sufficient reliability coefficient. In the context of the present study, the TPB constructs were operationalized as follows:

Intention to take an HIV-test within the next three months was measured with two items. For example: "I intend to take an HIV-test within the next three months ", measured on a seven-point scale (very surely not - very surely so), correlation: .89. Attitude towards taking an HIV-test within the next three months was measured with four items. For example: "I consider taking an HIVtest within the next three months to be ...", measured on a seven-point scale (very unwise - very wise), Cronbach's alpha: .84 
Table 1. Overview of demographics among MSM participants at three different points in the study

\begin{tabular}{|c|c|c|c|c|c|}
\hline \multirow{2}{*}{ DEMOGRAPHICS } & \multirow[t]{2}{*}{$\begin{array}{l}\text { Full sample } \\
(\mathrm{N}=2886)\end{array}$} & \multicolumn{2}{|c|}{$\begin{array}{l}\text { At randomization } \\
(\mathrm{N}=1704)\end{array}$} & \multicolumn{2}{|c|}{$\begin{array}{l}3 \text { months follow-up } \\
(\mathrm{N}=529)\end{array}$} \\
\hline & & EXP & CTRL & EXP & CTRL \\
\hline Age & 36 & 36 & 36 & 38 & 38 \\
\hline \multicolumn{6}{|l|}{ Educational levela $^{a}$} \\
\hline Lower & 1345 (47\%) & $403(47 \%)$ & $388(47 \%)$ & $99(41 \%)$ & $138(48 \%)$ \\
\hline Higher & $1525(53 \%)$ & $457(53 \%)$ & $443(53 \%)$ & $141(59 \%)$ & $148(52 \%)$ \\
\hline \multicolumn{6}{|c|}{ Cultural background ${ }^{b}$} \\
\hline Dutch & $2485(86 \%)$ & $740(85 \%)$ & $728(87 \%)$ & $208(86 \%)$ & $261(91 \%)$ \\
\hline Dutch and other & $179(6 \%)$ & $57(7 \%)$ & $57(7 \%)$ & $12(5 \%)$ & $16(6 \%)$ \\
\hline Non-Dutch & $218(8 \%)$ & $72(8 \%)$ & $49(6 \%)$ & $22(9 \%)$ & $10(3 \%)$ \\
\hline \multicolumn{6}{|l|}{ Randstad } \\
\hline Randstad & $1437(50 \%)$ & $459(53 \%)$ & $410(49 \%)$ & $135(56 \%)$ & $135(47 \%)$ \\
\hline Other & $1449(50 \%)$ & $411(47 \%)$ & $424(51 \%)$ & $107(44 \%)$ & $152(53 \%)$ \\
\hline \multicolumn{6}{|l|}{ Living area } \\
\hline Rural & $1160(40 \%)$ & $336(39 \%)$ & $342(41 \%)$ & $101(42 \%)$ & $110(38 \%)$ \\
\hline Urban & $1726(60 \%)$ & $534(61 \%)$ & $492(59 \%)$ & $141(58 \%)$ & $177(62 \%)$ \\
\hline \multicolumn{6}{|l|}{ Sexual orientation } \\
\hline Bisexual & $519(18 \%)$ & $116(13 \%)$ & $108(13 \%)$ & $29(12 \%)$ & $23(8 \%)$ \\
\hline Homosexual & $2367(82 \%)$ & $754(87 \%)$ & $726(87 \%)$ & $213(88 \%)$ & $264(92 \%)$ \\
\hline \multicolumn{6}{|l|}{ Steady partner } \\
\hline No & $1912(66 \%)$ & $564(65 \%)$ & $534(64 \%)$ & $157(65 \%)$ & $181(63 \%)$ \\
\hline Yes & $974 \quad(34 \%)$ & $306(35 \%)$ & $300(36 \%)$ & $85(35 \%)$ & $106(37 \%)$ \\
\hline \multicolumn{6}{|l|}{ Risk casual partners } \\
\hline No & $2038(71 \%)$ & $593(68 \%)$ & $585(70 \%)$ & $162(67 \%)$ & $195(68 \%)$ \\
\hline Yes & $848(29 \%)$ & $277(32 \%)$ & $249(30 \%)$ & $80(33 \%)$ & $92(32 \%)$ \\
\hline \multicolumn{6}{|l|}{ HIV-testing } \\
\hline Never tested & $1232(43 \%)$ & $334(39 \%)$ & $332(40 \%)$ & $98(40 \%)$ & $112(39 \%)$ \\
\hline$>9$ months ago & $791(27 \%)$ & $254(29 \%)$ & $246(29 \%)$ & $65(27 \%)$ & $88(31 \%)$ \\
\hline$<9$ months ago & $863(30 \%)$ & $282(32 \%)$ & $256(31 \%)$ & $79(33 \%)$ & $87(30 \%)$ \\
\hline \multicolumn{6}{|l|}{ STI-testing } \\
\hline No & $1968(68 \%)$ & $577(66 \%)$ & $563(67 \%)$ & $156(65 \%)$ & $195(68 \%)$ \\
\hline Yes & $918(32 \%)$ & $293(34 \%)$ & $271(33 \%)$ & $86(35 \%)$ & $92(32 \%)$ \\
\hline
\end{tabular}

Note: a means $\mathrm{N}=2870$ in full sample due to missing data $\mathrm{b}$ means $\mathrm{N}=2882$ in full sample due to missing data

No statistically significant differences between the experimental (EXP) and the control (CTRL) condition were found on any of the demographic characteristics

Subjective social norm towards taking an HIV-test within the next three months was measured with two items. For example: "My best friends think that I should take an HIV-test within the next three months", measured on a sevenpoint scale (very surely not - very surely so), correlation: .77. 
Self-efficacy towards taking an HIV-test in the next three months was measured with eight items. For example: "I consider making an appointment to take an HIV-test at a testing location to be ... ", measured on a seven-point scale (very difficult - very easy), Cronbach's alpha: 0.84 .

After completing the set of questions on the TPB constructs, participants were randomly assigned to one of two intervention conditions ( $0=$ experimental, $1=$ control), which can be considered the second part of the program that comprised the pretest phase of our intervention study. Immediately after finishing their intervention, participants' intention to take an HIV- and/or an STI-test (referred to as a Sexual Health Checkup in the experimental condition) was measured (immediate posttest). Our hypothesis was that after exposure to the intervention material, participants' intention to test would be significantly higher among participants in the experimental condition compared to participants in the control condition.

Ninety days after participants had finished Queermasters, they received an e-mail, which invited them to participate in a follow-up session. Variables of interest that were measured during follow-up were whether or not participants had taken an HIV-test and/or an STI-test (referred to as a Sexual Health Checkup throughout the follow-up session of Queermasters) in the past three months, TPB constructs concerning taking a Sexual Health Checkup at a yearly basis, and a set of questions to allow part of the process-evaluation of Queermasters. Most of the TPB constructs were measured using multiple items, which were subjected to reliability analysis to allow item summation and calculation of a mean score for each of the constructs (range $1-7$ ), given a sufficient reliability coefficient. The TPB constructs were operationalized as follows:

Intention towards taking a Sexual Health Checkup every year was measured with one item: "Do you intend to take a Sexual Health Checkup every year", measured on a seven-point scale (very surely not - very surely so).

Attitude towards taking a Sexual Health Checkup every year was measured with four items. For example: "I consider taking a Sexual Health Checkup every year to be ...", measured on a seven-point scale (very unwise - very wise), Cronbach's alpha: 81 .

Subjective social norm towards taking a Sexual Health Checkup every year was measured with three items. For example: "My best friends think that I should take a Sexual Health Checkup every year", measured on a seven-point scale (very surely not - very surely so), Cronbach's alpha: .77. 
Self-efficacy towards taking a Sexual Health Checkup every year was measured with two items. For example: "I consider taking a Sexual Health Checkup on a yearly basis to be ... ", measured on a seven-point scale (very difficult - very easy), correlation: .75.

After completing this set of TPB questions, participants in both intervention conditions were also asked to indicate on a seven-point scale (totally disagree totally agree) whether they: "had enjoyed participating in Queermasters", "considered the content of Queermasters to be useful", "Queermasters gave them a better perspective on taking an HIV- and an STI-test" and "would advice others to participate in Queermasters".

\section{Statistical analysis}

Given the large sample size in all analyses, differences were considered statistically significant at a p-value $<.01$, two-tailed.

\section{RESULTS}

\section{Dropout analyses}

As can been seen in Figure 1, the number of respondents decreased during the flow of our online intervention study. Therefore, we checked whether demographic and other background variables were related to dropout at any point during the study, using logistic regression with dropout ( $1=y e s ; 0=n o)$ as outcome and treatment condition and demographics as predictors. In each dropout analysis, non-significant predictors were removed, using $\mathrm{p}>.01$ as the criterion for removal, to obtain a parsimonious final logistic regression model. Collinearity between predictors was checked by computing the variance inflation factors (VIF, see e.g. Field, 2005). No VIFs $>3$ were found, ruling out collinearity between predictors. The results of the different dropout analyses can be found in Table 2 .

As can be seen in Table 2, dropout analysis 1 shows that compared to younger men, and to homosexual men, both older men and bisexual men had a significantly higher chance to drop out of our intervention study when they were asked for a valid e-mail address. The outcome of dropout analysis 2 shows that of the men who provided us with a valid e-mail address, younger men had a significantly higher chance to drop out of our intervention study compared to older men when TPB questions were asked. Also, bisexual men had a significantly higher chance to drop out compared to homosexual men at this stage. 
Table 2. Overview of final logistic regression models, predicting participant dropout $(1=$ yes; $0=$ no $)$ at any point in the study

\begin{tabular}{|c|c|c|c|c|c|c|c|}
\hline \multirow[b]{2}{*}{ Dropout analysis } & \multirow[b]{2}{*}{ Predictors } & \multirow[b]{2}{*}{ B } & \multirow[b]{2}{*}{ SE } & \multirow[b]{2}{*}{ Sign } & \multirow[b]{2}{*}{$\operatorname{Exp}(B)$} & \multicolumn{2}{|c|}{$\begin{array}{l}95 \% \mathrm{Cl} \\
\operatorname{Exp}(\mathrm{B})\end{array}$} \\
\hline & & & & & & Low & Up \\
\hline \multicolumn{8}{|c|}{ Before randomization } \\
\hline D.O. 1 & Age & .013 & .004 & .002 & 1.01 & 1.00 & 1.02 \\
\hline \multirow[t]{2}{*}{$(\mathrm{N}=2866)$} & Sexual orientation & -.549 & .108 & .000 & .577 & .467 & .713 \\
\hline & Constant & -1.02 & .177 & .000 & .362 & & \\
\hline D.O. 2 & Age & -.024 & .005 & .000 & .976 & .967 & .986 \\
\hline \multirow[t]{2}{*}{$(\mathrm{N}=2204)$} & Sexual orientation & -.711 & .128 & .000 & .491 & .382 & .631 \\
\hline & Constant & .335 & .203 & .099 & 1.39 & & \\
\hline \multicolumn{8}{|c|}{ After randomization } \\
\hline D.O. 3 & Intervention condition & -1.80 & .169 & .000 & .167 & .120 & .232 \\
\hline$(\mathrm{N}=1704)$ & Constant & -.178 & .292 & .544 & .837 & & \\
\hline D.O. 4 & Age & -.025 & .005 & .000 & .976 & .967 & .985 \\
\hline$(\mathrm{N}=1425)$ & Constant & 1.18 & .187 & .000 & 3.27 & & \\
\hline D.O. 5 & Sexual orientation & -1.12 & .306 & .000 & .325 & .178 & .592 \\
\hline$(\mathrm{N}=529)$ & Constant & -1.66 & .504 & .001 & .190 & & \\
\hline
\end{tabular}

Note: predictors included in dropout analysis 1 and 2: age, educational level (0=lower;1=higher), sexual orientation $(0=$ bisexual; $1=$ homosexual), STI-test $(0=$ no; $1=y e s)$, steady partner $(0=$ no; $1=y e s)$, risk casual partners ( $0=$ no; $1=y e s)$, HIV-testing ( $0=$ never tested; $1=$ tested more than 9 months ago; $2=$ tested within past 9 months), living area ( $0=$ rural; $1=$ urban), Randstad ( $0=$ other; $1=$ Randstad), cultural background ( $1=$ Dutch; $2=$ Dutch and other; $3=$ non-Dutch), intervention condition ( $0=$ experimental; $1=$ control); dropout analyses 3,4 and 5 also included pretest measures of intention to take an HIV-test, attitude and self-efficacy towards taking an HIV-test. Actual $\mathrm{N}$ about $1 \%$ less then indicated due to missing values on predictors.

$\mathrm{SE}=$ Standard Error

Both dropout analysis 1 and 2 concerned participant dropout before random assignment to one of two intervention conditions. Therefore, they are relevant to the issue of generalizability of our results, to be discussed in the last section of our paper.

Dropout analysis 3 shows that men who were assigned to the experimental condition had a significantly higher chance to drop out during the intervention, compared to men who were assigned to the control condition. Dropout analysis 4 shows that of the men who were invited to participate in the 
follow-up session of Queermasters, older men had a significantly lower chance to drop out. Finally, dropout analysis 5 shows that of the men who started the follow-up session of Queermasters, homosexual men had a significantly lower chance to drop out of the follow-up session, compared to bisexual men. Dropout analyses 3, 4 and 5 concerned participants dropout after the random assignment to one of two intervention conditions, and are thus relevant to the question of internal validity and selection bias. This type of dropout was taken into account in all further reported analyses by entering the significant variables from dropout analyses 3,4 and 5 into the statistical models as covariates and by intention to treat outcome analyses including all available data of all participants randomized to either treatment.

\section{Effect of the intervention on participants' intention to test at immediate posttest}

To test our hypothesis concerning the effect of exposure to intervention material on participants' intention to take an HIV/STI-test (i.e., a Sexual Health Checkup), a repeated measures analysis with mixed linear regression was conducted. Relevant data of all 1704 randomized participants were used in this method of analysis. In contrast with a repeated measures ANOVA or ANCOVA, this method allows the inclusion of all participants with a missing value on either time point (pretest or immediate posttest) without requiring imputation 5 . Our basic mixed model assumed that participants' intention to take a Sexual Health Checkup depended on time (0=pretest; $1=$ immediate posttest), intervention condition $(0=$ experimental; $1=$ control), and time by intervention condition interaction (assuming a so-called unstructured covariance matrix for the repeated measures, for further details of this mixed model compared with standard ANOVA and ANCOVA, see: Van Breukelen, 2006). All background variables that were predictive of dropout after random assignment to intervention condition were included as covariates in our final mixed model as predictors of participants' intention to test. Other, nonsignificant predictors (see Table 2 note for an overview) were removed from the model, using $\mathrm{p}>.01$ as the criterion for removal, to obtain a parsimonious final mixed model. Mean scores of participants' intention to test are displayed in Table 3 and are also shown graphically in figure 2 .

\footnotetext{
${ }^{5}$ This method of analysis is valid under so-called MAR missingness, whereas both ANOVA and ANCOVA require the more restrictive MCAR assumptions (Verbeke \& Molenberghs, 2000; Schafer \& Graham, 2002)
} 
Table 3. Participants' mean intention score on pretest (time $=0$ ) and on immediate posttest (time $=1)$, per intervention condition $(0=$ experimental, $1=$ control $)$

\begin{tabular}{lll}
\hline Intervention condition & Pretest (N) & Immediate posttest (N) \\
\hline Experimental & $3.98(870)$ & $5.27(638)$ \\
Control & $3.92(834)$ & $4.41(787)$ \\
Total & $3.95(1704)$ & $4.79(1425)$ \\
\hline
\end{tabular}

Figure 2. Graphical display of participants' mean intention score (Y-axis) on pretest $($ Time $=0)$ and on immediate posttest $($ Time $=1)$, per intervention condition $(0=$ experimental, $1=$ control)

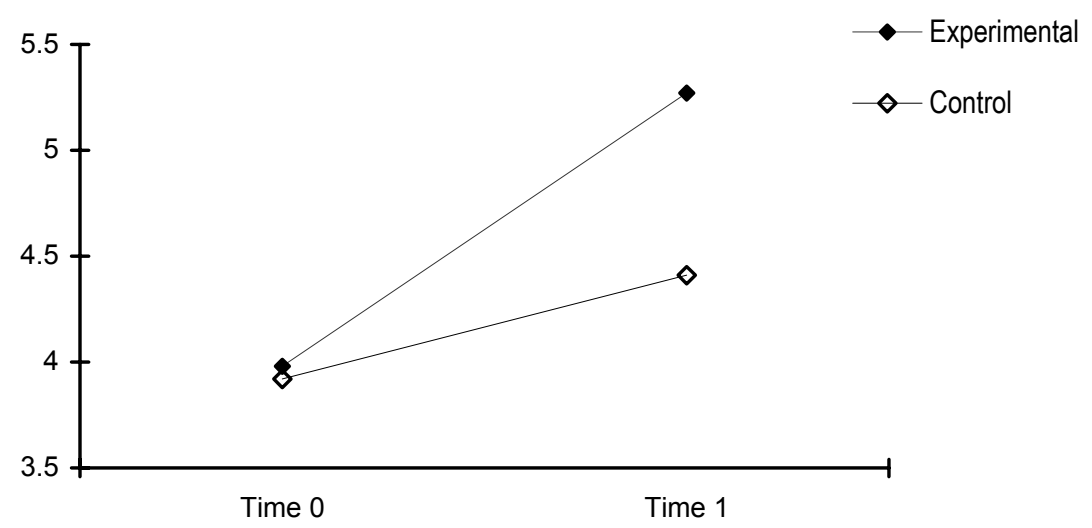

Table 4 summarizes the final mixed regression model for participants' intention to test. Given the randomized assignment to intervention condition $(0=$ experimental, $1=$ control) and the coding of time $(0=$ pretest; $1=$ immediate posttest), the main effect of intervention condition represents the difference in participants' intention at pretest, which is expected to be absent as a result of randomization. Likewise, given the coding of intervention condition $(0=$ experimental; $1=$ control) in our mixed model analysis, the main effect of time represents the change of intention in the experimental group from pretest to immediate posttest, and the time by treatment interaction represents the difference between both groups at immediate posttest. This interaction effect is highly significant and substantial, that is: .78 points on the 7-point scale for intention ( $1=$ very low intention; $7=$ very high intention) in favor of the experimental group. Additionally, participants' intention at immediate posttest is lower for older participants, and higher for homosexual men compared with bisexual men. 
Table 4. Final mixed linear regression model of participants' intention to test $(\mathrm{N}=1704)$

\begin{tabular}{lcccccc}
\hline \multirow{2}{*}{ Predictor } & & \multicolumn{2}{c}{9} & \multicolumn{2}{c}{$95 \%$ C.I. } \\
& Estimate & $\mathrm{SE}$ & $\mathrm{t}$ & Sign. & lower & Upper \\
\hline Intervention condition & -.05 & .10 & -.44 & .661 & -.25 & .16 \\
Time & 1.27 & .07 & 17.95 & .000 & 1.13 & 1.41 \\
Intervention condition x Time & -.78 & .10 & -8.06 & .000 & -.97 & -.59 \\
Age & -.02 & .00 & -4.1 & .000 & -.02 & -.01 \\
Sexual orientation & .35 & .13 & 2.63 & .008 & .09 & .61 \\
Intercept & 4.26 & .20 & 21.73 & .000 & 3.88 & 4.65 \\
\hline
\end{tabular}

Note: $\mathrm{SE}=$ Standard Error

\section{Effects of the intervention on testing behavior at follow-up}

Motivating participants to take an HIV-test was one aspect of the evaluation of the effects of our program. As was shown in the previous section, participants' intention to take an HIV-test differed significantly between both intervention conditions after exposure to the intervention material, in favor of the experimental condition. Whether or not participants actually got tested after completing their intervention, in a time frame of three months, was another important indicator of the effectiveness of our program. Theory predicts that high intentions towards taking a test increase the chances of actually taking a test. As such, we hypothesized that compared to the control condition, significantly more participants in the experimental condition would have taken a Sexual Health Checkup at the moment of follow-up. In view of the substantial dropout between randomization and follow-up, a mixed logistic regression of testing behavior, analogously to the mixed linear regression of participants' intention to test, is the optimal method of analysis (Van Breukelen, 2006). However, behavior was measured with respect to the last three months at follow-up versus the last nine months at pretest, making pretest and follow-up less comparable. Therefore, we ran two effect analyses in order to check agreement between both with respect to the resulting effect of intervention condition on testing behavior:

1. A logistic regression with testing behavior (taking a Sexual Health Checkup) at follow-up as outcome, and intervention condition ( $0=$ experimental, $1=$ control), intention and HIV-testing behavior at pretest, and background variables as predictors ( $\mathrm{N}=529$ complete cases). As background variables we included all variables that predicted dropout after randomization (see Table 2). In view of the severe dropout from pretest $(\mathrm{N}=1704)$ to follow-up $(\mathrm{N}=529)$, we 
also checked whether any of the background variables were correlated with intervention condition ( $0=$ experimental; $1=$ control) in the final sample of 529 complete cases. From this analysis, it appeared that men living in the "Randstad" ( $0=$ other; $1=$ Randstad) had a significantly lower chance to be represented in the control condition, compared to men not living in the "Randstad" $(B=-.622 ; \operatorname{Exp}(B)=.537 ; p=.003$, also see Table 1$)$. This variable was therefore included as covariate in the effect analyses. All background variables that were predictive of dropout after random assignment to intervention condition, and background variables that were predictive of intervention condition in the final sample of 529 cases were kept in the final logistic regression model. Other, non-significant background variables were removed, using $\mathrm{p}>.01$ as the criterion for removal, to obtain a parsimonious final logistic regression model.

2. A mixed logistic regression using MLwiN, with testing behavior as outcome, and time ( $0=$ pretest, $1=$ follow-up), intervention condition $(0=$ experimental, $1=$ control), time by intervention condition and background variables as predictors ( $\mathrm{N}=1704$ participants, using all available data).

Table 5 shows the results for the first method of analysis. The results of the second method were similar to the results of the first, and are therefore not reported here.

Table 5. Logistic regression of taking a Sexual Health Checkup (HIV- and/or STI-test) at three months follow-up, with predictors: intervention condition ( $0=$ experimental; $1=$ control), HIV-testing and intention to test at pretest, and background variables related to dropout $(\mathrm{N}=529)$

\begin{tabular}{lcccccc}
\hline & & & & \multicolumn{3}{c}{$95 \%$ Cl for Exp(B) } \\
Predictor & B & SE & Sign & Exp(B) & Lower & Upper \\
\hline Intervention condition & 0.341 & .236 & .150 & 1.407 & .885 & 2.23 \\
Age & -0.002 & .011 & .828 & .998 & .977 & 1.02 \\
Sexual orientation & 0.104 & .485 & .830 & 1.110 & .430 & 2.87 \\
Randstad & 0.113 & .233 & .626 & 1.120 & .710 & 1.77 \\
HIV-testing & 0.629 & .181 & .001 & 1.876 & 1.32 & 2.67 \\
Intention (pretest) & 0.260 & .071 & .000 & 1.297 & 1.13 & 1.50 \\
Constant & -3.45 & .696 & .000 & .032 & & \\
\hline
\end{tabular}

Note: $\mathrm{SE}=$ Standard Error

Results from the logistic regression analysis to test for a difference in behavioral outcome between the experimental condition and the control condition show 
that there is no significant difference between both intervention conditions. As such, our program did not have the hypothesized effect on behavior at three months follow-up. This can also be seen in the behavioral outcome data that are presented in Table 6. The analysis presented in Table 5, does show that participants with a more positive intention towards taking an HIV-test, measured before exposure to any intervention material, have a significantly higher chance to have taken a Sexual Health Checkup at three months followup. Also, participants who indicated that they had ever taken an HIV-test (recently) have a significantly higher chance to have taken a Sexual Health Checkup at three months follow-up. Table 6 shows the distribution of testing behavior at three months follow-up per intervention condition, per level of HIV-testing behavior at pretest.

Table 6. Distribution of taking a Sexual Health Checkup (SHC) at 3 months follow-up, by intervention condition ( $0=$ experimental; $1=$ control), and by HIV-testing behavior at pretest

\begin{tabular}{lcclll}
\hline Intervention condition & \multicolumn{3}{l}{ HIV-test at pre-test } \\
& SHC at follow-up & \multicolumn{3}{c}{ Yes } & No \\
\hline Experimental & Yes & $47(20 \%)^{\mathrm{a}}$ & $30(38 \%)^{\mathrm{c}}$ & $17(11 \%)^{\mathrm{c}}$ \\
& No & $195(80 \%)^{\mathrm{a}}$ & $49(62 \%)^{\mathrm{c}}$ & $146(89 \%)^{\mathrm{c}}$ \\
Control & Yes & $67(23 \%)^{\mathrm{b}}$ & $40(46 \%)^{\mathrm{d}}$ & $27(14 \%)^{\mathrm{d}}$ \\
& & No & $220(77 \%)^{\mathrm{b}}$ & $47(54 \%)^{\mathrm{d}}$ & $173(86 \%)^{\mathrm{d}}$ \\
& Total & & 529 & & \\
\hline
\end{tabular}

Note: $\mathrm{a}=$ percentage of the total amount of participants in the experimental condition $(\mathrm{N}=242)$ at three months follow-up

$\mathrm{b}=$ percentage of the total amount of participants in the control condition $(\mathrm{N}=287)$ at three months follow-up

$\mathrm{c}=$ percentage of the amount of men in the experimental condition who indicated that they had $(\mathrm{N}=79)$, or had not $(\mathrm{N}=163)$ been tested for HIV at pre-test

$\mathrm{d}$ = percentage of the amount of men in the control condition who indicated that they had $(\mathrm{N}=87)$, or had $\operatorname{not}(\mathrm{N}=200)$ been tested for HIV at pre-test 


\section{Effects of the intervention on determinants of taking a regular Sexual Health Checkup at follow-up}

A final aspect of the evaluation of the effects of Queermasters concerns its effects on participants' attitude, social norm, self-efficacy and intention to take a Sexual Health Checkup on a regular basis (at least once every year). Table 7 summarizes participants' mean score on all four outcome variables of interest here.

Table 7. Participants' mean score on attitude, social norm, self-efficacy and intention to take a regular Sexual Health Checkup, per intervention condition $\left(\mathrm{N}_{\max }=527\right)$

\begin{tabular}{lllll}
\hline Intervention condition & \multicolumn{3}{c}{ Outcome variable } \\
& Attitude & Self-efficacy & Social norm & Intention \\
\hline Experimental & 5.37 & 5.13 & 4.83 & 4.68 \\
Control & 5.12 & 5.12 & 4.85 & 4.37 \\
Total & 5.23 & 5.12 & 4.84 & 4.51 \\
\hline
\end{tabular}

Note: Lower N (527) than expected (529) for attitude, self-efficacy and intention because HIVpositive men at follow-up received a different set of questions. Lower N (460) than expected for social norm due to missing data

Evaluation of the effects of Queermasters on participants' attitude, perceived social norm, self-efficacy and intention to take a Sexual Health Checkup on a regular basis (at least once every year) was also hampered by the substantial dropout between randomization $(\mathrm{N}=1704)$ and follow-up $(\mathrm{N}=529)$ and by the difference between follow-up and pretest with respect to the time scale for taking a checkup (i.e. the next year at follow-up versus the next three months at pretest). In view thereof, we ran two effect analyses to check agreement between both with respect to the outcome variables of interest:

1. Linear regression, with attitude, social norm, self-efficacy or intention to take a Sexual Health Checkup on a regular basis (at least once per year) as outcome, and intervention condition $(0=$ experimental, $1=$ control $)$, attitude, social norm, self-efficacy or intention at pretest, and background variables as predictors $(\mathrm{N}=529)$. As background variables we included all variables that predicted dropout after randomization (see Table 2). In each regression analysis, non-significant predictors were removed to obtain a parsimonious model. Collinearity between predictors was checked by computing the VIF (Field, 2005). No VIFs $>3$ were found, ruling out collinearity between predictors. 
2. A repeated measures with mixed linear regression $(\mathrm{N}=1704$, using all available data), to check agreement with the results obtained in the above described complete cases analysis. For the mixed regression analyses, attitude, social norm, self-efficacy and intention to take an HIV-test at pretest and at follow-up were both treated as repeated measures, following the same model as for intention at immediate posttest in Table 4.

Table 8 shows the results for the first method of analysis. The results obtained with the mixed linear regression procedure were similar to these results and are therefore not reported here.

Table 8. Final linear regression models of attitude, social norm, self-efficacy and intention to take a regular Sexual Health Checkup at three months follow-up, with as predictors: intervention condition ( $0=$ experimental; $1=$ control), attitude, social norm, self-efficacy or intention at pretest, and background variables related to dropout $\left(\mathrm{N}^{\max }=527\right)$

\begin{tabular}{|c|c|c|c|c|c|c|c|c|}
\hline \multirow[b]{2}{*}{ Predictors } & \multicolumn{2}{|c|}{ Attitude } & \multicolumn{2}{|c|}{ Social norm } & \multicolumn{2}{|c|}{ Self-efficacy } & \multicolumn{2}{|c|}{ Intention } \\
\hline & $\beta$ & Sign & $\beta$ & Sign & $\beta$ & Sign & $\beta$ & Sign \\
\hline Intervention condition & -.082 & .019 & .022 & .616 & -.039 & .299 & -.061 & .072 \\
\hline Sexual orientation & .010 & .783 & -.026 & .565 & .072 & .056 & .002 & .957 \\
\hline Age & .065 & .062 & .084 & .055 & .044 & .240 & .099 & .004 \\
\hline Randstad & -.047 & .191 & .044 & .302 & -.010 & .796 & .016 & .645 \\
\hline \multicolumn{9}{|l|}{ Cultural background } \\
\hline Educational level & -.092 & .010 & & & & & & \\
\hline Steady partner status & & & -.156 & .001 & & & -.111 & .001 \\
\hline STI-testing & .129 & .001 & .129 & .006 & & & & \\
\hline HIV-testing & & & & & .322 & .000 & .150 & .001 \\
\hline \multicolumn{9}{|l|}{ Sexual risk behavior } \\
\hline \multicolumn{9}{|l|}{ Living area } \\
\hline Attitude (pretest) & .556 & .000 & & & & & & \\
\hline Social norm (pretest) & & & .534 & .000 & & & & \\
\hline Self-efficacy (pretest) & & & & & .330 & .000 & & \\
\hline Intention (pretest) & & & & & & & .520 & .000 \\
\hline
\end{tabular}


The results presented in Table 8, show that at a p-level of .01, none of the four determinants differ significantly between both intervention conditions. However, with respect to participants' attitude and intention to take a regular Sexual Health Checkup, the results presented in Table 8 do suggest a trend towards a significant difference between both intervention conditions in favor of Queermasters $(0=$ experimental, $1=$ control). Also, participants' attitude to take a regular Sexual Health Checkup is significantly higher among lower educated participants, among participants who had taken an STI-test in the nine months before they participated in Queermasters, and among participants who reported a more positive attitude towards taking an HIV-test at pretest. From the results presented in Table 8, it can also be seen that participants' perception of the social norm towards taking a regular Sexual Health Checkup is significantly higher among participants who reported not being involved in a steady relationship, among participants who had taken an STI-test in the nine months before they participated in Queermasters, and among participants who reported a higher perceived social norm towards taking an HIV-test at pretest. Participants' self-efficacy towards taking a regular Sexual Health Checkup is significantly higher among participants who reported having taken a (recent) HIV-test in the past, and among participants who had a higher self-efficacy towards taking an HIV-test at pretest. Finally, the results presented in Table 8 also show that participants' intention towards taking a regular sexual Health Checkup is significantly higher among older participants, among participants who reported not being involved in a steady relationship, among participants who had taken an STI-test in the nine months before they participated in Queermasters, and among participants who reported a more positive intention to take an HIV-test at pretest.

\section{Process evaluation of our intervention}

As stated in the introduction section of this paper, adequate adoption and implementation of our intervention was anticipated on during program development, and was ensured by the fact that it was a preprogrammed piece of software which was delivered directly to its intended users through the Internet.

The set of indicators that was used for another aspect of the processevaluation of our intervention was related to participants' opinions about Queermasters. First of all, participants who finished their intervention, either the experimental or the control condition, were given the opportunity to rate the intervention that they were exposed to on a scale from 0 to 10 . The newly developed intervention received an average score of $7.9(\mathrm{~N}=598)$. The intervention that served as a control conditions received an average score of 7.6 
$(\mathrm{N}=734)$. Analysis of the difference between both numbers by means of an independent sample T-test indicated no significant difference $(t=.975, \mathrm{p}=.330)$ between the average rating of both interventions. Secondly, all participants who finished the follow-up session of Queermasters also provided us with data that reflect their general appreciation of Queermasters. Mean scores of participants in both intervention conditions on this set of 5-point scales were tested for statistical differences with ANOVA. The results of these analyses are summarized in Table 9.

Table 9. Participants' means score and Standard Error (SE) on four indicators reflecting their opinion about Queermasters $(\mathrm{N}=527)$

\begin{tabular}{llll}
\hline \multirow{2}{*}{ Indicator } & \multicolumn{3}{l}{ Intervention condition } \\
\hline Participating in Queermasters was a lot of fun & Experimental & Control & \multirow{2}{*}{ Sign } \\
The content of the show was very useful & $4.03(.87)$ & $3.91(1.00)$ & .14 \\
The show gave me a better view on HIV-/ STI-testing & $3.50(1.1)$ & $3.37(1.12)$ & .19 \\
I would advise everyone to participate in the show & $4.01(1.0)$ & $3.77(1.12)$ & .01 \\
\hline
\end{tabular}

Note: items were measured on a 5 -point scale: $1=$ totally disagree; $5=$ totally agree

The results presented in Table 9 show that both interventions are evaluated positively by their respective participants since all scores are above the scale mean (note that the indicators in Table 9 are 5-point scales). No statistically significant differences were found between both intervention conditions on any of the four indicators that reflect participants' opinion about Queermasters and the respective intervention that they were exposed to. A marginally significant difference between participants in both intervention conditions was however found with respect to the level at which they agreed upon advising others to participate in the intervention to which they had been exposed themselves ( $0=$ experimental; $1=$ control): participants in the experimental condition, who had been exposed to the newly developed intervention materials, were more positive on this matter compared to participants in the control condition.

\section{DISCUSSION AND CONCLUSION}

The evaluation of a newly developed Internet HIV-prevention intervention named Queermasters is described in this chapter. The intervention was systematically developed within the Intervention Mapping framework and aims at promoting HIV-testing among MSM in the Netherlands. Based on a set 
of relevant outcome variables such as Dutch MSMs' intention to get tested, actual testing behavior and their subjective evaluation of the intervention, both the effect-evaluation and the process-evaluation of Queermasters have been carried out. The results of both types of evaluation have been reported in this paper.

With respect to the evaluation of the effects of Queermasters, the results are mixed and partly confirm our hypotheses and expectations about its effectiveness. In terms of motivating - i.e., intention - participants to take a Sexual Health Checkup, which includes taking an HIV-test, our results show that the newly developed intervention is significantly more effective in doing so, compared to the intervention that served as a control, at least at immediate posttest. Given the critical differences between both interventions, this allows us to conclude that using risk communication as a method to motivate Dutch MSM to take an HIV-test may be less effective in actually motivating men to do so, compared to the set of motivational strategies applied in Queermasters.

At three months follow-up, the observed difference in motivation at posttest between participants in both intervention conditions is not reflected in the behavioral outcome measure. According to theory, one would expect a difference in the behavioral outcome measure between both intervention groups at three months follow-up, in line with the significant difference in intention at immediate posttest. One explanation for the fact that no difference in behavior between both intervention groups was found at three months follow-up, may be related to the relatively short timeframe of three months between intervention and follow-up. Possibly, this timeframe is too short for participants to actually act upon their intention to get tested after exposure to the intervention material. Another explanation may be that external factors that were not influenced by the intervention, prevented participants from translating their intention into actual behavior. A final explanation may be that certain relevant internal determinants may not be included, or fully covered in our intervention.

With respect to participants' attitude, perceived social norm, self-efficacy and intention towards taking a Sexual Health Checkup on a regular basis, the obtained results are also mixed. No difference between the experimental and the control condition was observed with respect to self-efficacy and perceived social norm. The latter is unexpected, since Queermasters included strategies to achieve a change in participant's perception of the social norm towards taking a (regular) Sexual Health Checkup. Possibly, the Internet does not serve as a strong enough context to influence social norms. Another explanation may be that the strategies that we included in Queermasters were unsuited to establish a long term effect on participants' perception of the social norm regarding 
taking a regular Sexual Health Checkup. On the other hand, our results do provide evidence of a marginally significant difference between both intervention conditions with respect to participants' attitude towards taking a Sexual Health Checkup on a regular basis. In addition, our results also show that participants' intention towards taking a regular Sexual Health Checkup differs substantially between both intervention groups, at least at immediate posttest. In both cases, the strategies that we included in Queermasters appear to have resulted in a positive long term effect on both attitude and intention towards taking a regular Sexual Health Checkup. Whether this actually contributes to taking a regular sexual Health Checkup remains unanswered within the scope of the present study, and should be subject of future research.

Some limitations should be taken into account when generalizing the results presented in this paper. First of all, sampling bias may have affected the results obtained in our study. Although we did great effort to include a representative sample of Dutch MSM in our study, the latter cannot be completely ruled out. Secondly, the level of participant drop-out in our study was relatively high. Although Internet studies generally suffer from relatively high levels of participant drop-out over time (Bull, Lloyd, Rietmeijer \& McFarlane, 2004), we attempted to minimize this through good design, advanced tailored communication throughout Queermasters (regardless of intervention condition) and personalized e-mail invitations and incentives to encourage participants to take part in the three months follow-up session. The relatively high level of participant drop-out does not only indicate that we were not completely successful in our efforts to minimize it, but it also has consequences for the interpretation and generalizability of our findings. With respect to the latter, the analyses on drop-out before randomization show that our results may not be easily generalized to bisexual men. In both analyses, they have a significantly higher chance of drop-out compared to homosexual men. It should be noted that bisexual men are generally a hard to reach group for research and prevention activities. With respect to age, another significant predictor of participant drop-out before randomization, results from the dropout analyses indicate that our results may not be easily generalized to both older MSM, since they initially drop out significantly more, and to younger MSM, since they drop out significantly more further on in the intervention. Possibly, additional strategies are needed to ensure that both older and younger MSM are preserved in future versions of Queermasters. A further reason for concern is the higher dropout between randomization and posttest in the experimental group (see Table 2). The method of analysis used, i.e. mixed regression, is valid under so-called MAR dropout and thereby much less prone to selection bias than classical ANOVA which listwise deletes any person with a 
missing pretest or posttest (Verbeke \& Molenberghs, 2000). However, so-called MNAR missingness cannot be ruled out and may have biased our results. Unfortunately, MNAR missingness is not easily detected since it depends on unobserved variables by definition.

A final limitation of the present study that should be taken into account, is the imperfect match of pretest measurement of behavior and follow-up measurement of behavior. Whereas at pretest, HIV-testing behavior in the past six months was measured, the behavioral outcome measure at follow-up concerned a timeframe of three months. A similar concern holds for the TPB measures which referred to the next three months at pretest, but to the next year at follow-up.

One of the implications of our findings for future research in the area of HIV-prevention, more particularly the promotion of HIV-testing, among MSM in the Netherlands relates to the apparent gap between intention on the one hand, and actual behavior on the other hand. Future research should clarify which (set of) strategies, can be applied in future interventions to effectively bridge the gap between intention and behavior. One can think of cognitive strategies such as the formation of an implementation intention (Gollwitzer \& Brandstaetter, 1997; Sheeran, Webb, Gollwitzer, 2005) or goal setting in a broader sense, but also of more practical strategies such as offering the possibility to make an online appointment for a test immediately after exposure to the intervention material on the Internet. Such strategies could be added to Queermasters and might consequently lead to the intervention being effective not only in motivating MSM to get tested but also in actually getting them tested. Future research is needed to clarify the latter.

Finally, despite the somewhat mixed results in the evaluation of the effects of our intervention, this does not imply that future development of HIVprevention interventions should no longer be systematically planned and based on available theory and evidence. On the contrary, both early (Kalichman, Carey, \& Johnson, 1996; Mullen, Green \& Persinger, 1985) and more recent (Van Empelen, Kok, Van Kesteren, Van den Borne, Bos \& Schaalma, 2003) reviews on the effectiveness of health promotion programs have consistently shown that systematically developed intervention have the highest chance of being effective in achieving their goals. As such, the results obtained in our study illustrate that the systematic development of an HIV-prevention intervention does not guarantee that it will be effective in achieving all its goals and objectives. Finding out that an intervention does not completely result in the expected effects, on the basis of good experimental research, should thuS motivate both researchers and health promotion planners to further adapt the content of the intervention in an informed and theory- and evidence-based way. 



\section{CHAPTER EIGHT}

General discussion 


\section{INTRODUCTION}

The aim of the research presented in this thesis was to describe the application of Intervention Mapping (Bartholomew, Parcel, Kok \& Gottlieb, 2006) to the development of an online HIV-prevention intervention to promote HIV-testing among Men who have Sex with Men (MSM) in the Netherlands. This final chapter provides a summary of the main findings in the previous chapters and discusses the implications thereof for future health promotion activities in the area of HIV and HIV-testing in particular, for health promotion professionals in the area of HIV and HIV-testing, and for future research in the area of HIVprevention.

The project that is described in this thesis was initiated because of the need for effective health promotion programs that aim to motivate Dutch MSM to take an HIV-test. This particular need emerged after a shift in the Netherlands' HIV-testing policy from discouraging HIV-testing towards actively promoting it. Development of such health promotion programs should ideally be systematically planned and based on theory and evidence, since this maximizes the chances that the program will be effective (Kok, Schaalma, Ruiter, van Empelen \& Brug, 2004). Therefore, development of our health promotion program was guided by the Intervention Mapping protocol, which is a tool for systematic program planning (Bartholomew et al., 2006).

\section{SOCIAL-COGNITIVE DETERMINANTS OF HIV-TESTING}

\section{A qualitative study}

At the start of the project relatively little was known about the psychosocial aspects of HIV-testing among MSM in the Netherlands. Although epidemiological data had been collected since the onset of the HIV-epidemic in the Netherlands, which was of great value to get a clear picture of the epidemic and its dynamics, only one qualitative study (Facente, 2001) provided empirical evidence concerning the social-cognitive determinants related to HIV-testing among MSM in the Netherlands. Given that most voluntary human behaviors are (at least partly) driven by cognitions, - within a broader environmental and genetic context - a more profound understanding of the social-cognitive determinants of HIV-testing among MSM in the Netherlands was needed. The main reason being that these determinants can be influenced and consequently changed by means of effective interventions. Therefore, we first set up a smallscale qualitative study (Mikolajczak, van Kesteren, Hospers \& Kok, 2004), in which we aimed to answer the following research question: "Why do Dutch MSM not take an HIV-test". By conducting individual in-depth interviews with 
32 untested MSM, we were able to identify a number of social-cognitive determinants that could be related to not taking an HIV-test. First of all, it appeared that a majority of the respondents lacked sufficient knowledge about issues related to taking an HIV-test, for example about testing procedures or about the costs that are involved in taking a test. In addition, the men appeared to know little about the advantages of treatment with HAART. Secondly, the results also showed that HIV-testing was hardly ever talked about with (good) friends or relevant others, and taking an HIV-test was not openly encouraged in participants' social environment. Thirdly, most participants indicated that they feared detrimental consequences for their lives and future if they would find out being HIV-positive. Fourthly, most participants also considered the risk they ran for HIV-infection to be low, despite the fact that a majority concurrently reported past sexual risk behavior, i.e. unprotected anal intercourse with casual partners. Evidence from the interviews suggests that participants' low perceived risk for HIV-infection may be explained as the outcome of a defensive reaction in terms of cognitive dissonance reduction (Offir, Fisher, Williams \& Fisher, 1993), initiated by the level of fear they experienced after an episode of unprotected anal intercourse. This explanation was supported by the finding that at-risk respondents came up with various reasons which, according to them, justified the absence of any risk for HIVinfection in past episodes of sexual risk behavior. As a consequence, no perceived risk for HIV-infection rules out the need to take an HIV-test and cognitive dissonance is effectively counteracted. An implication of this explanation of participants' low perceived risk for HIV-infection is that focusing on risk perception and attempting to increase the perceived risk for $\mathrm{HIV}$-infection in an intervention that aims to motivate (at-risk) MSM to take an HIV-test, may not be effective in actually doing so. Increasing perceived risk for HIV-infection might lead to an increase in the level of fear that is experienced, which might consequently lead to a defensive reaction in which one attempts to reduce unpleasant feelings as quickly as possible - for example by denying the threat or avoiding information about past sexual risk behavior - in order to achieve a feeling a safety (Ruiter, Verplanken, De Cremer \& Kok, 2004). Finally, the results from the qualitative study also showed that participants were not aware of any health promotion campaign that focused on motivating them to take an HIV-test, and informed them about the advantages of treatment with HAART for example. As such, this again emphasized the need for effective health promotion programs that motivate MSM in the Netherlands to take an HIV-test, and also the need to put HIV-testing on the agenda of MSM, health promotion researchers and planners, and politicians responsible for or involved in ensuring health and welfare in the Netherlands. 


\section{A quantitative study}

Whereas the findings in the small-scale qualitative study provided us with an initial understanding of different social-cognitive determinants related to HIVtesting, quantitative confirmation of these findings in a larger and more representative sample of Dutch MSM was necessary before actual intervention development could be initiated. Therefore, we set up a large-scale Internet study (Mikolajczak, Hospers \& Kok, 2007), to seek confirmation of our qualitative findings on the one hand and to explore additional social-cognitive determinants of HIV-testing derived from the Theory of Planned Behavior (TPB; Ajzen, 1991) on the other hand. The results from this study confirmed our previous qualitative findings, and thus provided us with additional empirical evidence of social-cognitive determinants related to HIV-testing which could be tackled via methods for behavior change in the intervention that we were planning to develop. For example, the finding that a more positive attitude towards taking an HIV-test was related to a higher intention to actually do so, indicated that this particular determinant - among others - needed to be targeted and changed in our intervention (Mikolajczak et al., 2007). The same logic applies for the other set of social-cognitive determinants that we found to be related to the intention to take an HIV-test among at-risk Dutch MSM, namely: the perceived norm towards HIV-testing among good friends, how much HIV-testing was talked about with good friends (and others), knowledgerelated issues such as HIV-test locations, and perceived risk for HIV-infection. In addition, the analysis showed that both participants' age and sexual orientation - which are so called demographic features - remained related to the intention to take an HIV-test among at-risk MSM, after inclusion of cognitive predictors. This might be an indication that we were unable to grasp all aspects related to taking an HIV-test within the different social-cognitive determinants that we measured in our study. On the basis of theory (Ajzen, 1991; Bartholomew et al., 2006, Chapter 3), one would expect that more distal determinants, such as demographics, do not influence intention directly, but through more proximal determinants of intention (and behavior), such as attitude or self-efficacy.

\section{FROM UNDERSTANDING BEHAVIOR TO CHANGING BEHAVIOR}

The next step in developing an intervention that aimed to promote HIV-testing among MSM in the Netherlands was to link the different relevant determinants found in both our qualitative and quantitative studies to adequate theoretical methods for behavior change. Instead of theories of behavior, theories of behavior change now came into focus. The main difference between both types 
of theories is that the latter type of theories describes one or more mechanisms or processes through which behavior change can be accomplished. An example of a theory of behavior is the Theory of Planned Behavior (TPB: Ajzen, 1991), which has been applied to explain the intention to take an HIV-test among atrisk MSM in the Netherlands in the project that is described in this thesis. However, TPB does not describe specific processes through which behavior change can be accomplished. Conceptually, it follows from TPB that a more positive attitude, a more positive perception of social norms, and higher levels of self-efficacy, will contribute to a more positive behavioral intention, which consequently leads to a higher probability of actually executing a particular behavior. However, a different set of theories is needed to actually influence and change one's attitude, perceived social norm or self-efficacy. An example of a theory of behavior change is Bandura's (1986) Social Cognitive Theory, which describes modeling as the theoretical principle through which change at the level of skills and/or self-efficacy can be accomplished.

\section{EXPLORING EXTERNAL DETERMINANTS OF HIV-TESTING}

\section{A qualitative study}

Developing an intervention that aims to motivate Dutch MSM to take an HIVtest requires that not only social-cognitive factors related to the behavior at hand are addressed, but also requires health promotion program planners to pay attention to external factors that may have an impact on behavior. Whereas social-cognitive determinants of behavior rest within an individual and are therefore also referred to as personal factors, such external factors rest outside the individual. Examples of external factors are social influences such as actual social norms, the level of social support, or structural influences such as current policies or financial costs. In developing our intervention, we studied external factors related to HIV-testing among MSM in Sydney, Australia (Mikolajczak, Hospers \& Kok, 2005). In doing so, we wanted to learn from a country that has been very successful in establishing high HIV-testing rates among MSM since the onset of the HIV-epidemic at the beginning of the 1980's. Compared to the Netherlands, where at the moment an average of $63 \%$ of MSM has ever taken an HIV-test (Hospers, Dörfler, Zuilhof \& Nijman, 2007), HIV-testing rates among MSM in Australia of over $90 \%$ have been consistently reported during the past decades (NCHSR, 2005). The findings from the qualitative study in Australia convinced us that several external factors had to be taken into account in our intervention, if we wanted to be successful in motivating MSM in the Netherlands to take an HIV-test. First of all, general practitioners in the Netherlands needed to take up a more proactive role in the promotion of HIV- 
testing among MSM. Instead of advising MSM to take an HIV-test or not on the basis of the outcome an extensive assessment of their past sexual risk behavior, general practitioners should advise sexually active MSM to take an HIV-test at least once every year and use the assessment of past sexual risk behavior as a context in which the outcome of the HIV-test can be discussed. It should be noted that data from the Dutch Monitoring studies showed that in 2000, 50\% of HIV-tested MSM in the study had gone to their general practitioner for their most recent HIV-test (Hogeweg \& Hospers, 2000). Although this number decreased from 50\% in 2000 to 35\% in 2007 (Hospers et al., 2007), the general practitioner remained most frequently visited by MSM to take an HIV-test, compared to other HIV-testing locations such as an STI-clinic for example. In the context thereof, and keeping in mind that it was expected that many - if not most - MSM would continue to go to their general practitioner to get tested for HIV (again), the window of opportunity to promote HIV-testing among MSM, and the crucial role of general practitioners in realizing these opportunities were clear. Additional evidence on this matter was provided by Fernández, Bowen, Parrino, Royal, Mattson, Arheart and Cohn (2003), who demonstrated that in promoting HIV-testing among never-tested Hispanic men in the United States, a doctor's recommendation may suffice. Secondly, results from the qualitative study in Australia urged us to pay specific attention in our intervention to social norms regarding HIV- and STI-testing among MSM and the perception thereof. Among MSM in Sydney, we found that taking an HIVand/or an STI-test was simply considered as part of being a sexually active man. Moreover, taking an HIV- and/ or an STI-test appeared to be widely encouraged and supported by men in the MSM community. Furthermore, findings from the qualitative study in Australia inspired us to introduce a new term in the MSM community in the Netherlands via the intervention, namely Sexual Health Checkups. Conform the Dutch current policy on HIV- and STItesting, a Sexual Health Checkup comprises a test for the so called "Big Five": HIV, syphilis, gonorrhea, hepatitis B and chlamydia. In Australia, a similar strategy had been successfully developed and implemented, contributing to maintaining high HIV- and STI-testing rates among MSM. Particularly, these sexually transmitted infection testing guidelines for sexually active MSM along with a set of other planned activities contributed to getting more asymptomatic MSM tested (STIGMA, 2005). 


\section{THE EFFECTS OF HIV-TESTING AND COUNSELING ON RISK BEHAVIOR}

\section{A systematic review of available evidence}

For a long time, it was unclear what the effects were of taking an HIV-test and finding out one's serostatus on subsequent sexual behavior. If research would show that finding out one's serostatus subsequently leads to an increase in sexual risk behavior, widespread promotion of HIV-testing among MSM would not be an effective form of health promotion. However, if research would show that HIV-testing leads to no changes in sexual risk behavior or a decrease therein, developing an intervention that promotes HIV-testing among MSM would be justified. Moreover, in case of a reduction of sexual risk behavior after taking an HIV-test, HIV-testing would not only serve its secondary prevention purpose, which is early detection of HIV-infection, but also serve primary prevention purposes in terms of reducing the chances that one would become infected with HIV in the future.

Early reviews of studies that looked into the effect of HIV-testing and counseling - referred to as voluntary testing and counseling (VCT) in the literature and in the remainder of this chapter - on subsequent sexual risk behavior were unable to draw any conclusions about the nature of the relationship between both (Higgins, Galavotti, O'Reilly, Schnel, Moore, Rugg \& Johnson, 1991; Wolitski, MacGowan, Higgins \& Jorgensen, 1997).

A more recent meta-analytic review on this topic, conducted by Weinhardt, Carey, Johnson and Bickham (1999), provided evidence that supported the idea that VCT leads to a decrease in subsequent sexual risk behavior. Particularly among HIV-positive MSM, the studies included in the meta-analysis showed that sexual risk behavior decreased significantly after finding out being HIV-positive. With respect to MSM who found out that they were HIV-negative, no increase in subsequent sexual risk behavior was found. In sum, their findings lead Weinhardt et al. (1999) to conclude that VCT is an effective means of secondary prevention for HIV-positive MSM but is not an effective primary prevention strategy for uninfected MSM. Keep in mind that the fact that no increase in sexual risk behavior among uninfected MSM was found, is an important finding in this meta-analytic review since it adds to the support for active promotion of HIV-testing and counseling among MSM.

It should be noted that the meta-analytic review conducted by Weinhardt et al. (1999) comprised studies carried out before Highly Active Antiretroviral Therapy (HAART) became available. Therefore, we reviewed relevant studies published after 1996, when HAART became available, to seek whether the findings of Weinhardt et al. (1999) remained valid (Mikolajczak, Hospers \& Kok, 2006). This was important, given that we were planning to develop an intervention that aims to promote HIV-testing among MSM in the Netherlands. 
Our review showed that the conclusions that were drawn by Weinhardt et al. (1999) are still valid in the so-called HAART era. It should be noted however, that our review - like all other previously conducted reviews or meta-analytic reviews - of studies on the relationship between VCT and subsequent sexual risk behavior suffered from some methodological limitations. First of all, a majority of the studies included in the review was not set up specifically to investigate the relationship between VCT and subsequent sexual risk behavior. In most cases, these studies comprised an evaluation of a newly developed protocol or intervention for promoting VCT (Mikolajczak et al., 2006), and the available data collected for these purposes also allowed researchers to also investigate the relationship between VCT and subsequent sexual risk behavior. It should be noted that it can be considered unethical to set up an experimental study that would allow researchers to find out the exact nature of the relationship between VCT and subsequent sexual risk behavior, since it would include one or more conditions in which people are tested for HIV - and possibly test HIV-positive - but receive no test result and counseling feedback. Secondly, comparison between the different studies included in the review was hampered by the fact that different outcome measures of sexual risk behavior were used in different studies, different populations were investigated in different studies, different timeframes were applied in different studies, and the type of counseling that was provided after receiving the result of an HIV-test varied across studies and was often not well described.

Notwithstanding the limitations cited above, we believe that there is compelling empirical evidence in both our own review (Mikolajczak, Hospers \& Kok, 2006), in the meta-analytic review conducted by Weinhardt et al. (1999), as well as in a recent meta-analysis of sexual risk behavior among HIV-positive MSM (Marks, Crepaz, Senterfitt \& Janssen, 2005), that shows that among HIVpositive MSM, HIV-testing is an adequate form of prevention. It leads to early detection of HIV-infection and consequently access to treatment with HAART where available, and a significant reduction in sexual risk behavior. In addition, it does not lead to an increase in sexual risk behavior among MSM who find out that they are HIV-negative.

\section{APPLYING INTERVENTION MAPPING}

Developing an Internet intervention to promote HIV-testing among MSM in the Netherlands Based on our qualitative and quantitative findings concerning the personal, social-cognitive determinants related to HIV-testing among Dutch MSM, supplemented with the findings of our qualitative study into external factors related to HIV-testing in Sydney, and supported by the findings in our review 
concerning the effectiveness of HIV-testing as a means of secondary prevention among HIV-positive MSM, we initiated the actual development of the intervention. In doing so, we applied the Intervention Mapping protocol (Bartholomew et al., 2006) to ensure theory- and evidence-based intervention development. As a consequence thereof, the chances of the intervention actually being successful in achieving its goals and objectives are maximized. Keep in mind however that Intervention Mapping does not provide researchers and health promotion planners any guarantee on the actual effectiveness of any intervention in beforehand.

Besides the systematic development of interventions and the thorough application of both theory and evidence therein, it is important that the process of intervention development is described in detail and published (Abraham \& Michie, 2008; Michie \& Abraham, 2004; Mikolajczak, van Breukelen, Kok \& Hospers, 2008). This does not only require researchers to spend time and effort in doing so, but also requires journal editors to accept this specific type of publication in their journals for a number of reasons. First of all, to allow other researchers to conduct adequate meta-analyses of health promotion interventions, detailed descriptions of interventions - particularly the methods for behavior change on which interventions were based - are indispensible. Secondly, such descriptions allow other researchers to rebuild an intervention and allow them to replicate the findings obtained in an experimental study on the effectiveness of an intervention. As such, this allows researchers to conduct one of the principal driving processes in science, namely replicating empirical findings. It should be noted that recently, more researchers acknowledge and emphasize the importance of publishing intervention development in detail and getting this type of knowledge into the journals. The latter is reflected in an increase in this type of publication, including our paper in which the development of the intervention is systematically described (Mikolajczak, Kok \& Hospers, 2008).

\section{A systematic evaluation the effects of Queermasters}

A thorough evaluation of the effectiveness of an intervention comprises the final step in the process of systematic intervention development. Within the Intervention Mapping protocol, the evaluation of (newly developed) interventions is already anticipated on from the beginning of the process. A randomized controlled trial (RCT) was set up to allow proper quantitative evaluation of the effects of our intervention, which was called Queermasters (Mikolajczak et al., 2008). In the RCT, Queermasters was compared with an existing online intervention to promote HIV- and/or an STI-testing among MSM in the Netherlands. The latter intervention applied risk communication as a 
method to motivate Dutch MSM to take an HIV- and/or an STI-test. After providing us with demographic information and finishing a pretest measurement of TPB variables, participants in the RCT were randomly assigned to one of both interventions. This allowed us to find out whether exposure to Queermasters would lead to a significantly higher increase in the intention to take an HIV/STI-test (referred to as a Sexual Health Checkup in Queermasters) and consequently more actual testing behavior, compared to exposure to the control condition. Our data showed that Queermasters was significantly more effective in motivating Dutch MSM to take an HIV-test. The latter was reflected in a higher increase in their intention to take a Sexual Health Checkup, which includes taking an HIV-test, after exposure to the intervention. This finding allowed us to conclude that applying risk communication as a method to motivate MSM to take an HIV/STI-test, is less effective in motivating them to do so compared to the different methods for behavior change that were applied in Queermasters. Moreover, this finding provides us with additional experimental evidence in support of our hypotheses on the relationship between risk perception and behavior change in the context of HIV/STI-testing. Further research should be conducted to help clarify the exact nature of the relationship between perceived risk for HIV and HIV-testing behavior, and to seek out if, and consequently under which conditions, applying risk communication to motivate MSM to take an HIV/STI-test may be feasible.

In terms of achieving actual behavior change, we were unable to demonstrate a difference between both interventions. This is particularly surprising and somewhat disappointing since theory predicts that high intentions lead to an increased probability of actually executing the behavior. As such, we expected that the observed difference in intention between participants in both interventions would consequently be reflected in subsequent HIV/STI-testing behavior. The absence of a difference between both interventions in terms of HIV/STI-testing behavior implies modifications to Queermasters before actually implementing it on a large-scale. Such modifications can be achieved by including an additional set of strategies that help bridge the gap between intention and behavior. Various researchers have demonstrated that having individuals generate implementation intentions contributes to acting on their good intentions (Gollwitzer \& Brandstaetter, 1997; Sheeran, Webb \& Gollwitzer, 2005). On the other hand, a more practical adaptation or expansion of Queermasters would be to develop a module that allows motivated MSM to make an online appointment at their preferred testing location, immediately after exposure to the intervention. Possibly, sending out one or more reminders to make an appointment to get tested via email or SMS could be introduced as an additional strategy that may add to the 
effectiveness of Queermasters in terms of behavior as well. An additional positive effect of applying one or more of these strategies, may be the retention of more respondents in future online intervention studies over time. Contrary to some other researchers who also set up an online RCT to evaluate the effects of their intervention, we were able to retain more respondents over time. In some cases, these researchers ended up being unable to conduct statistical analyses on their data due to an extreme attrition rates (e.g., Bull, Lloyd, Rietmeijer \& McFarland, 2004). Nonetheless, the level of attrition in our intervention study was also relatively high. Of the 1704 participants who were initially randomized to either the experimental of the control condition in our evaluation study, only 529 completed the three month follow-up session. Keep in mind that this three month follow-up period (instead of six months) was chosen deliberately to overcome high levels of attrition in our evaluation study. It should be noted that the attrition problem is only an issue of concern when an intervention is still embedded in a research design. The loss of (a significant amount of) respondents in research makes data analyses more complex, which may consequently pose certain limits to the conclusions that can be drawn on the basis of the available data and the generalizability thereof. However, once an intervention is no longer part of a research design, and is presented to its target population as a tool or a product in itself, attrition is no longer relevant. Ironically, detaching an intervention from its research surroundings may also contribute to loosing less respondents, or participants of the intervention, during the flow of the intervention since they are now no longer exposed to relatively extensive pre-test and follow-up measurements of relevant indicators. When an intervention is still subjected to research, the latter are needed to allow proper effect evaluation of an intervention. More insight is needed to see how such burdens and barriers can be overcome in future online evaluations of (health promoting) interventions.

Besides applying some of the above mentioned strategies to increase the effectiveness of Queermasters, changing specific environmental factors related to HIV-testing might also increase the probability of Dutch MSM actually taking an HIV-test. Earlier in this chapter, the critical role of general practitioners in promoting HIV-testing among MSM in the Netherlands was emphasized. As a matter of fact, this type of environmental change was actually part of our intervention in and around the city of Nijmegen. Here, we were able to come to an agreement with the general practitioners to always comply with a request from MSM to get tested, al least for as long as Queermasters was up and running. As such, we were able to create a so called enhanced experimental condition. In line with theory (Bartholomew et al., 2006) we hypothesized that effective motivation - through exposure to the newly developed intervention - 
in combination with a supportive, rewarding and motivating environment including the general practitioners' way of complying with a request to get tested - would create the optimal condition for realizing behavior change, i.e. to get Dutch MSM to take a Sexual Health Checkup (which includes an HIV-test). However, due to the loss of respondents during the flow of our intervention, too few MSM respondents from Nijmegen remained in the follow-up sample to allow statistical analyses. As a result, we were unable to investigate the hypothesized additional effect of this specific environmental intervention on the intention of this particular group of MSM to take an HIV-test and actual testing behavior. Future research should bring more clarity on this specific matter.

\section{FINAL REMARKS}

The systematic analysis of the effects of our newly developed intervention have shown that at this point in time and in its current form, Queermasters was effective in motivating MSM to take a sexual Health Checkup on the one hand, but needs further modification to ultimately lead to a theory- and evidencebased intervention that is fully effective on the other hand. Keep in mind that the Intervention Mapping process does not consider intervention development to be a linear process, but rather as an iterative process in which developers can move forward and backward. As such, adaptation of an intervention on the basis of the results of an evaluation of its effects is considered a natural and logical step in the process of its development.

In sum, the work that is described in this thesis provides insight in the social-cognitive and external determinants related to HIV-testing among MSM in the Netherlands. Both quantitative and qualitative research methods have been applied to gain insight therein. In addition, this thesis also describes the application of Intervention Mapping for the development of an intervention that aims to promote HIV-testing among MSM in the Netherlands. The knowledge that is provided in this thesis can be of value for future health promotion activities, specifically in the area of HIV-prevention among MSM in the Netherlands. 
REFERENCES 
Abraham, C., \& Michie, S. (2007). A taxonomy of behavior change techniques used in interventions. Health Psychology, in press.

Ajzen, I. (1991). The Theory of Planned Behavior. Organizational Behavior and Human Decision Processes, 50, 179-211.

Allen, S., Meinzen-Derr, J., Kautzman, M., Zulu, I., Trask, S., Fideli, U., Musonda, R., Kasolo, F., Gao, F., \& Haworth, A. (2003). Sexual behavior of HIV discordant couples after HIV counseling and testing. AIDS, 17, 733-740.

Apanovitch, A.M., McCarthy, \& Salovey, P. (2003). Using message framing to motivate HIV testing among low-income, ethnic minority women. Health Psychology, 22, 60-67.

Armitage, C. J., \& Conner, M. (2001). Efficacy of the theory of planned behaviour. A meta-analytic review. British Journal of Social Psychology, 40, 471499.

Australian Commonwealth. (1998). ANCARD \& IGCARD HIV Testing policy. Canberra.

Bandura, A. (1986). Social foundations of thought and action: A social-cognitive theory. Englewood Cliffs, NJ: Prentice Hall.

Bartholomew, L. K., Parcel, G. S., Kok, G., \& Gottlieb, N. H. (2001). Intervention Mapping: designing theory- and evidence-based health promotion programs. London Toronto: Mayfield Publishing Company.

Bartholomew, L. K., Parcel, G. S., Kok, G., \& Gottlieb, N. H. (2006). Planning health promotion programs: an Intervention Mapping approach. San Francisco, CA: Jossey-Bass.

Bentley, M.E., Spratt, K., Shepherd, M.E., Gangakhedkar, R.R., Thilikavathi, S., Bollinger, R.C., \& Mehendale, S.M. (1998). HIV testing and counseling among men attending sexually transmitted disease clinics in Pune, India: changes in condom use and sexual behavior over time. AIDS, 12, 1869-1877.

Bickmore, T., Gruber, A., \& Picard, R. (2005). Establishing the computer-patient working alliance in automated health behavior change interventions. Patient Education and Counseling, 59, 21-30.

Bochow, M., Chiarotti, F., Davies, P., Dubois-Arber, F., Dur, W., Fouchard, J., Gruet, F., McManus, T., Markert, S., \& Sandfort, T. (1994). Sexual behaviour of gay and bisexual men in eight European countries. AIDS Care, 6, 533-549.

Bos, A. E. R., Kok, G., \& Dijker, A. J. (2001). Public reactions to people with HIV/AIDS in the Netherlands. AIDS Education and Prevention, 13, 219-228. 
Brechtl, J.R., Breitbart, W., Galietta, M., Krivo, S., \& Rosenfeld, B. (2001). The use of Highly Active Antiretroviral Therapy (HAART) in patients with advanced HIV-infection: Impact on medical, palliative care, and quality of life outcomes. Journal of Pain and Symptom Management, 21, 41-51.

Brug, J., Schaalma, H., Kok, G., Meertens, R. M., \& Molen, H. T. van der (2000). Gezondheidsvoorlichting en gedragsverandering: Een planmatige aanpak. Assen: van Gorcum.

Bull, S., Lloyd, L., Rietmeijer, C., \& McFarland, M. (2004). Recruitment and retention of an online sample for an HIV prevention intervention targeting men who have sex with men: The Smart Sex Quest Project. AIDS Care, 16, 931943.

Campsmith, M. L., Goldbaum, G. M., Brackbill, R. M., Tollestrup, K., Wood, R. W., \& Weybright, J. (1997). HIV testing among men who have sex with men results of a telephone survey. Preventive Medicine, 26, 839-844.

CDC. (1981). Kaposi's sarcoma and Pneumocystis pneumonia among homosexual men - New York city and California. Morbidity \& Mortality Weekly Report, 30, 305-308.

CDC. (1981). Pneumosystic Pneumonia - Los Angeles. Morbidity \& Mortality Weekly Report, 30, 250-252.

Chadborn, T. R., Baster, K., Delpech, V. C., Sabin, C. A., Sinka, K., Rice, et al. (2005). No time to wait: how many HIV-infected homosexual men are diagnosed late and consequently die? (England and Wales, 1993-2002). AIDS, 19, 513-520.

Chamot, E., Coughlin, S.S., Farley, T.A., \& Rice, J. (1999). Gonorrhea incidence and HIV-testing and counseling among adolescent and young adults seen at a clinic for sexually transmitted diseases. AIDS, 13, 971-979.

Chen, H.T. (1990). Theory driven evaluations. Newbury Park, CA: Sage.

Chesney, M. A., \& Smith, A. W. (1999). Critical delays in HIV testing and care. American Behavioral Scientist, 42, 1162-1174.

Cialdini, R.B. \& Goldstein, N.J. (2004). Social influence: compliance and conformity. Annual Review of Psychology, 55, 591-621.

Clark, L.R., Brasseux, C., Richmond, D., Getson, P., \& D'Angelo, L.J. (1998). Effect of HIV counseling and testing on sexually transmitted diseases and condom use in an urban adolescent population. Archives of Pediatric and Adolescent Medicine, 152, 269-273. 
Cohen, C., Revicki, D.A., Nabulsi, A., Sarocco, P.W., \& Jiang, P. (1998). A randomized trial of the effect of ritonavir in maintaining quality of life in advanced HIV disease. AIDS, 12, 1495-1502.

Davidovich, U., de Wit, J.B.F., Stroebe, W. (2000). Assessing sexual risk behaviour of young gay men in primary relationships: the incorporation of negotiated safety and negotiated safety compliance. AIDS, 14, 701-706.

De Vries, H., Brug, J. (1999). Computer-tailored interventions motivating people to adopt health promoting behaviours: Introduction to a new approach. Patient Education and Counseling, 36, 99-105.

De Zwart, O., Sandfort, T., \& van Kerkhof, M. (1998). No anal sex please: we're Dutch. A dilemma in HIV prevention directed at gay men. In T. Sandfort (Eds.), The Dutch response to HIV: pragmatism and consensus. London: UCL press.

Deren, S., Beardsley, M., Tortu, S., \& Goldstein, M.F. (1998). HIV serostatus and changes in risk behaviors among drug injectors and crack users. AIDS, 2, 171176.

Dilley, J.W., Woods, W.J., Sabatino, J., Lihatsh, T., Adler, B., Casey, S., Rinaldi, J., Brand, R., \& McFarland, W. (2002). Changing sexual behavior among gay male repeat testers for HIV: a randomized, controlled trial of a single-session intervention. Journal of Acquired Immune Deficiency Syndromes, 30, 177-186.

Dodds, J.P., Mercey, D.E., Parry, J.V., \& Johnson, A.M. (2003). Increasing risk behaviour and high levels of undiagnosed HIV-infection in a community sample of homosexual men. Sexually Transmitted Infections, 80, 236-240.

Downing, M., Knight, K., Reiss, T. H., Vernon, K., Mulia, N., Ferreboeuf, M., Carrol, A., \& Vu, C. (2001). Drug users talk about HIV testing: motivating and deterring factors. AIDS Care, 13, 561-577.

Dubois-Arber, F., Moreau-Gruet, F., \& Jeannin, A. (2002). Men having sex with men and HIV/AIDS prevention in Switzerland: 1987-2000. Euro Surveillance, 7, 16-18.

Elford, J., Bolding, G., \& Lorraine, S. (2001). Peer education has no significant impact on HIV risk behaviours among gay men in London. AIDS, 15, 535-538.

Elford, J., Bolding, G., \& Sherr, L. (2002). High-risk sexual behaviour increases among London gay men between 1998 and 2001: what is the role of HIV optimism? AIDS, 16, 1537-1544. 
Empelen, P. van (2001). AIDS prevention among Dutch drug users: an Intervention Mapping approach. Maastricht: Unigraphic.

Facente, S. (2001). HIV testing: a study of why gay men in the Netherlands choose not to test. Amsterdam: School for International Training.

Fernández, M.I., Bowen, G.S., Perrino, T., Royal, S., Mattson, T., Arheart, K.L., \& Cohn, S. (2003). Promoting HIV testing among never-tested Hispanic men: a doctor's recommendation may suffice. AIDS and Behavior, 7, 253-262.

Field, A.P. (2005). Discovering statistics using SPSS (Second Edition). London: Sage.

Fleuren, M., Wiefferink, K., \& Paulussen, T. (2004). Determinants of innovation within health care organizations: a literature review and Delphi-study. International Journal for Quality in Health Care, 16, 107-123.

George, N., Green, J., \& Murphy, S. (1998). Sexually transmitted disease rates before and after HIV testing. International Journal of STD \& AIDS, 9, 291-293.

Gezondheidsraad: Beraadsgroep Infectie en Immuniteit. (1999). Herziening van het HIV-testbeleid, publicatie nr. 1999/02. Den Haag: Gezondheidsraad.

Glanz, K., Rimer, B.K., \& Lewis, M.F. (2002). Health behavior and health education: Theory, research and practice (3rd ed.). San Francisco, CA: Jossey-Bass.

Gollwitzer, P.M., \& Brandstaetter, V. (1997). Implementation intentions and effective goal pursuit. Journal of Personality and Social Psychology, 73, 186-199.

Gosling, S.D., Vazire, S., Srivastava, S., \& John, O.P. (2004). Should we trust web-based studies? A comparative analysis of six preconceptions about Internet Questionnaires. American Psychologist, 59, 93-104.

Gras, L., Sighem, van, A., Smit, C., Zaheri, S., \& Wolf, de, F. (2006). Scientific report 2006: Monitoring of human immunodeficiency virus (HIV) infection in the Netherlands. Amsterdam: Stichting HIV Monitoring.

Green, L.W. \& Kreuter, M.W. (2005). Health program planning: an educational and ecological approach ( $4^{\text {th }}$ ed.). New York: McGraw-Hill.

Herek, G. M. (1999). AIDS and stigma. American Behavioral Scientist, 42, 1106116.

Hickson, F., Weatherburn, P., \& Reid, D. (2002). Vital statistics Scotland 2001: findings from the gay men's sex survey. London: Sigma Research. 
Hickson, F., Weatherburn, P., Reid, D., \& Stephens, M. (2003). Out and about: findings from the United Kingdom gay men's sex survey 2002. London: Sigma Research.

Higgins, D.L., Galavotti, C., O'Reilly, K., Schnell, D., Moore, M., Rugg, D., \& Johnson, R. (1991). Evidence for the effects of HIV antibody counseling and testing on risk behaviors. Journal of the American Medical Association, 266, 24192429.

Hocking, J.S., Rodger, A.J., Rhodes, D.G., \& Crofts, N. (2000). Late presentation of HIV infection following AIDS diagnosis - characteristics of individuals. International Journal of STD \& AIDS, 11, 503-508.

Hogeweg, J.A., \& Hospers, H.J. (2000). Monitoronderzoek 2000. Maastricht: Maastricht.University.

Hospers, H. J. (1999). Homosexual men and the HIV epidemic: Understanding and changing risk behavior. Maastricht: Unigraphic.

Hospers, H.J., Dörfler, T.T., \& Zuilhof, W. (2006). Schorer Monitor 2006. Amsterdam: Schorer.

Hospers, H.J., Dörfler, T.T., \& Zuilhof. W. (2003). Monitoronderzoek 2003. Amsterdam: Schorer.

Hospers, H.J., Dörfler, T.T., Zuilhof, W., \& Nijman, A.M. (2007). Schorer Monitor 2007. Amsterdam: Schorer.

Hospers, H.J., Kok, G., Harterink, P., \& de Zwart, O. (2005). A new meeting place: Chatting on the Internet, e-dating and sexual risk behaviour among Dutch men who have sex with men. AIDS, 19, 1097-1101.

Hou, S.I., Fernandez, M.E., \& Parcel, G.S. (2004). Development of a cervical cancer educational program for Chinese women using Intervention Mapping. Health Promotion and Practice, 5, 80-87.

Ickovics, J.R., Grigorenko, E., Beren, S.E., Druley, J.A., Morrill, A.C., \& Rodin, J. (1998). Long-term effects of HIV counseling and testing for women: behavioral and psychological consequences are limited at 18 months posttest. Health Psychology, 17, 395-402.

Inciardi, J.A., Surratt, H.L., Kurtz, S.P., \& Weaver, J.C. (2005). The effect of serostatus on HIV risk behaviour change among women sex workers in Miami, Florida. AIDS Care, 17, 88-101. 
Ingham, R., Vanwesenbeeck, I., \& Kirkland, D. (1999). Interviewing on sensitive topics. In A. Memon \& R. Bull (Eds.), Handbook of the psychology of interviewing (pp. 145-163). Chichester: John Wiley.

Ives, N.J., Gazzard, B.G., \& Easterbrook, P.J. (2001). The changing pattern of AIDS-defining illnesses with the introduction of Highly Active Antiretroviral Therapy in a London clinic. Journal of Infection, 42, 134-139.

Kalichman, S.C., Carey, M.P., \& Johnson, B.T. (1996). Prevention of sexually transmitted HIV infection: A meta-analytic review of the behavioral outcome literature. Annals of Behavioral Medicine, 18, 6-15.

Kippax, S., Noble, J., Prestage, G., Crawford, J.M., Campbell, D., Baxter, D., et al. (1997). Sexual negotiation in the AIDS era: Negotiated safety revisited. AIDS, 11, 191-197.

Kok, G. (1999). Targeted prevention for people with HIV/ AIDS: feasible and desirable? Patient Education and Counseling, 36, 239-246.

Kok, G., Harterink, P., Vriens, P., de Zwart, O., \& Hospers, H.J. (2006). The Gay Cruise: developing a theory- and evidence-based Internet HIV-prevention intervention. Journal of Sexuality Research and Social Policy, 3, 52-67.

Kok, G., Schaalma, H., De Vries, H., Parcel, G., \& Paulussen, T. (1996). Social psychology and health education. European Review of Social Psychology, 7, 242282.

Kok, G., Schaalma, H., Ruiter, R., van Empelen, P., and Brug, J. (2004). Intervention Mapping: protocol for applying health psychology theory to prevention programs. Journal of Health Psychology, 9, 85-98.

Kotranski, L., Semaan, S., Collier, K., Lauby, J., Halbert, J., \& Feighan, K. (1998). Effectiveness of an HIV risk reduction counseling intervention for out-oftreatment drug users. AIDS, 10, 19-33.

Kraag, G., Kok, G., Abu-Saab, H.H., Lamberts, P., \& Fekkes, M. (2005). Development of a stress management programme - Learn Young, Learn Fair - for fifth and sixth formers in the Netherlands using Intervention mapping. International Journal of Mental Health Promotion, 7, 37-44.

Kroeze, W., Werkman, A., \& Brug, J. (2006). A systematic review of randomized trials on the effectiveness of computer-tailored education on physical activity and dietary behaviors. Annals of Behavioral Medicine, 44, 209-217.

Lauby, J.L., Bond, L., Erğolu, D. \& Batson, H. (2006). Decisional balance, perceived risk and hiv testing practices. AIDS and Behavior, 10, 83-91. 
Lefever, S., Dal, M., Matthiasdóttir, A. (2007). Online data collection in academic research: advantages and limitations. British Journal of Educational Technology, 38, 574-582.

Lupton, D., Mccarthy, S., \& Chapman, S. (1995). 'Doing the right thing': The symbolic meanings and experiences of having an HIV antibody test. Social Science and Medicine, 41, 173-180.

MacGowan, R.J., Brackbill, R.M., Rugg, D.L., Swanson, N.M., Weinstein, B., Couchon, A., Scibak, J., Molde, S., Mclaughlin, P., Barker, T., \& Voigt, R. (1997). Sex, drugs and HIV-counseling and testing: a prospective study of behavior-change among methadone-maintenance clients in New England. AIDS, 11, 229-235.

Marks, G., Crepaz, N. Senterfitt, W., \& Janssen, R.S. (2005). Meta-analysis of high-risk sexual behavior in persons aware and unaware they are infected with HIV in the United States: implications for HIV prevention programs. Journal of Acquired Immune Deficiency Syndromes, 39, 446-453.

Marks, G., Crepaz, N., \& Janssen, R.S. (2006). Estimating sexual transmission of HIV from persons aware and unaware that they are infected with the virus in the USA. AIDS, 20, 1447-1450.

Matic, S. (2006). Twenty-five years of HIV/AIDS in Europe. In S. Matic, J.V. Lazarus, \& M.C. Donoghoe (Eds.), HIV/AIDS in Europe: moving from death sentence to chronic disease management. Denmark: World Health Organization.

Matic, S., Lazarus, J.V., \& Donoghoe, M.C. (2006). HIV/AIDS in Europe: moving from death sentence to chronic disease management. Denmark: World Health Organization.

Mekonnen, Y., Sanders, E., Aklilu, M., Tsegaye, A., Rinke de Wit, T.F., Schaap, A., Wolday, D., Geskus, R., Coutinho, R.A., \& Fontanet, A.L. (2003). Evidence of changes in sexual behaviours among male factory workers in Ethiopia. AIDS, 17, 223-231.

Michie, S. \& Abraham, C. (2004). Interventions to change health behavior: evidence-based or evidence inspired? Psychology and Health, 19, 29-49.

Mikolajczak, J., Hospers, H. J., \& Kok, G. (2006). Reasons for not taking an HIVtest among untested men who have sex with men: an Internet study. AIDS and Behavior, 10, 431-435.

Mikolajczak, J., Hospers, H. J., \& Kok, G. (2007). Social cognitive determinants of hiv-testing intentions among untested men who have sex with men: An Internet study. Maastricht: Maastricht University. 
Mikolajczak, J., Hospers, H.J., \& Kok, G. (2005). HIV-testing in Australia: a qualitative study on environmental factors. Maastricht: Maastricht.University.

Mikolajczak, J., Hospers, H.J., \& Kok, G. (2006). Reasons for not taking an HIVtest among untested men who have sex with men: an Internet study. AIDS and Behavior, 10, 431-435.

Mikolajczak, J., Hospers, H.J., \& Kok, G. (2006). The effects of HIV-testing and counseling on sexual risk behavior: a systematic review of published articles between 1996 - 2006. Maastricht: Maastricht.University.

Mikolajczak, J., Hospers, H.J., \& Kok, G. (2007). Social-cognitive determinants of hiv-testing intentions among untested men who have sex with men: An Internet study. Maastricht: Maastricht University.

Mikolajczak, J., Kesteren, N. Van, Hospers, H.J., \& Kok, G.J. (2004). Een kwalitatief onderzoek naar redenen om niet te testen op HIV bij Nederlandse mannen die seks hebben met mannen [A qualitative study into reasons for not taking an HIV-test among Dutch men who have sex with men. Dutch Journal for Health Sciences]. TSG: Tijdschrift voor Gezondheidswetenschappen, 7, 450-456.

Mikolajczak, J., Kok, G., \& Hospers, H.J. (2008). Queermasters: developing a theory- and evidence-based Internet HIV-prevention intervention to promote HIV-testing among men who have sex with men (MSM). Applied Psychology: an international review, in press.

Mikolajczak, J., Van Breukelen, G.J.P., Kok, G., \& Hospers, H.J. (2008). Evaluating the effects of an online HIV-prevention intervention to motivate HIV-testing behavior among Men who have Sex with Men (MSM). Maastricht: Maastricht.University.

Mills, T. L., Stall, R., Pollack, L., Paul, J. P., Binson, D., Canchola, J., and Catania, J. A. (2001). Health related characteristics of men who have sex with men: A comparison of those living in "gay ghettos" with those living elsewhere. American Journal of Public Health, 91, 980-983.

Mooij, A. (2004). Geen paniek! Aids in Nederland 1982-2004 [Don't panic! Aids in the Netherlands 1982-2004]. Amsterdam: Uitgeverij Bert Bakker.

Moreau-Gruet, F., Jeannin, A., Dubois-Arber, F., and Spencer, B. (2001). Management of the risk of HIV-infection in male homosexual couples. AIDS, $15,1025-1035$. 
Mullen, P.D., Green, L.W., \& Persinger, G.S. (1985). Clinical trials of patient education for chronic conditions: A comparative meta-analysis of intervention types. Preventive Medicine, 14, 753-781.

National Center in HIV Social Research \& National Center in HIV Epidemiology and Clinical Research. (2006). Sydney gay community periodic survey: February 1996-August 2006. Sydney: University of New South Wales.

National Center in HIV Social Research. (2001). Annual report of behaviour 2001. Sydney: University of New South Wales.

National Center in HIV Social Research. (2002). Health in Men: baseline data. Sydney: University of New South Wales.

National Center in HIV Social Research. (2003). Gay Community Periodic Survey: Perth 2002. Sydney: University of new South Wales.

National Center in HIV Social Research. (2003). Gay Community Periodic Survey: Queensland 2002. Sydney: University of new South Wales.

National Center in HIV Social Research. (2003). Gay Community Periodic Survey: Sydney 1996-2002. Sydney: University of new South Wales.

National Center in HIV Social Research. (2004). Gay Community Periodic Survey: Adelaide 2003. Sydney: University of new South Wales.

National Center in HIV Social Research. (2004). Gay Community Periodic Survey: Canberra 2003. Sydney: University of new South Wales.

National Center in HIV Social Research. (2004). Gay Community Periodic Survey: Melbourne 2004. Sydney: University of new South Wales.

National Center in HIV Social Research. (2005). Annual report of behaviour 2005. Sydney: University of New South Wales.

National Centre in HIV Social Research (2003). Gay community periodic survey: Sydney 1996-2002. Sydney: University of New South Wales.

National Centre in HIV Social Research. (2002). Health in Men: baseline data. Sydney: University of New South Wales.

Offir, J.T., Fisher, J.D., Williams, S.S., \& Fisher, W.A. (1993). Reasons for inconsistent AIDS-preventive behavior among gay men. The Journal of Sex Research, 30, 62-69.

Palella, F.J., Delaney, K.M., Moorman, A.C., Loveless, M.O., Fuhrer, J., Satten, G.A., Aschman, D.J., Holmberg, S.D., \& HIV Outpatient Study Investigators. (1998). Declining morbidity and mortality among patients with advanced 
human immunodeficiency virus infection. New England Journal of Medicine, $338,853-860$.

Pequegnat, W., Simon Rosser, B.R., Bowen, A.M., Bull, S.S., DiClemente, R.J., Bockting, W.O., et al. (2007). Conducting Internet-based HIV/STD prevention survey research: considerations in design and evaluation. AIDS and Behavior, $11,505-521$.

Pérez, K., Rodes, A., \& Casabona, J. (2002). Monitoring HIV prevalence and behavior of men who have sex with men in Barcelona, Spain. Euro Surveillance, 7, 23-28.

Pligt, J. van der, \& Otten, W. (1993). Risico's. In P.Koele \& J. van der Pligt (Red.), Beslissen en beoordelen (pp.286-318). Amsterdam: Boom.

Pligt, J. van der. (1991). Risicoperceptie, onrealistisch optimisme en AIDSpreventief gedrag. Nederlands Tijdschrift voor de Psychologie, 46, 228-237.

Rietmeijer, C.A. (2004). Lessons in HIVISTD prevention. Haasbeek: Alphen aan den Rijn.

Rimer, B.K. \& Kreuter, M.W. (2006). Advancing tailored health communication: A persuasion and message effects perspective. Journal of Communication, 56, s184-s201.

RIVM. (2006). HIV and Sexually Transmitted Infections in the Netherlands in 2005. RIVM-report $n r .441100024 / 2006$. Bilthoven: RIVM.

Roodenburg, A. (1999). Kwalitatief onderzoek naar ervaringen van mensen met HIV met stigmatisering. Maastricht: Universiteit Maastricht.

Roth, D., Steward, K.E., Clays, O.J., van der Straten, A., Karita, E., \& Allen, S. (2001). Sexual practices of HIV discordant and concordant couples in Rwanda: effects of a testing and counselling programme for men. International Journal of STD and AIDS, 12, 181-188.

Ruiter, R. (2000). Scary warnings and rational precautions. Maastricht: Unigraphic.

Ruiter, R.A.C., Verplanken, B., De Cremer, D., \& Kok, G. (2004). Danger control and fear control in response to fear appeals : the role of need for cognition. Basic and Applied Social Psychology, 26(1), 13-24.

Saunders, D.S., \& Burgoyne, R.W. (2002). Evaluating health related wellbeing outcomes among outpatients with human immunodeficiency virus infection in the HAART era. International Journal of STD \& AIDS, 13, 683-690.

Schafer, J.L. \& Graham, J.W. (2002). Missing data: our view of the state of the art. Psychological Methods, 7, 147-177. 
Sendziuk, P. (2003). Learning to trust: Australian responses to AIDS. Sydney: University of New South Wales Press.

Sexually Transmissible Infections in Gay Men Action group (STIGMA). (2005). Sexually transmitted infection testing guidelines for men who have sex with men. Sydney: http://www.ashm.org.au/uploads/STIGMA_STI_Testing_Guidelines_for_ MSM.pdf

Sheeran, P., Webb, T.L. and Gollwitzer, P.M. (2005). The interplay between goal intentions and implementation intentions. Personality and Social Psychology Bulletin, 31, 87-98.

Sidani, S. \& Sechrest, L. (1999). Putting program theory into operation. American Journal of Evaluation, 20, 227-238.

Siegel, K., Raveis, V. H., \& Gorey, E. (1998). Barriers and pathways to testing among HIV infected women. AIDS Education and Prevention, 10, 114-127.

Siegel, K., Schrimshaw, E. W., \& Dean, L. (1999) Symptom interpretation: implications for HIV testing and care among HIV-infected late middle aged and older adults. AIDS Care, 11, 525-535.

Sigma Research (2005). Scotland Vital Statistics 2004. From: http://sigmaresearch.org.uk/data04/All_Scotland.pdf

Smit, C., Geskus, R., Uitenbroek, D., Mulder, D., van den Hoek, A., Coutinho, R.A., \& Prins, M. (2004). Declining AIDS mortality in Amsterdam: contributions of declining HIV incidence and effective therapy. Epidemiology, $15,536-542$.

Stall, R., Hoff, C., Coates, C. J., Paul, J., Phillips, K. A., \& Ekstrand, M. (1996). Decisions to get HIV tested and to accept antiretroviral therapy among gay/bisexual men: Implications for secondary prevention efforts. Journal of Acquired Immune Deficiency Syndrome, 11, 1151-1160.

Strecher, V. J., \& Rosenstock, I. M. (1997). The Health Belief Model. In K. Glanz, F. M. Lewis, \& K. B. Rimer (Eds.). Health behavior and health education (pp 113138). San Francisco: Jossey-Bass.

Tam, Y.K., \& Ho, S.Y. (2005). Web personalization as a persuasive strategy: An elaboration likelihood perspective. Information Systems Research, 16, 271-291.

The Durban Declaration. (2000). HIV causes AIDS. Nature, 406, 15-16.

The Voluntary HIV-1 Counseling and Testing Efficacy Study group. (2000). Efficacy of voluntary HIV-1 counselling and testing in individuals and 
couples in Kenya, Tanzania, and Trinidad: a randomized trial. Lancet, 356, 103-112.

Turner, C.F., Ku, L., Rogers, S.M., Leidberg, L.D., Pleck, J.H., \& Sonestein, F.L. (1998). Adolescent sexual behavior, drug use, and violence: increased reporting with computer survey technology. Science, 280, 867-873.

Tweede Kamer, vergaderjaar 2003-2004. (2003). Seksueel overdraagbare aandoeningen (soa): Kamerstuk 29220 1. Den Haag: Ministerie van Volksgezondheid Welzijn en Sport.

UNAIDS. (2003). AIDS epidemic update. Geneva: World Health Organization.

Valdiserri, R.O. (1997). HIV counseling and testing: its evolving role in HIV prevention. AIDS Education and Prevention, 9, 2-13.

Van Breukelen, G.J.P. (2006). ANCOVA vs. Change from baseline: more power in randomized studies, more bias in nonrandomized studies. Journal of Clinical Epidemiology, 59, 920-925.

Van de Ven, P., Prestage, G., Knox, S., \& Kippax, S. (2000). Gay men in Australia who do not have HIV test results. International Journal of STD $\mathcal{E}$ AIDS, 11, 456460.

Van Empelen, P., Kok, G., Schaalma, H.P., \& Bartholomew, L.K. (2003). An AIDS risk reduction program for Dutch drug users: an Intervention Mapping approach to planning. Health Promotion and Practice, 4, 402-412.

Van Empelen, P., Kok, G., Van Kesteren, N.M.C., Van den Borne, B., Bos, A., \& Schaalma, H.P. (2003). Effective methods to change sex-risk behavior among drug users: A review of psychosocial interventions. Social Science and Medicine, 57, 1593-1608.

Van Griensven, F. (1990). De Amsterdamse cohortstudie onder homoseksuele mannen. In S. Rozendaal, AIDS: de jacht op een virus. Maastricht: Natuur \& Techniek.

Van Kesteren, N.M.C., Kok, G., Hospers, H.J., Schippers, J., \& de Wildt, W. (2006). Systematic development of a self-help and motivational enhancement intervention to promote sexual health in HIV-positive men who have sex with men. AIDS Patient Care E STDs, 20, 858-875.

Verbeke, G. \& Molenberghs, G. (2000). Linear mixed models for longitudinal data. New York: Springer-Verlag.

Webster, R. D., Darrow, W. W., Paul, J. P., Roark, R. A., Woods, W. J., and Stempel, R. R. (2003). HIV infection and associated risks among young men 
who have sex with men in a Florida resort community. Journal of Acquired Immune Deficiency Syndromes, 33, 223-231.

Weinhardt, L.S., Carey, M.P., Johnson, B.T., \& Bickham, N.L. (1999). Effects of HIV counseling and testing on sexual risk behavior: a meta-analytic review of published research, 1985-1997. American Journal of Public Health, 89, 1397-1405.

Wolitski, R.J., MacGowan, R.J., Higgins, D.L., \& Jorgensen, C.M. (1997). The effects of HIV counseling and testing on risk-related practices and helpseeking behavior. AIDS Education and Prevention, 9, 52-67.

World Health Organization (2001). http://www.who.int/health-servicesdelivery/ hiv_aids/English/fact-sheet-1/index.html. 
SUMMARY 
Until recently, HIV-testing was not actively promoted in the Netherlands among individuals at higher risk for HIV-infection such as men who have sex with men (MSM). From the start of the HIV-epidemic in the beginning of the 1980 's, the Dutch response to the epidemic focused primarily on the promotion of condom use for anal sex. Men who wanted to find out whether or not they were infected with HIV were most often advised not to get tested since no adequate treatment for HIV-infected individuals was available, psychosocial consequences of finding out HIV-positive were unclear, and HIV-positive men were feared to become the victim of stigmatization.

However, with the introduction of Highly Active Antiretroviral Therapy (HAART) in 1996, new arguments in favor of active promotion of HIV-testing emerged. Most importantly, HAART provided a sufficient medical alternative for HIV-infected individuals. As a result thereof, the Netherlands reviewed its HIV-testing policy and HIV-testing was no longer to be discouraged among MSM but actively promoted. Early detection of HIV-infection would not only allow men to get timely access to adequate treatment but also contribute to reducing the spread of HIV in the MSM population in the Netherlands.

To motivate Dutch MSM to take an HIV-test an effective health promotion program was required. The systematic development of such a program is the central focus of the work that is described in this thesis. In the first chapter of this thesis, the historical background and the context in which the work that is described in this thesis should be considered, are described. Also, a brief introduction and an overview of the Intervention Mapping protocol are provided in the first chapter of this thesis.

In the second chapter, findings from a small scale qualitative study among 32 untested Dutch MSM are described. This qualitative study was set up to get an in-depth understanding of the issue of HIV-testing among Dutch MSM and explored which factors contributed to Dutch MSM not taking an HIV-test. Findings from this study showed that a majority of the respondents lacked sufficient knowledge about issues related to taking an HIV-test, for example about testing procedures or about the costs that are involved in taking a test. In addition, most participants appeared to know little about the advantages of treatment with HAART. Also, this study taught us that HIVtesting was hardly ever talked about with (good) friends or relevant others, and taking an HIV-test was not openly encouraged in participants' social environment. Another finding in this study was that most participants indicated that they feared detrimental consequences for their lives and future if they would find out being HIV-positive. Most participants also considered their personal risk for HIV-infection to be very low, despite the fact that a majority concurrently reported past sexual risk behavior as well, i.e. unprotected anal 
intercourse with casual partners. Finally, the results from this small scale qualitative study showed that hardly any of the participants were aware of health promotion campaigns that focused on motivating them to take an HIVtest, or informed them about the advantages of treatment with HAART for example.

The third chapter in this thesis describes the findings of a large scale online quantitative study, set up to get a better understanding of the determinants of HIV-testing on the one hand, and to seek confirmation of our qualitative findings reported in the previous chapter on the other hand. In addition, reasons for not taking an HIV-test among Dutch MSM were further explored in the study described in chapter three. Results from this study showed that the intention to take an HIV-test in the near future, among at risk MSM in the study sample could be related to a set of (social-cognitive) determinants, including their attitude towards taking an HIV-test, the perceived social norm concerning taking an HIV-test, and perceived behavioral control (also referred to as self-efficacy) about taking an HIV-test. Additional predictors that could be related to the intention of MSM to take an HIV-test were specific knowledge about taking an HIV-test (i.e., where to get tested), their perception of risk for HIV-infection (i.e., have never been at risk for HIVinfection), and how much they had talked about HIV-testing with significant others. The empirical evidence from both chapter two and chapter three served as input for the development of a health promotion program that aimed to promote HIV-testing among MSM in the Netherlands, which is described in later chapters in this thesis.

The fourth chapter of this thesis comprises a systematic review of the scientific literature on HIV-testing between 1996 and 2007. In doing so, it provides a state-of-the-art update of the current knowledge about the relationship between HIV-testing and counseling, and subsequent (sexual) risk behavior.

Chapter five contains the outcome of a qualitative study, conducted in Sydney (Australia) between November 2004 and February 2005. The aim of this study was to get a better understanding of the different environmental or external factors that contributed to Australia's successful HIV-testing program. It provides a historical perspective of the Australian response to the HIVepidemic and sought to find out whether any of the environmental factors that were identified could be implemented in the health promotion program that we were planning in the Netherlands.

In chapter six of this thesis, the systematic development of our HIVprevention intervention is described. Whereas the health promotion literature provides many papers on the evaluation of the effect(s) of a health promotion 
intervention, few papers contain a proper and detailed description of the content and the development of the actual intervention. In absence of such descriptions, it is hard for other researchers and health promotion professionals to get a full understanding of the different goals an intervention aims to achieve and which methods for behavior change are applied in the intervention to actually realize these goals. Moreover, the absence of such descriptions makes it virtually impossible for other researchers to do what science is all about in the long run, namely replicating the findings of a study.

Chapter seven describes the evaluation of the effects of our newly developed intervention which was called Queermasters. This chapter describes the effect of our HIV-prevention intervention on both the motivation of Dutch MSM to take an HIV-test and subsequent HIV-testing behavior. From the evaluation, it appeared that Queermasters was an effective intervention in terms of motivating Dutch MSM to take an HIV-test. The latter was reflected in a significant increase in participants' intention to take an HIV-test after exposure to Queermasters. Contrary to our expectations and contrary to theoretical predictions, this more positive intention did not result in an increase in HIV-testing behavior during the three month follow-up period after the intervention.

Finally, chapter eight contains a systematic summary of the main findings from all chapters of this thesis and discusses the outcomes of the different studies that are reported in this thesis.

The aim of the research presented in this thesis was to describe the application of Intervention Mapping (Bartholomew, Parcel, Kok \& Gottlieb, 2006) to the systematic development of an online HIV-prevention intervention to promote HIV-testing among MSM in the Netherlands. As such, the work that is described in the different chapters of this thesis provides insight in the socialcognitive and external determinants related to HIV-testing among this target group. Both quantitative and qualitative research methods have been applied to gain insight therein. The results from this research can be of value for future health promotion activities, specifically in the area of HIV-prevention among MSM in the Netherlands. 
SAMENVATTING 
Tot voor kort werd in Nederland het doen van een HIV-test niet actief bevorderd onder individuen met een verhoogd risico op een HIV-infectie, zoals mannen die seks hebben met mannen (MSM). Vanaf het begin van de HIVepidemie in de jaren '80 van de vorige eeuw, werd de Nederlandse respons op de epidemie gekenmerkt door een primaire focus op het bevorderen van condoomgebruik tijdens anale seks. Mannen die te weten wilden komen of ze al dan niet geïnfecteerd waren met HIV kregen meestal het advies om zich niet te laten testen omdat er voor HIV-geïnfecteerde individuen geen afdoende behandeling beschikbaar was. Daarnaast was het onduidelijk wat precies de psychosociale consequenties waren voor individuen die er achter kwamen dat ze HIV-positief waren, en was men bang dat HIV-positieve mannen het slachtoffer zouden worden van stigmatisering.

Echter, dankzij de introductie van Highly Active Antiretroviral Therapy (HAART) in 1996, werden nieuwe argumenten geïntroduceerd in het debat over al dan niet actief bevorderen van HIV-testen onder individuen met een verhoogd risico op HIV-infectie. Het belangrijkste argument was dat er met HAART eindelijk een afdoend medisch alternatief voor handen was voor individuen die HIV-positief bleken te zijn. Mede als gevolg hiervan, werd in Nederland het HIV-testbeleid herzien en werd het doen van een HIV-test niet langer afgeraden aan MSM maar juist actief bevorderd. Het vroegtijdig vaststellen van een HIV-infectie zou mannen niet alleen tijdig toegang kunnen verlenen tot adequate behandeling, maar bovendien ook een bijdrage leveren aan het verminderen van de verspreiding van het virus in de MSM populatie in Nederland.

Om MSM in Nederland te motiveren tot het doen van een HIV-test was er behoefte aan een effectief gezondheidsbevorderend programma dat zich hier op richt. De systematische ontwikkeling van een dergelijk programma vormt de rode draad doorheen het werk dat beschreven wordt in deze thesis. In het eerste hoofdstuk van deze thesis, worden de geschiedenis en de achtergrond geschetst van het werk dat erin beschreven wordt. Ook wordt een korte introductie en een overzicht van het zogenaamde Intervention Mapping protocol gegeven in dit eerste hoofdstuk.

In het tweede hoofdstuk, worden de bevindingen van een kleinschalig kwalitatief onderzoek onder 32 MSM die zich nooit eerder lieten testen op HIV beschreven. De kwalitatieve studie die in dit hoofdstuk wordt beschreven, werd opgezet om meer inzicht te krijgen in de problematiek rondom HIV-testen bij MSM in Nederland. Zo werd bijvoorbeeld onderzocht welke factoren er toe bijdragen dat MSM zich niet laten testen op HIV. De resultaten van deze studie laten zien dat een meerderheid van de mannen die aan de studie deelnemen niet zoveel afwisten van allerlei aspecten die te maken hebben met het doen 
van een HIV-test. Hierbij kan gedacht worden aan de test procedures, of de kosten die bij het doen van een HIV-test komen kijken. Bovendien bleek dat de meeste mannen die deelnamen aan het onderzoek weinig af te weten van de voordelen die verbonden zijn aan de behandeling van HIV met HAART. Het kwalitatieve onderzoek leerde ons ook dat er met (goede) vrienden zelden gesproken wordt over het onderwerp HIV-testen, en tevens bleek dat het doen van een HIV-test nauwelijks werd aangemoedigd vanuit de sociale omgeving van MSM. Een andere bevinding in deze studie was dat de meeste respondenten aangaven bang te zijn voor de verregaande consequenties voor hun eigen leven en toekomst indien zou blijken dat ze HIV-positief waren. De meeste respondenten vonden ook dat ze weinig risico liepen op een HIVinfectie, ondanks het feit dat een meerderheid van de hen tegelijkertijd ook aangaf in het verleden één of meerdere keren risicovolle seks, bijvoorbeeld onbeschermde anale seks, te hebben gehad met losse (seks)partners. Een laatste belangrijke bevinding in deze kwalitatieve studie was de vaststelling tot geen van de respondenten zich een voorlichtingscampagne kon herinneren waarin ze aangemoedigd werden om zich te laten testen op HIV, of waarin ze geïnformeerd werden over de voordelen die verbonden zijn aan de behandeling van HIV met HAART.

Het derde hoofdstuk van dit proefschrift beschrijft de bevindingen in een grootschalig kwantitatief onderzoek dat via het Internet werd uitgevoerd. De studie werd opgezet om een beter begrip te krijgen van de verschillende determinanten die samenhangen met het doen van een HIV-test, en om na te gaan of de uitkomsten van het eerder uitgevoerde kwalitatieve onderzoek op grotere schaal bevestigd konden worden. Daarnaast werd in deze studie ook dieper ingegaan op de redenen die MSM hebben om zich niet te laten testen op HIV. De resultaten van deze studie lieten zien dat de intentie om een HIV-test te gaan doen, onder MSM die risico liepen op een HIV-infectie, gerelateerd kon worden aan een aantal sociaal-cognitieve determinanten waaronder de attitude ten aanzien van het doen van een HIV-test, de waargenomen sociale norm ten aanzien van het doen van een HIV-test, en de mate van waargenomen gedragscontrole (ook wel self-efficacy genoemd) over het doen van een HIVtest. Daarnaast konden ook een aantal kennis aspecten over het doen van een HIV-test - bijvoorbeeld waar men zich kan laten testen op HIV -, het waargenomen risico voor een HIV-infectie en de mate waarin men met vrienden en kennissen sprak over het doen van een HIV-test in verband worden gebracht met de intentie van MSM om zich te laten testen op HIV. De empirische evidentie uit zowel hoofdstuk twee als hoofdstuk drie werd gebruikt als input voor de ontwikkeling van een nieuwe interventie met als doel het bevorderen van HIV-testen onder MSM in Nederland. De 
ontwikkeling hiervan wordt in een later hoofdstuk van deze thesis uitgebreid beschreven.

Het vierde hoofdstuk bevat een systematisch overzicht van de wetenschappelijke literatuur over HIV-testen tussen 1996 - 2007. In die zin, biedt het vierde hoofdstuk van deze thesis een state-of-the-art update van de huidige kennis voor wat betreft de relatie tussen het doen van een HIV-test enerzijds, en seksueel risicogedrag anderzijds.

Hoofdstuk vijf beschrijft de uitkomsten van een kwalitatieve studie die uitgevoerd werd in Sydney (Australië), tussen november 2004 en februari 2005. Het doel van deze kwalitatieve studie was het verkrijgen van meer inzicht in de verschillende omgevingsvariabelen - ook wel externe determinanten genoemd - die bijdroegen aan het succesvolle HIV-test programma in Australië. Hoofdstuk vijf biedt een historisch perspectief van de Australische respons op de HIV-epidemie, en geeft aan of én op welke manier een aantal relevante omgevingsvariabelen geïmplementeerd kunnen worden in de interventie die we gingen ontwikkelen.

In het zesde hoofdstuk van dit proefschrift, wordt de systematische ontwikkeling van de interventie uitgebreid beschreven. De (inter)nationale wetenschappelijke literatuur op het gebied van gezondheidsbevordering bevat een grote verscheidenheid aan papers waarin over de effectiviteit van een bepaalde interventie gerapporteerd wordt. Echter, wat hierin meestal ontbreekt, is een goede, uitgebreide en systematische beschrijving van de inhoud én de ontwikkeling van de betreffende interventie. Zonder zulke beschrijvingen is het voor andere onderzoekers en voor professionals op het gebied van gezondheidsbevordering erg moeilijk om goed te kunnen begrijpen welke doelen een interventie heeft, én welke methodieken er in de interventie worden toegepast om die doelen te realiseren. Bovendien maakt het ontbreken van zulke beschrijvingen het eveneens zo goed als onmogelijk voor andere onderzoekers om een interventie te repliceren. In die zin wordt het dus onmogelijk voor onderzoekers om één van de fundamentele processen op het gebied van de wetenscha, namelijk het repliceren van onderzoeksbevindingen, te kunnen realiseren.

Hoofdstuk zeven bevat een beschrijving van de evaluatie van de effecten van de nieuw ontwikkelde interventie, die de naam Queermasters kreeg. In dit hoofdstuk wordt het effect van onze HIV-preventie interventie op zowel de motivatie van MSM om zich te laten testen op HIV, alsook het effectief doen van een HIV-test beschreven. Uit de evaluatie bleek dat Queermasters een effectieve interventie was in termen van het motiveren van Nederlandse MSM om zich te laten testen op HIV. Dit bleek uit een significante toename in de intentie van MSM om zich te laten testen op HIV, na blootstelling aan het 
interventiemateriaal in Queermasters. In tegenstelling tot onze eigen verwachtingen en in tegenstelling tot theoretische voorspellingen, resulteerde deze positievere intentie niet in een toename in HIV-testgedrag gedurende de drie maanden na blootstelling aan de interventie.

Hoofdstuk acht van dit proefschrift bevat tenslotte een systematische samenvatting van de belangrijkste bevindingen in de voorgaande hoofdstukken. Tevens worden in dit hoofdstuk de uitkomsten van de verschillende studies die werden verricht bediscussieerd en kritisch bekeken.

Het doel van het onderzoek dat in de verschillende hoofdstukken van deze thesis besproken wordt, is het beschrijven van de toepassing van het Intervention Mapping protocol voor de systematische ontwikkeling van een online HIV-preventie interventie waarin HIV-testen wordt bevorderd onder MSM in Nederland. In die zin biedt deze thesis inzicht in de sociaal-cognitieve en de externe determinanten die gerelateerd zijn aan het doen van een HIV-test bij deze doelgroep. Zowel kwalitatieve als kwantitatieve onderzoeksmethodieken werden toegepast om inzicht in deze materie te verkrijgen. De resultaten van dit onderzoek kunnen in de toekomst van toegevoegde waarde zijn voor nieuwe gezondheidsbevorderende activiteiten, in het bijzonder op het gebied van de HIV-preventie onder MSM in Nederland. 

CURRICULUM VITAE 
Jochen Mikolajczak was born on April 21 st 1979, in Genk, Belgium. He completed secondary school at the "Sint-Jozef Instituut", in Bokrijk. In 1998, he started his Psychology study at Maastricht University, specializing in Cognitive Psychology with a particular interest in Social Psychology. After graduating as a Cognitive Psychologist in 2003, he started working on the line of research that is decribed in this thesis. From december 2004 till March 2005, he spent three months working at the National Centre in HIV Social Research, in Sydney Australia. Since november 2007, he works as a researcher at TNO Quality of Life, in Leiden. 
DANKWOORD 
Aan het eind deze lange rit rest me niets anders dan kort maar krachtig, iedereen die in de afgelopen jaren een bijdrage - hoe klein ook - heeft geleverd aan dit proefschrift, hiervoor oprecht en welgemeend te bedanken.

In het bijzonder Gerjo en Harm, voor hun geloof en vertrouwen in mij.

Vrienden en vriendinnen,

Ouders,

Neeltje lief,

Het proefschrift is klaar,

Tijd voor een feestje,

Vanavond,

Morgen,

Eender waar. 